\title{
ENTREPRENEURIAL DISCOVERY AND INFORMATION COMPLEXITY IN KNOWLEDGE-INTENSIVE INDUSTRIES
}

Amol Madhukar Joshi

A dissertation submitted to the faculty of the University of North Carolina at Chapel Hill in partial fulfillment of the requirements for the degree of Doctor of Philosophy in Business Administration in the Kenan-Flagler Business School (Strategy \& Entrepreneurship Department).

\section{Chapel Hill}

2011

Approved by:

Atul Nerkar (chair)

Howard Aldrich

Richard Bettis

Christopher Bingham

Dean Shepherd 
(C)2011

Amol Madhukar Joshi

ALL RIGHTS RESERVED 


\section{ABSTRACT \\ Amol Madhukar Joshi \\ ENTREPRENEURIAL DISCOVERY AND INFORMATION COMPLEXITY IN KNOWLEDGE-INTENSIVE INDUSTRIES}

(Under the direction of Atul Nerkar)

Why are some firms better able than others to exploit new opportunities? I posit that differences in the type and level of complexity of the information obtained through the entrepreneurial discovery process may be a meaningful indicator of the likelihood that a firm is able to exploit a new opportunity. Specifically, I investigate knowledge reproduction processes for product replication (internal copying) and imitation (external copying) as a means of exploiting opportunities and building competitive advantage. Integrating concepts from information theory and the knowledge-based view of the firm, I introduce a generalized model and quantitative methods for estimating the inherent complexity of any unit of knowledge, such as a strategy, technology, product, or service, as long as the unit is represented in algorithm form. Modeling organizations as information processing systems, I develop measures of the information complexity of an algorithm representing a unit of knowledge in terms of the minimum amount of data (algorithmic complexity) and the minimum number of instructions (computational complexity) required to fully describe and execute the algorithm. I apply this methodology to construct and analyze a 
unique historical dataset of 91 firms (diversifying and de novo entrants) and 853 new product introductions (1974-2009), in a knowledge-intensive industry, digital signal processing. I find that: (1) information complexity is negatively and significantly related to product replication and imitation; (2) replicators have the greatest advantage over imitators at moderate levels of information complexity; (3) intellectual property regimes strengthening the patentability of algorithms significantly increase product replication, without significantly decreasing imitation; (4) outbound licensing of patented technologies decreases product replication and increases imitation; (5) products introduced by de novo entrants are less likely to be replicated and more likely to be imitated than products introduced by diversifying entrants; and (6) diversifying entrants have the greatest advantage over de novo entrants at high and low levels of information complexity; neither type of entrant has a significant advantage at moderate levels of complexity. These empirical findings support and extend predictions from earlier simulation studies. The model is applicable to other aspects of organizational strategy and has important implications for researchers, managers, and policymakers.

Keywords: complexity, entrepreneurship, discovery, replication, imitation, algorithm 
In loving memory of my parents, Madhukar and Sulabha Joshi. 


\section{ACKNOWLEDGEMENTS}

I am honored and grateful to have the assistance of many people in completing this research. First and foremost, I would like to thank my wife, Alpa Joshi, my brother, Abhijeet Joshi, and my mother-in-law, Usha Kotecha, for their ongoing support and encouragement throughout the entire research process.

I am indebted to my dissertation chair and advisor, Atul Nerkar, and my Ph.D. program advisor, Rich Bettis, for sharing with me their limited time and their unlimited enthusiasm for actively pursuing this research idea from the initial proposal stage to the final defense. I am especially thankful for and appreciative of the scholarly direction and guidance provided by dissertation committee members Howard Aldrich, Christopher Bingham, and Dean Shepherd. I would also like to thank my dear colleague and fellow "entrepreneur-turned-academic," Ted Zoller, for inspiring me to join UNC's Ph.D. program and my old friend and classmate, Fernando Chaddad for keeping me focused on completing it.

This research is funded in part by a Dissertation Fellowship grant from the Ewing Marion Kauffman Foundation. (The contents of this publication are solely the responsibility of Amol Madhukar Joshi.) Undertaking and completing this research would simply not have been possible without the generous support of the Kauffman Foundation. I express my deepest thanks to the leadership and staff of the Kauffman Foundation for making financial resources and intellectual capital available to scholars to conduct entrepreneurship-related research. 
The development of this research benefited enormously from numerous formal and informal discussions and interactions with colleagues around the world. I would like to thank the faculty and staff of the following institutions for giving me the opportunity to formally present my work during Fall 2010:

- Escuela Superior de Administración y Dirección de Empresas (ESADE), Business School, Barcelona, SPAIN

- Instituto de Empresa (IE) University, IE Business School, Madrid, SPAIN

- Nanyang Technological University, Nanyang Business School, SINGAPORE

- National University of Singapore, NUS Business School, SINGAPORE

- Università Commerciale Luigi Bocconi, Milan, ITALY

- University of Hawaii at Manoa, Shidler College of Business, Honolulu, HI

- University of Maryland, Smith School of Business, College Park, MD

- University of Texas at Austin, McCombs School of Business, Austin, TX

- Vanderbilt University, Owen Graduate School of Management, Nashville, TN

I would specifically like to thank the following people (listed alphabetically) who provided extremely thoughtful and insightful feedback on this research as part of invited presentations at their respective universities, sessions at research conferences, doctoral workshops, or impromptu discussions: Rajshree Agarwal, Phil Anderson, Dharm Bhawuk, Max Boisot, Alfonso Gambardella, Martin Ganco, Brent Goldfarb, Robert Grant, Ben Hallen, Andy Henderson, Kiyohiko Ito, Daniel Malter, Ishtiaq Mahmood, Matt Marx, Nandini Lahiri, Mike Lawless, Ivan Png, Rhonda Reger, Dimo Ringov, Juan Santolo, M.B. Sarkar, and Giovanni Valentini.

I thank Ashish Arora for encouraging me to conduct a historical analysis of the evolution and commercialization of signal processing (see Appendix) as part of my course project in his doctoral seminar on the Economics of Innovation. I 
would like to extend a special thanks to the array of industry experts whose vast knowledge of the history, products, firms, and technologies related to digital signal processing (DSP) were an extremely valuable resource for conducting this research. In particular, I would like to thank Will Strauss, CEO, of Forward Concepts and Robert Cravotta, former Technical Editor of Electronic Design News, for their assistance with obtaining extensive archival data and background materials on the DSP industry. I also thank Paul Allison of the University of Pennsylvania and the wonderful staff of the Odum Institute at UNC for their help in setting up some of the preliminary statistical analyses used in this research.

I thank the judges, fellow finalists, and three anonymous reviewers from the 2010 INFORMS Organization Science Dissertation Proposal Competition for their constructive criticism of the original dissertation proposal upon which this research is based. I also thank session participants at the following events held in 2010 for their comments and suggestions for improving earlier versions of this research: the Consortium for Competitiveness \& Cooperation (CCC) Colloquium, the Strategic Management Society (SMS) Conference, the Atlanta Competitive Advantage Conference (ACAC), the Business History Conference (BHC) Annual Meeting, and the Industry Studies Association (ISA) Conference. 


\section{PREFACE}

From time immemorial, man has desired to comprehend the complexity of nature in terms of as few elementary concepts as possible.

Abdus Salam, 1979 Nobel Laureate in Physics 


\section{TABLE OF CONTENTS}

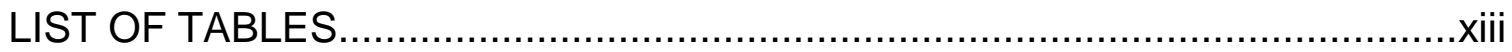

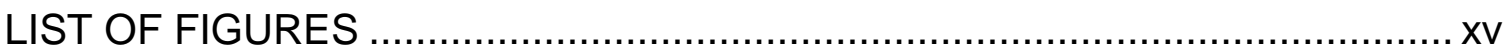

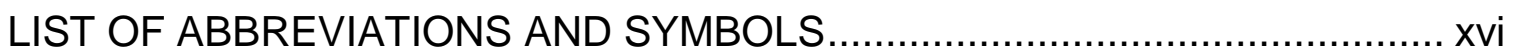

Chapter

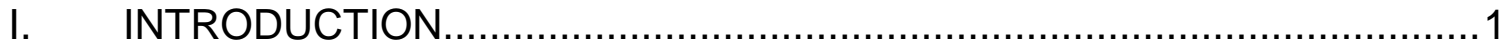

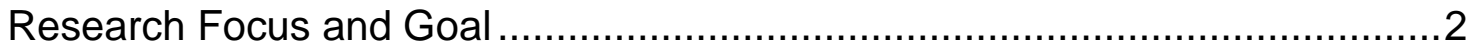

What is an Algorithm? .................................................................

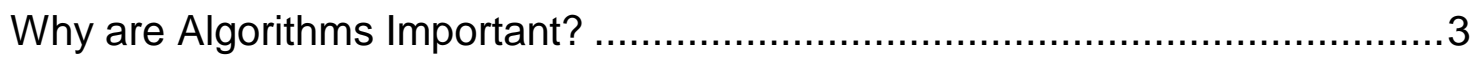

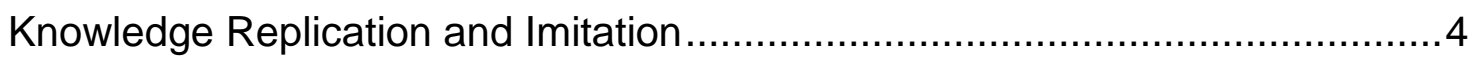

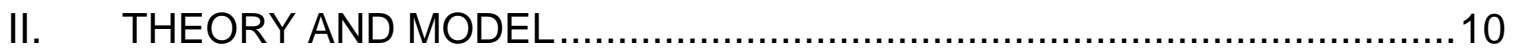

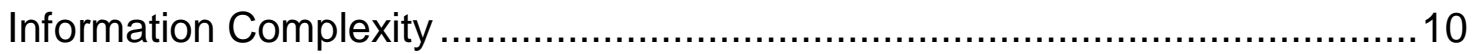

Algorithmic Complexity and Computational Complexity ..........................10

Organizations as Information Processing Systems .............................. 12

A Generalized Model of Information Complexity .................................... 14

Model Assumptions and Definitions ...............................................14

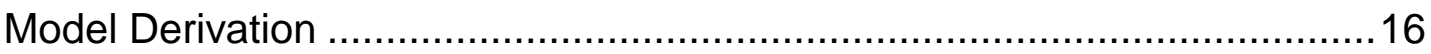

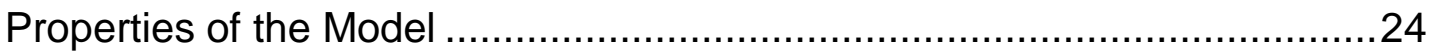

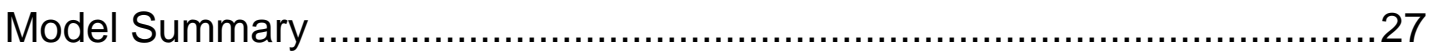

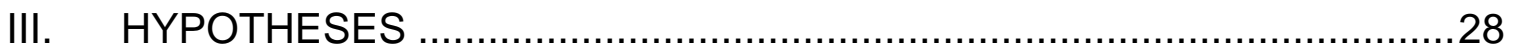

Hypotheses for Effects of Differences in Information Complexity ..................28

Algorithmic Complexity and the Likelihood of Replication and Imitation.......28 
Computational Complexity and the Likelihood of Replication and Imitation .29 Level of Information Complexity and the Likelihood of Replication and Imitation

Hypotheses for Effects of Differences in Intellectual Property (IP) Regime .....33

Change in Strength of IP Regime and the Likelihood of Replication and Imitation

Technology Licensing and the Likelihood of Replication and Imitation..........35

Hypotheses for Effects of Differences in Type of Entrant .............................38

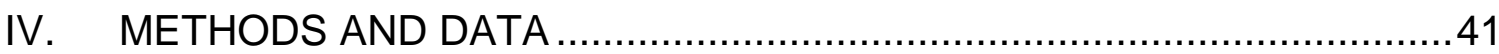

Empirical Setting: The Signal Processing Industry .....................................41

Data Sample and Data Collection Procedures ...........................................43

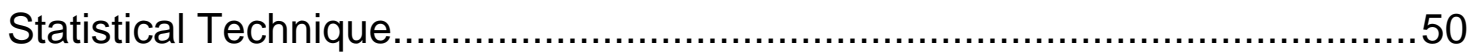

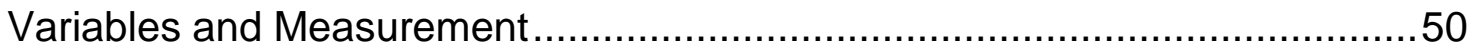

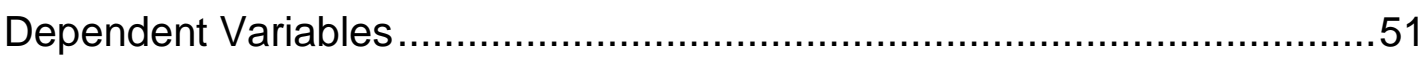

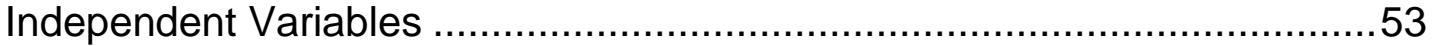

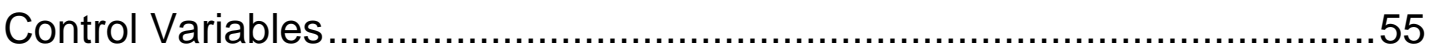

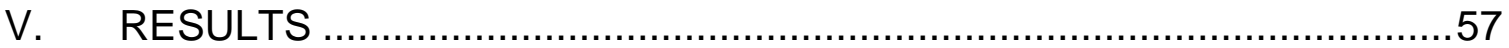

Descriptive Statistics and Correlations ….............................................57

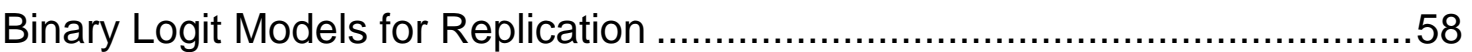

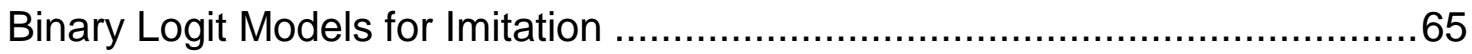

Sub-Sample Analyses for Different Levels of Complexity ..............................68

Multinomial Logit Models for Product Outcomes ........................................70

Analyses for Different Types of Entrants ……......................................... 71

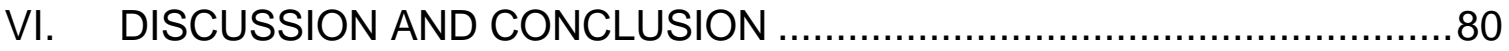

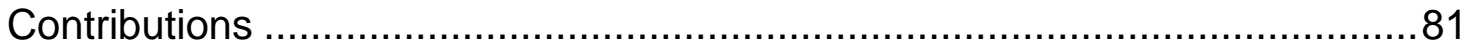




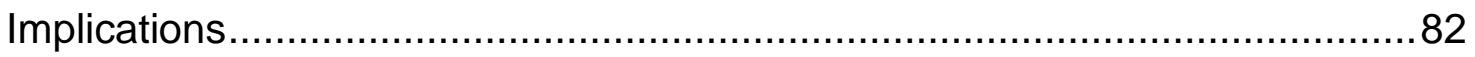

Limitations and Future Directions for Research ..........................................89

APPENDIX: INDUSTRY SETTING AND HISTORICAL CONTEXT ...................95

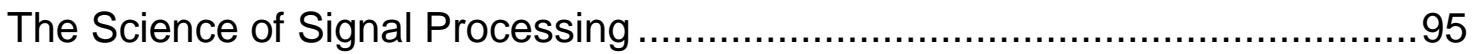

The Early Origins of Signal Processing, c. 2500 B.C..................................98

The "Palermo Stone" and Nilometers ...................................................98

Innovation in Primitive DSP System and Modern DSP Chips....................102

Modern Signal Processing as a Formalized Field of Research, 1948-1973 ..103 Information Theory in 1948: The Mathematical Logic for Designing DSPs 104 Transistors in 1948: The Physical Materials for Building DSPs .................106

Stored-Program Computing in 1948: The System Architecture for

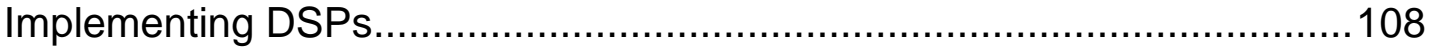

Timeline and Milestones in Modern Signal Processing, 1948-1974 ..........110

The Role of Computational Complexity in Driving Technological Adoption 115

The Role of Key Inventors in Generating More than One Type of

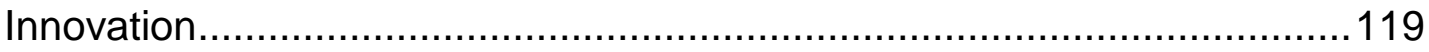

DSP as a Global High-Technology Industry, 1974-2008 ...........................120

Initial Generation of Commercial DSP ................................................121

1st Generation of Commercial DSP …..............................................122

2nd Generation of Commercial DSP .....................................................122

Subsequent Generations of Commercial DSP .....................................123

Moore's Second Law and Gene's Law: Addressing What Moore's Law

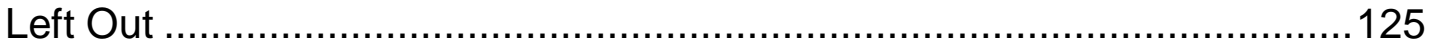

Discussion and Summary of Historical Analysis .......................................129

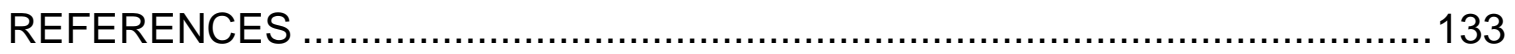




\section{LIST OF TABLES}

Table 1. Summary of the Generalized Model of Information Complexity ............27

Table 2. Established U.S. Legal Precedents on the Patentability of Algorithms .34

Table 3. Total Number of Product Introductions by Top 20 DSP Firms

Table 4. New Production Introductions by Each Generation of DSP

Technology

Table 5. Descriptive Statistics and Correlation Matrix.....................................60

Table 6. Binary Logit Models of Likelihood that a Product is Replicated.............61

Table 7. Binary Logit Models of Likelihood that a Product is Imitated .................62

Table 8. Estimating the "Paradox of Replication"............................................63

Table 9. Multinomial Logit Models of Likelihood of Product Outcomes...............64

Table 10. Contingency Tables and Odds Ratios...........................................73

Table 11. Estimating the "Paradox of Replication" for Diversifying vs. De

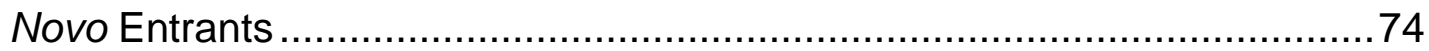

Table 12. Multinomial Logit Model of Likelihood of Product Outcomes for Diversifying vs. De Novo Entrants ...................................................... 75

Table 13. Summary of Results for Hypothesized Differences in Products,

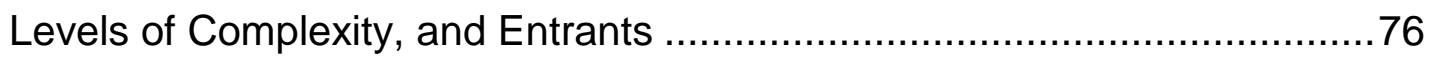

Table 14. "Rules of Thumb" for Estimating Replication and Imitation ................88

Table 15. Type of Innovation in Primitive DSP System and Modern DSP Chips 101

Table 16. Functional Specifications of the Small-Scale Experimental Machine (SSEM). 108

Table 17. Timeline of Events in the Field of Signal Processing, 1948-1949 .....111

Table 18. Timeline of Events in the Field of Signal Processing, 1950-1959 .....112

Table 19. Timeline of Events in the Field of Signal Processing, 1960-1969 .....113 
Table 20. Timeline of Events in the Field of Signal Processing, 1970-1974 .....114

Table 21. Discovery and Rediscovery of Computationally Efficient

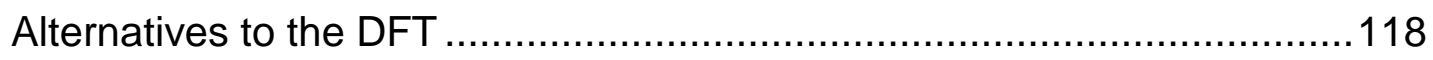

Table 22. Generations of DSP Technology and Market Drivers .....................124 


\section{LIST OF FIGURES}

Figure 1. Conceptual "Wedge" between Ease of Replication and Difficulty of Imitation

Figure 2. Knowledge Production and Key Milestones in Signal Processing, 1963-2008.

Figure 3. Feasible Complexity and Average Values of $A C$ and $C C$ for Each Generation of DSP Technology

Figure 4. Photograph of a Large Fragment of the "Palermo Stone"

Figure 5. Illustration of the Nilometer on the Isle of Rhoda, Cairo.....................100

Figure 6. Photograph of a Modern DSP Chip Manufactured by Texas Instruments, 1988

Figure 7. Photograph of a Replica of the SSEM, The World's First Stored-

Program Computer

Figure 8. The Computational Complexity of Fast Fourier Transform (FFT) in Comparison to the Discrete Fourier Transform (DFT). 


\section{LIST OF ABBREVIATIONS AND SYMBOLS}

$\begin{array}{ll}\text { A } & \text { Algorithm } \\ \text { AC } & \text { Algorithmic Complexity } \\ \text { BDTI } & \text { Analog Devices } \\ \text { C } & \text { Berkeley Design Technologies, Inc. } \\ \text { CC } & \text { Code or Description Method for Encoding Data or Instructions } \\ \text { CCPA } & \text { Computational Complexity } \\ \text { D } & \text { Court of Customs and Patent Appeals } \\ \text { E } & \text { Data Sequence } \\ \text { E } & \text { Expected Number of Errors } \\ \text { DFT } & \text { Error Rate (in number of errors per bit) } \\ \text { DSP } & \text { Discrete Fourier Transform } \\ \text { DSPs } & \text { Digital Signal Processing } \\ \text { EDN } & \text { Digital Signal Processors } \\ \text { FC } & \text { Electronic Design News } \\ \text { FFT } & \text { Forward Concepts } \\ \text { H } & \text { Fast Fourier Transform } \\ \text { IEEE } & \text { Candidate Model or Hypothesis for Compressing Data } \\ \text { I } & \text { Institute of Electrical and Electronics Engineers } \\ \text { IP } & \text { Instruction Sequence } \\ \text { L } & \text { Intellectual Property } \\ & \text { Length of a Data Sequence (in bits) } \\ \text { Candidate Model or Hypothesis for Compressing Instructions }\end{array}$




$\begin{array}{ll}\text { MDL } & \text { Minimum Description Length } \\ \mathrm{N} & \text { Set of all Natural Numbers } \\ \mathrm{P} & \text { Complexity Class of Problems Solvable in Polynomial Time } \\ \mathrm{R} & \text { Length of an Instruction Sequence (in bits) } \\ \text { SCOTUS } & \text { Supreme Court of the United States } \\ \text { SSEM } & \text { Small-Scale Experimental Machine } \\ \text { TI } & \text { Texas Instruments } \\ \text { USPTO } & \text { United States Patent and Trademark Office } \\ \Omega & \text { Language Used to Describe Data and Instructions }\end{array}$




\section{INTRODUCTION}

The beginning of knowledge is the discovery of something we do not understand.

Frank Herbert

Entrepreneurial discovery is a dynamic competitive process through which market participants obtain information about new opportunities (Fiet 1996; Kirzner 1997; Shane 2000). Entrepreneurial discovery is the initial spark which catalyzes the creation of new industries, fuels the formation of new firms, and ignites the introduction of new products. As prospective market participants, de novo entrants (startup and spinoffs) and diversifying entrants (established firms) alike may exploit entrepreneurial opportunities (Companys and McMullen 2007; Ganco and Agarawal 2009) by "carrying out new combinations" of technical or managerial innovations (Schumpeter 1934).

Ex ante validation of entrepreneurial opportunities is challenging for firms because "the only reliable confirmation that a previously unseen or unknown valuable opportunity does in fact exist occurs when a market has been created for the new item" (Eckhardt and Shane 2003). Thus, market participation in the form of a new product introduction by a firm may indicate the successful exploitation of the information obtained through the process of entrepreneurial discovery. Previous research suggests that there are two main sets of factors which are likely to impact the ability of entrepreneurs to discover new 
opportunities: "(1) the possession of the prior information necessary to identify an opportunity and (2) cognitive properties necessary to value it" (Shane and Venkataraman 2000). A key implication of this research is that a firm's ability to engage in entrepreneurial discovery and exploit new opportunities is essentially a function of the availability of prior information and the capacity to process this information (Galbraith 1977; Hayek 1945).

\section{Research Focus and Goal}

But what if the prior information that is available to firms is extremely complex, as is the case in many knowledge-intensive industries? Then does the inherent complexity of the available information in some way affect the ability of the firm to handle and use it in identifying and pursuing new opportunities? These questions stem from a more fundamental question which asks: "Why are some firms better able than others to exploit new opportunities?" This core issue in strategic management and entrepreneurship research has potentially significant implications for theory, practice, and policy, and is the primary focus of this study. My main goal is to answer this question in the context of how firms build competitive advantage in knowledge-intensive industries (Grant 1996a). In particular, I aim to extend earlier research (Rivkin 2000, 2001) by developing a methodology and testing a general model which explains how the complexity of the information (Boisot and Canals 2004) obtained through the process of entrepreneurial discovery affects the ability of firms to exploit new opportunities.

The general term complexity has a broad definition which is commonly used to describe the extent to which an entity exhibits the characteristics of 
intricacy, interdependency, complicatedness, multiplicity, etc. (Anderson 1999; Gell-Mann 1995; Simon 1962). In this study, the term complexity specifically refers to the concept of information complexity (Boisot and Child 1999; Boisot et al. 2007; Sorenson 2005), which is based on information theory (Blum 1967; Kolmogorov 1968; Shannon 1948) and describes the properties of algorithms.

\section{What is an Algorithm?}

Simply put, an algorithm is a set of instructions, a code. Though a seemingly basic concept, it is what made the modern world possible, for without the algorithm, there would be no computer. (Berlinski 2001)

An algorithm is defined as a collection or set of simple instructions for carrying out a task and may also be called a procedure or recipe (Sipser 1997). Patent law more precisely defines an algorithm as "a finite series of steps (or sequence of actions) for making a numerical or other mathematical calculation, terminating with provision of the result of the calculation" (Stem 1991).

\section{Why are Algorithms Important?}

Algorithms sound scary, of interest only to dome-headed mathematicians. In fact they have become the instruction manuals for a host of routine consumer transactions. Browse for a book on Amazon.com and algorithms generate recommendations for other titles to buy. Buy a copy and they help a logistics firm decide on the best delivery route. Ring to check your order's progress and more algorithms spring into action to determine the quickest connection to and through a call-centre. From analysing credit card transactions to deciding how to stack supermarket shelves, algorithms now underpin a large amount of everyday life.

Source: "Algorithms - Business by numbers," The Economist, Sept. 13, 2007

Beyond the consumer examples described above, within the knowledgeintensive sector of the economy, there are a number of emerging, high-growth industries which are based primarily on scientific and engineering advances in 
fundamental algorithms. In addition to digital signal processing (DSP) (Widrow and Stearns 1985), which is the empirical context for this study, these algorithmbased industries include the following: Internet search engines (Brin and Page 1998), the semantic web (Hendler and Berners-Lee 2010), bioinformatics and computational genomics (Sanger 2004), cryptography (Diffie and Hellman 1976), encryption (Goldwasser and Micali 1984), networking (Karmarkar 1984), telecommunications (Shannon 1948), fraud detection (Bolton and Hand 2002), and actuarial sciences (Jonker and Volgenant 1987). These examples reflect the diversity of segments of the knowledge-based economy where firms purposefully pursue innovation in algorithms in order to build competitive advantage.

\section{Knowledge Replication and Imitation}

In the previously described examples of algorithm-based industries, firms intentionally and systematically use algorithms to represent a unit of knowledge (Boulding 1966) such as a strategy, a product, a service, or a technology. Competitive advantage may arise from differences in the ability of firms to replicate and imitate (Grant 1996a, b) the algorithms representing these units of knowledge. Replication is the internal copying of a unit of knowledge (Nelson and Winter 1982) by the firm that originally produced it (Winter and Szulanski 2001), while imitation is the external copying of a unit of knowledge by the competitor(s) of the firm that originally produced it (Hill 1992). In other words, "imitation is simply replication performed by a competitor" (Teece and Pisano 1994).

In the context of the process of entrepreneurial discovery, knowledge replication and imitation activities may be strategic drivers of firm success or 
failure. Prior research suggests that "knowledge-based resources (applicable to discovery and exploitation of opportunities) are positively related to firm performance" (Wiklund and Shepherd 2003). The ability to replicate and imitate knowledge may also be an important determinant of the lead time (Bayus 1997; Cohen et al. 1996) required for introducing a new product and may affect the market share (Datar et al. 1997) and market value of the firm (Hendricks and Singhal 1997). A new product's lead time "acts as an enhancing moderator in entrepreneurs' exploitation decision policies" (Choi and Shepherd 2004). Furthermore, imitation in particular may be an underexplored factor (Mansfield 1961) in entrepreneurial discovery and related processes.

As Aldrich and Martinez (2007) explain "Overestimating the innovating capacity and personal traits of entrepreneurs has hidden the major role of imitation in entrepreneurial processes. Evolutionary theory calls our attention to the numerically dominant role of reproducers, rather than innovators." Whether a firm is primarily an originator of new innovations, or simply an imitator of existing innovations may have a profound influence on its chances of survival and growth (Aldrich and Kenworthy 1999; Lieberman 2006). However, originating an innovation is no guarantee of commercial success (Lieberman and Montgomery 1998; Srinivasan et al. 2004), and the "paradox of replication" (Kogut and Zander 1992) implies that originators and imitators face similar challenges in copying knowledge from internal and external sources (Cassiman and Veugelers 2006).

The "paradox of replication" embodies the concept that "efforts by a firm to grow by the replication of its technology enhances the potential for imitation" 
(Kogut and Zander 1992). For example, products based on technologies that are easy for a firm to replicate may also be easy for the firm's competitors to imitate, while products based on technologies that are difficult for a firm to replicate may also be correspondingly difficult for its competitors to imitate (Rivkin 2000). Thus, in terms of assessing competitive advantage, it is critical to understand the relative difference in the ease of replication versus the ease of imitation associated with the reproduction of a unit of knowledge (Grant 1996a). The magnitude of the difference between the ease of replication and imitation may be influenced by the strength of the prevailing intellectual property (IP) regime (Lerner 2002), which may be a "formidable imitation barrier" (Teece et al. 1997) for firms in many knowledge-intensive industries including semiconductors, (Ziedonis 2004), software (Bessen and Maskin 2009), telecommunications (Hill 1997), biotechnology (Gallini 2002), pharmaceuticals (Thomke and Kuemmerle 2002), and chemicals (Arora 1997).

In addition to legal barriers to imitation such as strong IP regimes, firms in knowledge-intensive industries may also encounter organizational barriers to imitation. Management theorists posit that causally ambiguous competencies create barriers to imitation and may increase the sustainability of competitive advantage (Barney 1991; Dierickx and Cool 1989). Causal ambiguity arises from three intrinsic characteristics of competencies (Reed and DeFillippi 1990): tacitness, specificity, and complexity. While previous conceptual work (Bharadwaj et al. 1993; Ganco and Agarwal 2009; Mosakowski 1997; Powell et al. 2006; Reed and DeFillippi 1990; Rivkin 2000, 2001) generates testable 
propositions for the individual and combined effects of these characteristics on knowledge replication and imitation processes in firms, there are relatively few empirical studies that validate and refine these propositions (King and Zeithaml 2001; Lippman and Rumelt 1982; Zander and Kogut 1995).

In particular, there is a dearth of empirical testing of the direct relationship between the complexity of a unit of knowledge and the subsequent replication and imitation of this knowledge. Investigating this relationship is critical for unlocking how firms in knowledge-intensive industries successfully exploit the information obtained through the process of entrepreneurial discovery. While prior research on complexity and knowledge replication and imitation is highly insightful, the bulk of this work is almost exclusively conceptual in nature and relies extensively on simulation studies (Ethiraj and Levinthal 2004; Ethiraj et al. 2008; Rivkin 2000, 2001) to test the propositions generated. Furthermore, the few existing empirical studies in this area (Sorenson 2005; Sorenson et al. 2006; Yayavaram and Ahuja 2008) all utilize some variation of the NK model (Kauffman and Levin 1987; Kauffman and Weinberger 1989; Lenox et al. 2006; Levinthal 1997; Siggelkow and Levinthal 2003) for capturing the relational complexity or interdependence among the modules of a complex system (Baldwin and Clark 2000; MacCormack et al. 2006; Sanchez and Mahoney 1996; Schilling 2000).

However, there are a number of situations in knowledge-intensive industries where the values of $N$ (the number of nodes in a complex system) and $K$ (the number of interconnections among these nodes) do not vary across units of knowledge. For example, two similar products that incorporate the same 
product architecture (Ulrich 1995) may not necessarily differ in terms of their values of $N$ and $K-$ measures which only capture the relational complexity of a product as a complex system (Frenken 2000,2006 ). These two architecturally similar products may in fact differ greatly in other dimensions of complexity such as the inherent complexity of the information associated with each product (Boisot et al. 2007; Solow et al. 1999; Sorenson 2005; Wilson and Latombe 1994). It is precisely this gap in the current research on complexity and knowledge reproduction processes that this study seeks to address both theoretically and empirically. I posit that under certain conditions that are prevalent in many knowledge-intensive industries, information complexity may serve as meaningful predictor of the likelihood that a newly introduced product is subsequently replicated, imitated, or both.

To evaluate this idea, I organize the study into five major steps described as follows. First, I outline the relevant theory related to information complexity. I integrate aspects of information theory and the knowledge-based view (KBV) of the firm to develop a generalized model of information complexity, replication, and imitation. Second, using this theoretical framework and generalized model, I formulate hypotheses which may be applied to any unit of knowledge such as a product, as long as the unit is representable in the form of an algorithm. Third, I explain the methodology including the data sample and collection methods, and specify the dependent, independent, and control variables in the model. Fourth, I test the model using a unique longitudinal dataset of new product introductions in a knowledge-intensive industry, digital signal processing (see Appendix for an in- 
depth analysis of the history and evolution of this industry). I quantify the previously described "paradox of replication" and present in detail the results of the analyses and summarize the key findings. Fifth and finally, I conclude with a discussion of the overall contributions, implications, limitations, and future directions of this research.

As a brief preview, this study provides empirical support for the following findings: (1) information complexity is negatively and significantly related to product replication and imitation; (2) in general, replicators have the greatest advantage over imitators at moderate levels of information complexity; (3) an IP regime change which strengthens the patentability of algorithms increases product replication, but does not significantly decrease imitation; (4) outbound licensing decreases product replication and increases imitation; (5) products introduced by de novo entrants are less likely to be replicated and more likely to be imitated than products introduced by diversifying entrants; and (6) diversifying entrants have the greatest advantage over de novo entrants at high and low levels of information complexity; neither type of entrant has a significant advantage over the other at moderate levels of complexity.

The background theory and derived model presented in the next chapter frames and guides the overall development of the study in subsequent chapters. 


\section{THEORY AND MODEL}

In this chapter, I outline a theoretical framework and generalized model of information complexity. I define the two main types of information complexity and conceptualize organizations as information processing systems with memory. I then develop a model for capturing the relationship between information complexity and knowledge reproduction via replication and imitation. Built on information-theoretic principles, the model is extensible to any information processing system, including organizations, and to any unit of knowledge that is represented as an algorithm.

\section{Information Complexity}

As introduced earlier, an algorithm is defined as a collection or set of simple instructions for carrying out a task and may also be called a procedure or recipe (Sipser 1997). If a unit of knowledge such as a strategy, a product, a service, or a technology can be fully specified as a finite and complete set of data and instructions, then it is representable in the form of an algorithm and the information complexity of the algorithm may be estimated (MacKay 2003). Based on the computational resources required, Gell-Mann (1995) describes two types of information complexity — algorithmic and computational.

\section{Algorithmic Complexity and Computational Complexity}

As a simple analogy, if one characterizes a unit of knowledge as a "recipe" (Nelson and Winter 1982), then the algorithmic complexity of this recipe 
corresponds to the number of words required to fully represent the entire recipe, while its computational complexity corresponds to the number of steps required to fully complete the recipe. As a general statistical theory for the estimation of the limits and efficiency of information processing, information theory (Shannon 1948 ) is ideally suited to the measurement and analysis of such recipes.

More formally defined in information-theoretic terms, algorithmic complexity measures the Minimum Description Length (MDL) (Barron et al. 1998) of the information required to represent an algorithm, while computational complexity measures the minimum amount of information processing capacity required to execute the algorithm (Blum 1967). Algorithmic complexity is based on the construct of space complexity, which measures the program size or memory required to completely encode and store an algorithm (Blum 1967). Algorithmic complexity is also referred to as the descriptive complexity (Chaitin 1997) of an algorithm or as its Kolmogorov (1968) complexity, or stochastic complexity (Rissanen 1986).

Computational complexity is based on the construct of time complexity, which is the number of instructions that it takes to solve "an instance of the problem as a function of the size of the input using the most efficient algorithm" (Blum 1967). Computational complexity is also referred to as the Blum (1967) complexity of an algorithm or as its communication complexity (Yao 1979), circuit complexity (Wegener 1987), or decision tree complexity (Buhrman and de Wolf 2002). Both types of information complexity, algorithmic and computational, embody a fundamental degree of irreducibility (Boisot 2000; Chaitin 2007). The 
two measures of complexity, algorithmic and computational, can be used to represent the availability of prior information and the capacity to process this information — two factors that are essential to the ability of a firm to exploit new opportunities. Now, specifically defined in terms of the process of entrepreneurial discovery, a firm's ability to exploit new opportunities is a function of the algorithmic and computational complexity of the algorithm(s) representing the firm's prior information.

\section{Organizations as Information Processing Systems}

A key assumption of this study is that organizations are informationprocessing systems with memory (Tushman and Nadler 1978). Organizational memory enables firms to encode, store, and retrieve information (Walsh and Ungson 1991). In this study, I define a firm's product architecture as a simplified subset of its organizational memory and a firm's new product introductions as the output of this organizational memory.

Product architecture is an over-arching methodology for organizing how a firm manages its innovation capabilities (Henderson and Clark 1990; Sanchez and Mahoney 1996). "Product architecture consists of three elements: a set of functions, a map of functions to modules, and interface specifications that explain how modules relate to one another" (Brown and Eisenhardt 1995). Within an organization, product architecture serves as a store of the modular information components or units of knowledge associated with a product or set of products (Frenken 2000; Hobday 1998; Hobday et al. 2000; Rosenkopf and Nerkar 1999, 2001). Product architecture is a form of organizational memory, which may be 
situated in standard operating procedures (March et al. 1958), routines (Nelson and Winter 1982), individuals (Loftus and Loftus 1976), dominant logics (Prahalad and Bettis 1986), dominant coalitions (Hambrick and Mason 1984), roles (Simon 1976), and culture (Smircich 1983).

New product introductions are viewed as the output of the firm's prior information stored in the organizational memory represented by product architecture and thereby indicate the earlier discovery and evaluation of an entrepreneurial opportunity (Eckhardt and Shane 2003). If one conceptualizes organizations as information processing systems (Tushman and Nadler 1978) and units of knowledge such as products as the input and output of these systems, the principle of irreducibility (Chaitin 2007) implies that the inherent complexity (Wilson and Latombe 1994) of the prior information used to generate a new product cannot be less than the inherent complexity of the product itself. Thus, by first observing the new product introductions made by firms in an industry, then representing these products in algorithm form, and finally measuring the algorithmic and computational complexity of these algorithms, the lower bound (Rissanen 1996) of the inherent complexity of each firm's prior information can be estimated. Following this approach, in the next section, I develop a generalized model for estimating information complexity. 


\section{A Generalized Model of Information Complexity}

First, I state core assumptions and define key concepts used in the formal construction of the generalized model of information complexity. Second, I derive the model using principles from information theory and the KBV of the firm. Third, I examine the basic properties of the model to generate insights for developing testable hypotheses. Fourth and finally, I summarize the generalized model of information complexity in relation to the replication and imitation of knowledge.

\section{Model Assumptions and Definitions}

The generalized model of information complexity is based on the explicit assumptions and definitions delineated below. Note that these fundamental information-theoretic concepts apply to any information processing system, including organizations. My approach directly follows the earlier work of Homer and Selman (2001). ${ }^{1}$ For consistency, I use identical notation as the authors.

1. "A finite set $\Sigma=\left\{a_{1}, a_{2}, a_{3}, \cdots, a_{k}\right\}$ of symbols is called a finite alphabet. $A$ word is a finite sequence of symbols. The length of a word $w$, denoted $|w|$, is the number of symbols composing it. The empty word is a unique word of length 0 and is denoted as $\lambda$. Note that $\lambda$ is not a symbol in the alphabet" (Homer and Selman, 2001, p. 1). ${ }^{2}$

2. " $\Sigma^{*}=$ denotes the set of all words over the alphabet $\Sigma$. A language is a set of words." Thus, $\Omega$ is a language if an only if $\Omega \subseteq \Sigma^{*}$. This means that every

\footnotetext{
${ }^{1}$ See "Chapter 1 - Preliminaries" of Homer and Selman (2001) ("Section1.1 Words and Languages" and "Section $1.2 \mathrm{~K}$-adic Representation" on pages 1-3) for a comprehensive set of assumptions, definitions, and functions.

${ }^{2}$ Note that any set is, by default, a subset of itself. Also, the empty set, \{\} , (sometimes called the null set) is a subset of any set. Further note that the empty word, $\lambda$, is not a set and has no relation to the empty set,\{\}. (Homer and Selman, 2001, p.1)
} 
element contained in set $\Sigma^{*}$ is also contained in set $\Omega$ (Homer and Selman, 2001, p. 2).

3. A prefix is a substring that begins the word, while a suffix is a substring that ends the word (Homer and Selman, 2001, p. 2).

4. "The concatenation of two words, $x$ and $y$, is the word $x y$. For any word $w, \lambda w$ $=w \lambda=w$. If $x=u v w$, then $v$ is a subword of $x$. If $u$ and $w$ are not both $\lambda$, then $v$ is a proper subword. ... The lexicographic ordering of $\Sigma^{*}$ is defined by $w<w^{\prime}$, if $|w|<\left|w^{\prime}\right|$, or if $|w|=\left|w^{\prime}\right|$ and $w$ comes before $w^{\prime}$ in ordinary dictionary ordering" (Homer and Selman, 2001, p. 2).

5. "Let $N$ denote the set of all natural numbers, i.e., $N=\{0,1,2,3, \ldots\}$... Let $\Sigma$ be a finite alphabet with $k$ symbols. Call the symbols $1, \ldots, k$. Every word over $\Sigma$ will denote a unique natural number" (Homer and Selman, 2001, p. 2-3). ${ }^{3}$

6. Let $x=\sigma_{n} \cdots \sigma_{1} \sigma_{0}$ be a word in $\Sigma^{*}$. Defined as a polynomial expression of finite length constructed from variables and constants, $N_{k}(x)$ is the natural number that word $x$ represents (Homer and Selman, 2001, p. 3):

$$
\begin{aligned}
N_{k}(\lambda) & =0, \\
N_{k}(x) & =N_{k}\left(\sigma_{n} \cdots \sigma_{1} \sigma_{0}\right) \\
& =\sigma_{n}{ }^{*} k^{n}+\cdots+\sigma_{1}{ }^{*} k^{1}+\sigma_{0}
\end{aligned}
$$

7. Defined recursively ${ }^{4}$,

$$
N_{k}(a x)=k^{*} N_{k}(x)+a
$$

\footnotetext{
${ }^{3}$ In order to represent the natural numbers as words over a finite alphabet, I use $k$-adic notation, which provides a one-to-one correspondence between $\Sigma^{*}$ and $N$ (Homer and Selman, 2001, p.3).

${ }^{4}$ To compute $N_{k}(a x)$, first find $a_{0}$ and then iterate until all values are known. For a formal mathematical proof showing that $N_{k}$ maps $\Sigma^{*}$ onto the natural numbers, see page 3 of Homer and Selman (2001).
} 


\section{Model Derivation}

The minimum description length ( $M D L$ ) principle is "based on the idea that the more we are able to compress (describe in a compact manner) a set of data, the more regularities we have found in it and therefore, the more we have learned from the data" (Grünwald 2007). A regularity in the data is a discernable pattern which can be used to compress the data, i.e., "describe it using fewer symbols than the number of symbols needed to describe the data literally" (Grünwald 2007). Utilizing the MDL principle, I derive the generalized model of information complexity in the series of steps enumerated below. My derivation closely follows the earlier work of Grünwald (2007) and uses similar notation and naming conventions throughout. ${ }^{5}$

1. Let $A$ be an algorithm representing a unit of knowledge $U$. The complete information content of algorithm $A$ consists of a finite sequence of data and instructions expressed in language $\Omega$.

2. Let data $D$ be the finite sequence of words $X=\left\{x_{1}, x_{2}, x_{3}, \cdots, x_{j}\right\}$ which fully describes $D$ and is associated with algorithm $A$. The natural number $N_{k}\left(x_{j}\right)$ represents the $j^{\text {th }}$ word, $x_{j}$ (Homer and Selman, 2001).

3. Let $C$ be a code or description method which encodes or maps $D$ to $D^{\prime}$. Under the MDL principle, all such description methods, $C$, satisfy the unique

\footnotetext{
${ }^{5}$ For a basic introduction to the MDL principle, see Chapter 1 "Learning, Regularity, and Compression," on pages 1-40 of Grünwald (2007). For additional background material on the fundamental mathematical concepts associated with algorithmic complexity, see (Barron et al. 1998; Chaitin 1975; 1997; Kolmogorov 1968; Li and Vitányi 2008; Rissanen 1986; 1996). For concepts related to computational complexity, see (Arora and Barak 2009; Cobham 1965; Goldreich 2008; Knuth 1968; MacKay 2003; Papadimitriou 1994). For a historical overview of the development of these concepts, see (Berlinski 2001; Chabert and Barbin 1999; Fortnow 2003) and the Appendix.
} 
decodability property: given a description $D^{\prime}$, one can fully reconstruct the original sequence $D$ (Grünwald, 2007, p.7).

4. The maximum value or upper bound of the total description length of $D$ is the summation of the length of all of the words $x$, represented as natural numbers $N_{k}\left(X_{j}\right)$, in the sequence $X$, such that

$$
L_{\max }=\left|x_{1}\right|+\left|x_{2}\right|+\left|x_{3}\right|+\cdots+\left|x_{j}\right|
$$

Note that the value of $L_{\max }$ is literally the full length of the entire word sequence $X$ representing data $D$ and includes all of the words, subwords, prefixes, and suffixes in $X$ (Homer and Selman, 2001).

5. If the sequence of words $X$ is not purely random, then there exists a code $C$ which results in a length value, $L$ that is a minimum value or lower bound of the total description length of $D$ (Grünwald, 2007, p.14-15). The value of $L$ is strictly less than $L_{\max }$ and satisfies the unique decodability property described earlier. The value of $L$ is the minimum description length or $M D L$ of the data sequence $D$ associated with algorithm $A$ and is defined in steps 6-8 below.

6. To select the best code, $C$, for encoding data sequence $D$ into $D^{\prime}$, let $\mathscr{H}_{1}, \mathscr{H}_{2}$, $\mathcal{H}_{3}, \cdots$ be a list of candidate models (e.g. $\mathcal{H}_{g}$ is the set of $g^{\text {th }}$ degree polynomials), each containing a set of point hypotheses (e.g., individual polynomials) (Grünwald, 2007, p.14). ${ }^{6}$

7. The best point hypothesis $H \in \mathscr{H}=\mathscr{H}_{1} \cup \mathscr{H}_{2} \cup \mathcal{H}_{3} \cdots$ for code $\mathrm{C}$ to represent the data $D$ is the one which minimizes the sum $L(H)+L(D / H)$, where

\footnotetext{
${ }^{6}$ For a detailed proof that such a code, $C$, always exists, see Chapter 5 of Grünwald (2007). As described in the section entitled "From Crude to Refined MDL" (Grünwald 2007, p. 15), "A model refers to a set of probability distributions or functions ... A hypothesis refers to an arbitrary set of probability distributions or functions ... A point hypothesis is a single probability distribution and ... may also be viewed as an instantiation of a model."
} 
$L(H)=$ the length in bits, of the description of the hypothesis, $H$; and

$L(D / H)=$ the length, in bits, of the description of the data when encoded using the hypothesis, $H$ (Grünwald, 2007, p.14).

8. Thus, the MDL, which is the minimum length of data sequence, $D$, may be formally expressed as (Grünwald, 2007, p.16):

$L(D)=\min _{H}\{L(D / H)+L(H)\}$ (in bits)

and may serve as an estimate of the algorithmic complexity of algorithm $A$.

9. Using the number of errors per bit, $\varepsilon$, for the expected error rate when copying data sequence $D$ either through replication or imitation, results in the following estimates of the expected number of errors, $E(D)$ :

$E_{\text {replication }}(D)=\left(\varepsilon_{\text {replication }}\right) \cdot L(D)$

is the expected number of replication errors; and

$E_{\text {imitation }}(D)=\left(\varepsilon_{\text {imitation }}\right) \cdot L(D)$

is the expected number of imitation errors. Note that $L(D)$ is a function of $N_{k}\left(X_{j}\right)$ expressed in polynomial form (Homer and Selman, 2001).

10. Instructions are the specific procedures or steps that algorithm $A$ must properly execute to complete a defined task. In the most general sense, instructions are simply another form of data and as such are representable using an alphabet, symbols, words, languages and numbers as defined earlier (Homer and Selman, 2001). Let $C$ be a code or description method which encodes or maps / to l' (Grünwald, 2007, p.7).

11. Let $P$ be the complexity class of computational problems that are solvable in polynomial time (Cobham 1965). For any decision problem that can be 
expressed as an algorithm $A$ in complexity class $P$, it is feasible to execute the algorithm and compute a solution to the problem (Homer and Selman, 1992). This implies that the amount of computational resources or information processing capacity required to execute all of the instructions contained in algorithm $A$ that is in class $P$ has a maximum value or upper bound, $R_{\max }$, that may be expressed in polynomial form (Goldreich 2008).

12. Let $I$ be the finite sequence of instructions $I=\left\{i_{1}, i_{2}, i_{3}, \cdots, i_{j}\right\}$ which fully describes the execution of algorithm $A$ that is in class $P$ and uses data sequence $D$. The natural number $N_{k}\left(i_{j}\right)$ represents the $j^{\text {th }}$ instruction, $i_{j}$, in polynomial form (Homer and Selman, 2001) ${ }^{7}$

13. The maximum value or upper bound of the total instruction length of $I$ is the summation of the length of all of the instructions $i$, represented as natural numbers $N_{k}\left(i_{n}\right)$, in the sequence $I$, such that

$R_{\max }=\left|i_{1}\right|+\left|i_{2}\right|+\left|i_{3}\right|+\cdots+\left|i_{j}\right|$

Note that the value of $R_{\max }$ is literally the full length of the entire instruction sequence $I$ associated with algorithm $A$ and includes all of the words, subwords, prefixes, and suffixes in I (Homer and Selman, 2001).

14. If the sequence of instructions $/$ is not purely random, then there exists a code $C$ which results in a length value, $R$ that is a minimum value or lower bound of the total instruction length of I(Grünwald, 2007, p.14-15).

15. The value of $R$ is strictly less than $R_{\max }$ and satisfies the unique decodability property described earlier (Grünwald, 2007, p.7). The value of $R$ corresponds to the minimum amount of information processing capacity required to fully

\footnotetext{
${ }^{7}$ Note that the values of $j$ for $I$ and $D$ do not have to be equal and can be any finite integer.
} 
execute the instruction sequence I associated with algorithm $A$. The value of $R$ is more explicitly defined in steps 16 through 18 below.

16. To select the best code, $C$, for encoding instruction sequence $I$ into $I$ ', let $\mathscr{M}_{1}$, $\mathscr{M}_{2}, \mathscr{M}_{3}, \cdots$ be a list of candidate models (e.g. $\mathscr{M}_{n}$ is the set of $n^{\text {th }}$ degree polynomials), each containing a set of point hypotheses (e.g., individual polynomials) (Grünwald, 2007, p.14).

17. The best point hypothesis $M \in \mathscr{M}=\mathscr{M}_{1} \cup \mathfrak{M}_{2} \cup \mathfrak{M}_{3} \cdots$ for code $C$ to represent the instructions $/$ is the one which minimizes the sum $R(M)+R(I / M)$, where $R(M)=$ the length in bits, of the description of the hypothesis, $M$; and $R(I / M)=$ the length, in bits, of the description of the instructions when encoded using the hypothesis, $M$ (Grünwald, 2007, p.14).

18. Thus, the minimum amount of information processing capacity required, $R$, may be expressed as (Grünwald, 2007, p.16):

$$
R(I)=\min _{M}\{R(I / M)+R(M)\} \text { (in bits) }
$$

19. Using the number of errors per bit, $\varepsilon$, for the error rate when copying instruction sequence I either through replication or imitation, results in the following estimates of the expected number of errors, $E(I)$ :

$E_{\text {replication }}(I)=\left(\varepsilon_{\text {replication }}\right) \cdot R(I)$

is the expected number of replication errors; and

$$
E_{\text {imitation }}(I)=\left(\varepsilon_{\text {imitation }}\right) \cdot R(I)
$$

is the expected number of imitation errors. Note that $R(I)$ above is a function of $N_{k}\left(i_{j}\right)$ expressed in polynomial form (Homer and Selman, 2001). Specifically, $R(I)$ is also a function of the $n^{\text {th }}$ degree or highest order point 
hypothesis $M_{n} \in M_{n}$ included in code $C$ which minimizes the sum $R(M)+\mathrm{R}(I /$ M).

20. Let $T_{C}(s)$ be the time or total number of steps (Papadimitriou 1994) required to execute algorithm $A$ using code $C$ for a given size input $s$ into algorithm $A$. Since the code $C$ includes $n^{\text {th }}$ degree or highest order point hypothesis $M_{n}$, the total number of steps required to execute algorithm $A$, must be a function of and proportional to the size of input $s$ to the $n^{\text {th }}$ degree, as shown below:

$$
T_{C}(n)=f\left(s^{n}\right) \propto s^{n}
$$

21. Let $O(z)$ be a function ${ }^{8}$ which returns the highest order polynomial contained in the polynomial expression $z$ (Knuth 1997, 2000). If $z=R(I)$, then

$$
\begin{aligned}
& O(R(I))=n, \text { and } \\
& O\left(T_{C}(s)\right)=O\left(f\left(s^{n}\right)\right)=n, \text { since } T_{C}(s)=f\left(s^{n}\right) \propto s^{n}
\end{aligned}
$$

22. Substituting $O(R(I))$ for $n$, results in the following

$$
O\left(T_{C}(s)\right)=O(R(I))=n
$$

Since the value of $R$ is strictly less than $R_{\max }$, it follows that the value of $O(R)$ must be less than or equal to $O\left(R_{\max }\right)$. Therefore the value of $n$ is the lower bound of the amount of polynomial time required to compute a solution to the decision problem represented by algorithm $A$ in complexity class $P$. Since $n$ is also the degree of highest order polynomial included in code $C$, which minimizes the encoding of instruction sequence $I$ into $l$,' then computing $O(R(I))$ yields exactly the same value as computing $O\left(T_{C}(s)\right)$. Thus, $O(R(I))$ may serve as an estimate of the computational complexity of algorithm $A$.

\footnotetext{
${ }^{8}$ This is commonly referred to as "big oh" or "big Omicron" notation (Knuth 2000) and is widely used in the analysis of algorithms. For a detailed explanation and proof of this function see (Knuth 1997; Sipser 1997).
} 
23. Based on the results obtained in steps $1-22$, I now formally define the expressions for the algorithmic complexity and computational complexity of algorithm $A$. The algorithmic complexity corresponds to the space complexity or program size associated with algorithm $A$, and it is denoted as AC. The computational complexity corresponds to the time complexity or number of steps associated with algorithm $A$, and it is denoted as CC. The formal expressions for estimating $A C$ and $C C$ are shown below.

Algorithmic Complexity: $A C=L(D)=\min _{H}\{L(D / H)+L(H)\}$

Computational Complexity: $C C=O\left(T_{C}(n)\right)=O(R(I))=n$

24. Based on the preceding steps, I formally define the probability that a unit of knowledge $U$ represented by algorithm $A$ is successfully copied via replication or imitation as shown below.

$$
\begin{aligned}
& \operatorname{Pr}\left(U_{\text {replication }}\right)=f\left(A C, C C, \varepsilon_{\text {replication }}\right) \\
& \operatorname{Pr}\left(\cup_{\text {imitation }}\right)=f\left(A C, C C, \varepsilon_{\text {imitation }}\right)
\end{aligned}
$$

The probability of successfully replicating a unit of knowledge $U$ is a function

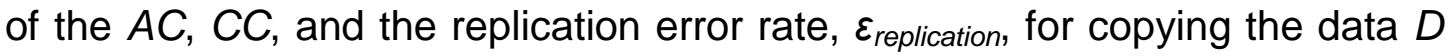
and instructions $I$ associated with algorithm $A$. Similarly, the probability of successfully imitating a unit of knowledge $U$ is a function of the $A C, C C$, and the imitation error rate, $\varepsilon_{\text {imitation, }}$ for copying the data $D$ and instructions $I$ associated with algorithm $A$.

25. If the occurrence of copying is modeled as a binary event (a unit of knowledge $U$ either is copied or it is not copied), then the logistic function can be used to model the outcome (Allison 2003; Hosmer and Lemeshow 2008). 
Since replication and imitation are both forms of copying and the only difference is in the actor that is doing the copying, the general model shown below applies to both. For $k$ explanatory variables and the $i^{\text {th }}$ unit of knowledge $U_{i}$ the model (Allison 2003) is specified as follows:

$$
\begin{aligned}
& \ln \left[\frac{p_{i}}{1-p_{i}}\right]=\alpha+\beta_{1} x_{i 1}+\beta_{2} x_{i 2}+\beta_{3} x_{i 3} \cdots+\beta_{k} x_{i k} \\
& p_{i}=\frac{1}{1+e^{-\alpha-\beta_{1} x_{i 1}-\beta_{2} x_{i 2}-\beta_{3} x_{i 3} \cdots-\beta_{k} x_{i k}}}
\end{aligned}
$$

26. Let $k=3$ and let $A C, C C$, and the error rate, $\varepsilon$, be the three explanatory variables in the model as shown below:

$$
\begin{aligned}
& x_{i 1}=\mathrm{AC}=L\left(D_{i}\right) \\
& x_{i 2}=\mathrm{CC}=n_{i} \\
& x_{i 3}=\varepsilon=\varepsilon_{\text {replication }} \text { for replication and } \varepsilon=\varepsilon_{\text {imitation }} \text { for imitation }
\end{aligned}
$$

27. Substituting Eq. 23-25 into Eq.22, results in the following generalized model of information complexity, which may be used the estimate the probability $p_{i}$ that $y_{i}=1$ for the replication and imitation of unit of knowledge $U$ represented by algorithm $A$.

$p_{i}=\frac{1}{1+e^{-\alpha-\beta_{1} A C-\beta_{2} C C-\beta_{3} \varepsilon}}$

28. For replication, the general model is

$$
p_{i}(\text { replicated })=\frac{1}{1+e^{-\alpha-\beta_{1} A C-\beta_{2} C C-\beta_{3} \varepsilon_{\text {replication }}}}
$$

29. Similarly, for imitation, the general model is

$$
p_{i}(\text { imitated })=\frac{1}{1+e^{-\alpha-\beta_{1} A C-\beta_{2} C C-\beta_{3} \varepsilon_{\text {imitation }}}}
$$




\section{Properties of the Model}

I examine some basic mathematical properties of the previously derived generalized model of information complexity. The purpose of this "thought experiment" (Davis et al. 2007) is to generate insights for developing testable hypotheses. A summary of the thought experiment is outlined below:

1. Assume that the value of the coefficient $\beta_{1}$ in the general model (Eq. 26) is negative, then ceteris paribus, an increase in the algorithmic complexity AC will decrease the probability $p_{i}$ of successfully copying a unit of knowledge $U$ represented by algorithm $A$.

2. Assume that the value of the coefficient $\beta_{2}$ in the general model (Eq. 26) is negative, then ceteris paribus, an increase in the computational complexity CC will decrease the probability $p_{i}$ of successfully copying $U$.

3. Assume that the value of the coefficient $\beta_{3}$ in the general model (Eq. 26) is negative, then ceteris paribus, an increase in the error rate $\varepsilon$ will decrease the probability $p_{i}$ of successfully copying $U$.

4. If $\varepsilon_{\text {replication }}<\varepsilon_{\text {imitation, }}$ implying that replicators have an advantage over imitators in terms of the error rate $\varepsilon$ for copying a unit of knowledge $U$, then ceteris paribus, $p_{i}($ replicated $)>p_{i}($ imitated $)$.

5. As $\varepsilon_{\text {imitation }}$ approaches the value of $\varepsilon_{\text {replication, }}$ the value of $p_{i}$ (replicated) approaches $p_{i}$ (imitated). If $\varepsilon_{\text {replication }}=\varepsilon_{\text {imitation, }}$ implying that replicators do not have an advantage over imitators in terms of the error rate for copying a unit of knowledge $U$, then ceteris paribus, $p_{i}($ replicated $)=p_{i}($ imitated $)$. 
6. If the values of the coefficients $\beta_{1}, \beta_{2}$, and $\beta_{3}$ in the general model (Eq. 26) are all negative and the values of $\mathrm{AC}$ and $\mathrm{CC}$ both approach zero, then ceteris paribus, the probability $p_{i}$ of successfully copying $U$ may be represented as

$$
p_{i} \approx \frac{1}{1+e^{-\alpha-\beta_{3} \varepsilon}}
$$

In other words, at low levels of algorithmic complexity $A C$ and computational complexity $C C$, the probability $p_{i}$ of successfully copying $U$ is primarily a function of the error rate $\varepsilon$. As $\varepsilon$ approaches zero in Eq. 29, $p_{i}$ approaches 1. In this case, if replicators have only a slight advantage over imitators such that the replication error rate is approximately equal to the imitation error rate, $\varepsilon_{\text {replication }} \approx \varepsilon_{\text {imitation, }}$, then ceteris paribus, $p_{i}($ replicated $) \approx p_{i}($ imitated $)$.

7. If the values of the coefficients $\beta_{1}, \beta_{2}$, and $\beta_{3}$, in the general model (Eq. 26) are all negative and the values of $A C$ and $C C$ both approach infinity, then ceteris paribus, the probability $p_{i}$ of successfully copying $U$ may be represented as

$p_{i} \approx \frac{1}{1+e^{-\alpha-\beta_{1} A C-\beta_{2} C C}}$

In other words, at high levels of algorithmic complexity $A C$ and computational complexity $C C$, the probability $p_{i}$ of successfully copying $U$ is primarily a function of $A C$ and $C C$ as shown in Eq. 30. In this case, regardless of the possible size of the copying advantage of replicators versus imitators (reflected in the relative magnitude of the respective values of $\varepsilon_{\text {replication }}$ and

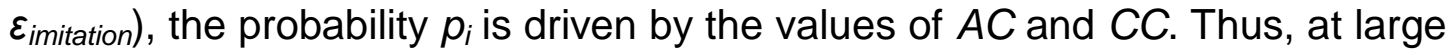
values of both $A C$ and $C C$, ceteris paribus, $p_{i}($ replicated $) \approx p_{i}($ imitated $)$. 
8. If the values of the coefficients $\beta_{1}, \beta_{2}$, and $\beta_{3}$, in the general model (Eq. 26) are all negative and the value of $A C$ approaches infinity while the value of $C C$ approaches zero, then ceteris paribus, the probability $p_{i}$ of successfully copying $U$ is primarily a function of $A C$.

9. Similarly, If the values of the coefficients $\beta_{1}, \beta_{2}$, and $\beta_{3}$, in the general model (Eq. 26) are all negative and the value of $A C$ approaches zero while the value of CC approaches infinity, then ceteris paribus, the probability $p_{i}$ of successfully copying $U$ is primarily a function of $C C$.

10. If the value of the coefficient $\beta_{1}$, is negative in the model for replication, but positive in the model for imitation, then ceteris paribus, an increase in $A C$ increases the difference between $p_{i}($ replicated $)$ and $p_{i}$ (imitated). In this case, an increase in $A C$ increases the relative advantage of replicators over imitators.

11. If the value of the coefficient $\beta_{2}$, is negative in the model for replication, but positive in the model for imitation, then ceteris paribus, an increase in $C C$ increases the difference between $p_{i}\left(\right.$ replicated) and $p_{i}$ (imitated).In this case, an increase in CC increases the relative advantage of replicators over imitators. 


\section{Model Summary}

The generalized model of information complexity developed in this chapter is summarized in Table 1 below.

Table 1. Summary of the Generalized Model of Information Complexity

\begin{tabular}{|c|c|}
\hline Variable or Function of Interest & Definition or Description \\
\hline$A C=L(D)=\min _{H}\{L(D / H)+L(H)\}$ & $\begin{array}{l}\text { Algorithmic Complexity - the minimum } \\
\text { description length (MDL) of the algorithm } A \\
\text { used to represent a unit of knowledge } U \text {, } \\
\text { corresponds to the number of words in a } \\
\text { "recipe" }\end{array}$ \\
\hline$C C=O\left(T_{C}(n)\right)=O(R(I))=n$ & $\begin{array}{l}\text { Computational Complexity - the minimum } \\
\text { number of instructions required to execute } \\
\text { algorithm } A \text { used to represent a unit of } \\
\text { knowledge } U \text {, corresponds to the number of } \\
\text { steps in a "recipe" }\end{array}$ \\
\hline$\varepsilon_{\text {replication }}$ & $\begin{array}{l}\text { Replication Error Rate }- \text { a constant } \\
\text { representing the number of errors/bit when } \\
\text { replicating an algorithm } A\end{array}$ \\
\hline$\varepsilon_{\text {imitation }}$ & $\begin{array}{l}\text { Imitation Error Rate }- \text { a constant } \\
\text { representing the number of errors/bit when } \\
\text { imitating an algorithm } A\end{array}$ \\
\hline$p_{i}=\frac{1}{1+e^{-\alpha-\beta_{1} A C-\beta_{2} C C-\beta_{3} \varepsilon}}$ & $\begin{array}{l}\text { Probability } p_{i} \text { that } y_{i}=1 \text { for the replication } \\
\text { and imitation of by algorithm } A \text {. The error } \\
\text { rate } \varepsilon=\varepsilon_{\text {replication }} \text { or } \varepsilon_{\text {imitation }}\end{array}$ \\
\hline
\end{tabular}




\section{HYPOTHESES}

Based on the theoretical framework and generalized model presented in the previous chapter, I present hypotheses for the effects on replication and imitation of differences in (1) the type and level of information complexity of a product; (2) the IP regimes under which a product is introduced; and (3) the type of entrants introducing the product.

\section{Hypotheses for Effects of Differences in Information Complexity}

\section{Algorithmic Complexity and the Likelihood of Replication and Imitation}

In this study, algorithmic complexity corresponds to the minimum description length (MDL as defined earlier) or the minimum amount of information required to fully represent a unit of knowledge in the form of an algorithm (Chaitin 1975). In terms of organizational information processing activities, which may be subject to chunking limits (Gobet and Simon 1998; Miller 1956; Simon 1974), the greater the amount of information associated with a product, the smaller the number of information chunks and the larger the size of each chunk required to fully represent the product (Baddeley 1994; Shannon 1948). In other words, the longer the MDL required for representing a unit of knowledge such as a product, the greater the potential number of errors in copying the information associated with the product (Grünwald 2007).

If the expected error rate of copying information is constant for a firm, then as the algorithmic complexity of a firm's products increases, the total number of 
errors made in the replication of the firm's own products should also increase. The total number of errors made in the imitation of the firm's products by competitors should also increase, since the inherent complexity of the product is the same for the firm and its competitors and is independent of possible differences in the respective error rates of copying information for firms and their competitors (Cowan et al. 1999). In addition, an increasing number of errors in copying previously introduced products may result in a decreasing number of new product introductions, once the cumulative number of copying errors reaches a threshold which impacts the proper functioning of the product (Rivkin 2000), which suggests Hypotheses H1a and H1b shown below:

Hypothesis H1a. The greater the algorithmic complexity of a product, the lower the likelihood that the product is subsequently replicated by the firm that first introduced it.

Hypothesis H1b. The greater the algorithmic complexity of a product, the lower the likelihood that the product is subsequently imitated by competing firms.

\section{Computational Complexity and the Likelihood of Replication and Imitation}

In this study, computational complexity corresponds to the minimum amount of information processing capacity required to fully execute an algorithm (Goldreich 2008). In terms of organizational information processing activities, instructions are simply another form of information associated with a unit of knowledge such as a product, and as such are also subject to chunking limits 
(Baddeley 1994; Miller 1956; Shannon 1948). Independent of the number of information chunks and size of each chunk, the number of instructions and the size of each instruction associated in the product also impacts the number of errors in copying the information content of the product (Grünwald 2007).

Just as a larger data length increases potential errors in copying information, a larger instruction set increases potential errors in copying instructions. At constant expected error rates of copying information, if the computational complexity of a firm's products increases, then the total number of errors that a firm makes in replicating its own products should also increase. Because the inherent complexity of the product is the same for the firm and its competitors and is independent of the respective error rates of copying information (Cowan et al. 1999), then the total number of errors made in the imitation of the firm's products by competitors should also increase. Furthermore, if the cumulative number of copying errors exceeds a level which impairs the intended operation of the product (Rivkin 2000), then for both replicators and imitators, the likelihood of new product introductions should decrease. This suggests Hypotheses $\mathrm{H} 2 \mathrm{a}$ and $\mathrm{H} 2 \mathrm{~b}$ presented below:

Hypothesis H2a. The greater the computational complexity of a product, the lower the likelihood that the product is subsequently replicated by the firm that first introduced it.

Hypothesis $\mathbf{H} \mathbf{2 b}$. The greater the computational complexity of a product, the lower the likelihood that the product is subsequently imitated by competing firms. 


\section{Level of Information Complexity and the Likelihood of Replication and Imitation}

Although increased complexity generally favors firms that are replicators versus imitators in knowledge reproduction activities, there are organizational limits on the ability to handle increasing levels of complexity (March and Sutton 1997; Reed and DeFillippi 1990; Rivkin 2000) that apply to both replicators and imitators. In reproducing knowledge, replicators appear to have the greatest relative advantage or "wedge" versus imitators (see Figure 1) when faced with decision problems of intermediate complexity (Cohen and Levinthal 1990; Knudsen and Levinthal 2007; Rivkin 2001). This is because replicators are more likely than imitators to have preferential access to "superior yet imperfect information about good solutions to complex problems," which results in a larger "wedge" between the ease of replication and ease of imitation (Rivkin 2001).

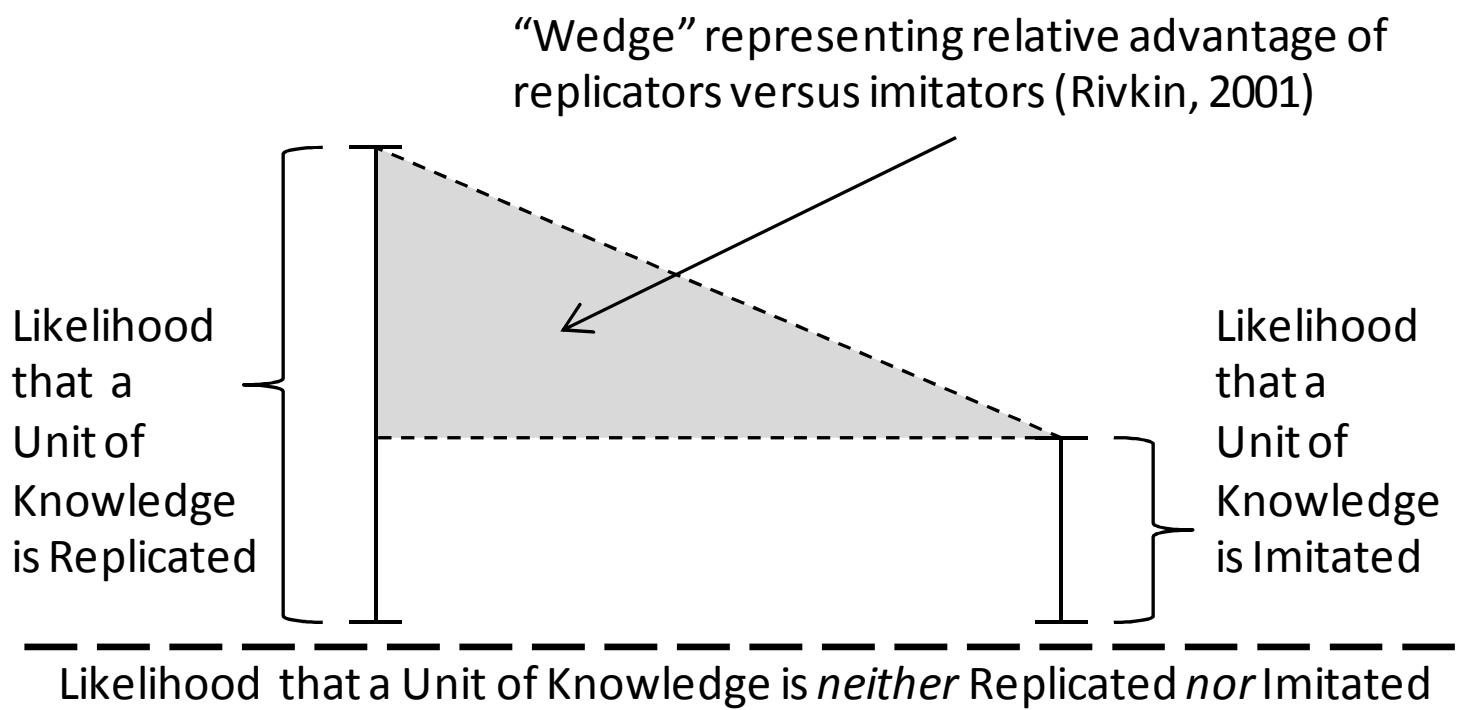

Figure 1. Conceptual "Wedge" between Ease of Replication and Difficulty of Imitation 
In contrast, when faced with decision problems of low complexity and correspondingly low causal ambiguity (Lippman and Rumelt 1982), both replicators and imitators appear to be able to effectively engage in the incremental search for solutions. Thus, at low levels of complexity, the informational advantage of replicators is short-lived and "easy imitation implies the rapid dissipation of rents" (Teece and Pisano 1994). When faced with decision problems of high complexity and correspondingly high causal ambiguity (King and Zeithaml 2001), both replicators and imitators appear to be similar in their ineffectiveness in conducting incremental searches for solutions. Because systems of greater complexity are sensitive to errors (Anderson 1999) in copying data and instructions, "the replicator's slightly imperfect knowledge then has little more value than the imitator's highly imperfect knowledge" and the "wedge" size is small (Rivkin 2001). Based on this logic, I propose Hypotheses H3a and H3b:

Hypothesis H3a. The relative difference between the likelihood that a product is replicated and the likelihood that is it is imitated will be higher at moderate levels of information complexity, in comparison to low levels of information complexity.

Hypothesis $\mathbf{H 3 b}$. The relative difference between the likelihood that a product is replicated and the likelihood that is it is imitated will be higher at moderate levels of information complexity, in comparison to high levels of information complexity. 


\section{Hypotheses for Effects of Differences in Intellectual Property (IP) Regime}

The hypotheses presented thus far examine the direct relationship between the types and levels of information complexity and the likelihood that a product is subsequently replicated and imitated. As introduced earlier, in addition to organizational barriers to imitation, a legal barrier to imitation is the strength of the IP regime. In this section, I propose two sets of hypotheses related to IP regimes. The first set of hypotheses $(\mathrm{H} 4 \mathrm{a}$ and $\mathrm{H} 4 \mathrm{~b})$ concerns the establishment of a legal precedent strengthening the patentability of algorithms. ${ }^{9}$ The second set of hypotheses ( $\mathrm{H} 5 \mathrm{a}$ and $\mathrm{H} 5 \mathrm{~b})$ concerns IP regimes that foster the formation of markets for technology which enable firms to make their patents available to other firms via licensing arrangements.

Change in Strength of IP Regime and the Likelihood of Replication and Imitation

If products are representable in algorithm form, and IP regimes confer patents to the firms that invent these algorithms, inventor firms may have clear economic incentives which encourage product replication and discourage product imitation (Klemens 2006; Oddi 1993). A prime example of an IP regime strengthening the patentability of algorithms occurred in 1988 when the United States Patent and Trademark Office (USPTO) granted AT\&T a patent (U.S. Patent 4,744,028) for Narendra Karmarkar's (1984) linear programming algorithm used to optimize the routing of calls over telecommunications networks. This

\footnotetext{
${ }^{9}$ Given the overall technological and economic importance of algorithms, there are remarkably few empirical studies of the innovation consequences of granting patents for algorithms (Bessen 2008; Bessen and Maskin 2009; Graham and Mowrey 2004; Hall and MacGarvie 2010). For a comprehensive analysis of aggregate trends in patenting and research, including software patents for algorithms, see Kortum and Lerner (1998). For a literature review of theoretical and empirical research on major patent policy shifts, see Jaffe (2000).
} 
landmark grant by the USPTO established, for the first time, that specific applications of algorithms are patentable as long as they meet the criteria of being novel, useful, and non-obvious (Stem 1991). The established U.S. legal precedents on the patentability of algorithms (Chisum 1985; Oddi 1993; Stem 1991) are summarized in Table 2 below.

Table 2. Established U.S. Legal Precedents on the Patentability of Algorithms

\begin{tabular}{|c|c|c|c|}
\hline Year & Case(s) & Institution & Impact on Patent Policy \\
\hline 1972 & $\begin{array}{l}\text { Gottschalk v. } \\
\text { Benson }\end{array}$ & $\begin{array}{l}\text { Supreme } \\
\text { Court of the } \\
\text { U.S. } \\
\text { (SCOTUS) }\end{array}$ & $\begin{array}{l}\text { Defined for the first time what legally } \\
\text { constitutes an algorithm } \\
\text { Weakened the patentability of algorithms by } \\
\text { specifically ruling that mathematical } \\
\text { algorithms are not patentable }\end{array}$ \\
\hline 1978 & $\begin{array}{l}\text { Parker v. } \\
\text { Flook }\end{array}$ & SCOTUS & $\begin{array}{l}\text { - Rejected the idea of a defined field of use for } \\
\text { algorithms } \\
\text { - Ruled that not just the algorithm, but also its } \\
\text { implementation had to be novel and non- } \\
\text { obvious } \\
\text { - Weakened the patentability of algorithms }\end{array}$ \\
\hline 1980 & $\begin{array}{l}\text { Diamond v. } \\
\text { Diehr }\end{array}$ & SCOTUS & $\begin{array}{l}\text { - Purged the concept of treating an inventor's } \\
\text { mathematical discoveries as known prior art } \\
\text { - Ruled that an algorithm-related patent } \\
\text { should be allowed when the implementation } \\
\text { of the algorithm is novel and the system as a } \\
\text { whole is non-obvious } \\
\text { - Weakened the patentability of algorithms }\end{array}$ \\
\hline 1982 & $\begin{array}{l}\text { Taner, Abele, } \\
\text { Pardo, and } \\
\text { Meyer cases }\end{array}$ & $\begin{array}{l}\text { Court of } \\
\text { Customs } \\
\text { and Patent } \\
\text { Appeals } \\
(\text { CCPA) }\end{array}$ & $\begin{array}{l}\text { Largely reaffirmed earlier SCOTUS } \\
\text { decisions } \\
\text { - Weakened the patentability of algorithms }\end{array}$ \\
\hline 1988 & $\begin{array}{l}\text { Granting of } \\
\text { patent to } \\
\text { AT\&T for } \\
\text { Karmarkar's } \\
\text { algorithm }\end{array}$ & $\begin{array}{l}\text { U.S. Patent } \\
\text { and } \\
\text { Trademark } \\
\text { Office } \\
\text { (USPTO) }\end{array}$ & $\begin{array}{l}\text { - Contradicted earlier SCOTUS and CCPA } \\
\text { decisions } \\
\text { - Strengthened the patentability of algorithms } \\
\text { by ruling for the first time that specific } \\
\text { applications or uses of algorithms are } \\
\text { patentable as long as they are new, useful, } \\
\text { and non-obvious }\end{array}$ \\
\hline
\end{tabular}

${ }^{10}$ As of October 1, 1982 the appellate jurisdiction of the Court of Customs and Patent Appeals was officially abolished. Since then, all appeals by patent applicants regarding claims rejected by the United States Patent and Trademark Office are handled by the Court of Appeals for the Federal Circuit. This appellate court adopted all of the earlier precedents for the patentability of algorithms from its predecessor (Chisum, 1985). 
Legal precedents strengthening the patentability of algorithms may enable replicators of algorithm-based products to capture greater economic rents (Amit and Schoemaker 1993; Teece and Pisano 1994) from these products, while simultaneously increasing the costs for competitors to engage in imitation or "reverse engineering" (Chang 1995; Klemens 2006; Markman et al. 2004; Samuelson and Scotchmer 2002). The preceding logic suggests Hypotheses $\mathrm{H} 4 \mathrm{a}$ and $\mathrm{H} 4 \mathrm{~b}$ shown below:

Hypothesis H4a. After a legal precedent strengthening the patentability of algorithms is established, the likelihood that new products are subsequently replicated by the firms that first introduced them is greater in comparison to products introduced before the precedent.

Hypothesis H4b. After a legal precedent strengthening the patentability of algorithms is established, the likelihood that new products are subsequently imitated by competing firms is lower in comparison to products introduced before the precedent.

\section{$\underline{\text { Technology Licensing and the Likelihood of Replication and Imitation }}$}

Markets for technology are arrangements in which IP representing intermediate technological inputs may be commercially exchanged among market participants via licensing transactions (Arora et al. 2001). Stronger IP rights frequently enable high degrees of specialization among firms within markets for technology (Arora et al. 2001) in knowledge-intensive industries (Hall and Ziedonis 2001; Linden and Somaya 2003). For example, in the 
semiconductor industry in the 1980s, the "strengthening of U.S. patent rights spawned 'patent portfolio races' among capital-intensive firms, but it also facilitated entry by specialized design firms" (Hall and Ziedonis 2001).

By facilitating trade in IP assets such as patents, markets for technology enable participating firms to harness the productivity gains that come from the division of labor into specialized activities by each firm (Arora and Merges 2004). As Adam Smith states in the opening line of The Wealth of Nations (1776), "the greatest improvement in the productive powers of labour, and the greater part of the skill, dexterity, and judgment with which it is anywhere directed, or applied, seem to have been the effects of the division of labour." Smith (1776) further explains that the division of labor is determined by the extent of the market. Limited markets will exhibit limited specialization, while larger markets will provide firms with greater opportunities for specialization (Stigler, 1951).

In a market for technology fostered by the existence and enforcement of strong IP rights, a firm's strategy space includes three main options for trading or commercializing units of knowledge that are protected by patents (Arora et al. 2001). A firm may choose to (1) setup inbound licensing for technology from external suppliers instead of pursuing internal development (Porter 1985); (2) offer outbound licensing of its own proprietary technology to other firms (Chesbrough and Crowther 2006); or (3) produce an integrated product by itself (Arora and Fosfuri 2003). Accordingly, a firm may be classified as an Inbound Licensee, an Outbound Licensor, or an Integrated Producer, based on its dominant mode of interaction with the market for technology. The strategic 
rationale for a Licensee to externally source IP is framed from a transaction cost minimization perspective as the classic "make vs. buy" decision (Teece 1986; Walker and Weber 1984) Similarly, the managerial logic for a firm to act as a Licensor or an Integrated Producer is framed in terms of determining whether the "revenue effect" outweighs the "rent dissipation effect" when licensing out (Arora and Fosfuri 2003).

Firms that find this trade-off unattractive will choose to take actions to enhance revenue (through higher unit pricing) and reduce rent dissipation (via exclusivity in licensing uses) or produce the integrated product themselves (Motohashi, 2008). Thus, a firm that makes its patented technologies available to other firms via outbound licensing does so with the explicit understanding that such licensing arrangements disclose knowledge (Arrow 1962; Dasgupta and David 1985) that may make its protected technologies easier to imitate. At the same time, the firm's economic incentives to replicate the technologies that are being licensed out are also reduced (Arora and Ceccagnoli 2006; Fosfuri 2006; Walker and Weber 1986). Based on the potential for increased ease of imitation and decreased incentives for replication associated with the intentional and strategic choice to license out patented technologies, I propose Hypotheses H5a and $\mathrm{H} 5 \mathrm{~b}$ below:

Hypothesis H5a. For products available through outbound licensing, the likelihood that the product is replicated is lower than that of products that are not available through licensing. 
Hypothesis H5b. For products available through outbound licensing, the likelihood that the product is imitated is higher than that of products that are not available through licensing.

\section{Hypotheses for Effects of Differences in Type of Entrant}

As stated out the outset of this study, startups and spinoffs (Klepper and Sleeper 2005) are nascent firms that are de novo entrants into a new market, while established firms are classified as diversifying entrants (Ganco and Agarawal 2009; Helfat and Lieberman 2002). Consistent with the taxonomy proposed by Helfat and Lieberman (2002), in this study, a de novo entrant is a separate legal entity from an established firm, while a diversifying entrant is the same legal entity as an established firm. As noted earlier, markets for technology expand the feasible strategy space for all firms (de novo entrants and diversifying entrants alike) by making it possible to trade and commercialize IP assets such as patents by engaging in inbound licensing, outbound licensing, or the integrated production of final products. Although the strategic options created by the formation of a market for technology are possible for all firms to pursue, different types of market entrants may find some options substantially more attractive than others.

For example, de novo entrants participating in a market for technology may have fewer resources available (Heirman 2005) than diversifying entrants and a greater strategic incentive to engage in outbound licensing. If a de novo entrant is an originator of innovations (Aldrich and Martinez 2007) then it may be able to effectively pre-empt the research and development (R\&D) activities 
(Gallini 1984) of potential competitors by licensing out its patented technologies to these other prospective market participants. Doing so may be a less costly and more profitable technology commercialization path for de novo entrants to pursue (Hall and Ziedonis 2001; Kim and Vonortas 2006; Lichtenthaler and Ernst 2009; Motohashi 2008), especially in knowledge-intensive industries which require substantial investments in R\&D. ${ }^{11}$

In contrast, diversifying entrants participating in a market for technology may have more resources available (Bayus and Agarwal 2007) than de novo entrants and a greater strategic incentive to engage in integrated production. If a diversifying entrant is an originator of innovations (Grindley and Teece 1997), then it may be able to maximize its potential profits by replicating its own patented technologies to produce final products rather than sell intermediate technological inputs via outbound licensing (Hall and Ziedonis 2001; Linden 2003; Ziedonis 2004). Note that although diversifying entrants are typically larger than de novo entrants, "large size per se does not impart the advantage in R\&D. Rather, it results from the limited character of firm growth and the nature of appropriability mechanisms that confine firms to exploiting their innovations chiefly through their own output" (Cohen and Klepper 1996). In other words, the pursuit of replication is advantageous to firms that have the technologies, resources, and organizational capabilities to "make" rather than "buy" (Walker

\footnotetext{
${ }^{11}$ For de novo entrants, outbound licensing may be considerably more attractive in knowledgeintensive industries such as semiconductors, where "Rising fixed costs give rise to Moore's Second Law: as the cost of transistors comes down, the cost of fabs goes up, albeit not at quite the same rate." Source: "The Semiconductor Industry: Under New Management," The Economist, April 2, 2009. For these same reasons, integrated production may be considerably more attractive for diversifying entrants than de novo entrants in these types of industries.
} 
and Weber 1984; 1986). In many knowledge-intensive industries, diversifying entrants may be better equipped than de novo entrants to engage in integrated production (Malerba 2010; Yoon and Malerba 2009).

As an intentional strategic choice, outbound licensing increases the likelihood that a product is imitated (see Hypothesis H5b), while integrated production increases the likelihood that a product is replicated (see Hypothesis H5a). Since de novo entrants have stronger incentives to engage in outbound licensing, while diversifying entrants have stronger incentives to engage in integrated production, I propose Hypotheses $\mathrm{H6a}$ and $\mathrm{H} 6 \mathrm{~b}$ below, which are consistent with the IP regime hypotheses $(\mathrm{H} 4 \mathrm{a}, \mathrm{H} 4 \mathrm{~b}, \mathrm{H} 5 \mathrm{a}$, and $\mathrm{H} 5 \mathrm{~b})$ presented earlier.

Hypothesis H6a. The likelihood that a product is replicated is lower for products introduced by de novo entrants in comparison to products introduced by diversifying entrants.

Hypothesis H6b. The likelihood that a product is imitated is higher for products introduced by de novo entrants in comparison to products introduced by diversifying entrants.

In the next chapter, I describe in detail the methods and data used to systematically test all of the hypotheses developed in this chapter. 


\section{METHODS AND DATA}

First, I describe the signal processing industry ${ }^{12}$ and the special characteristics which it shares with other algorithm-based industries and which facilitate the proposed analysis. Next, I discuss the data sample and data collection procedures. Finally, I outline the statistical technique and specify the key dependent, independent, and control variables.

\section{Empirical Setting: The Signal Processing Industry}

The KBV of the firm (Grant 1996b) suggests that "knowledge generation, accumulation, and application may be the source of superior performance" for firms (Decarolis and Deeds 1999). My choice of the signal processing industry is driven by the core premise of the study — that the inherent complexity of any product that is represented in algorithm form may be estimated by measuring its information complexity, and that the level of information complexity affects the likelihood that the product is subsequently replicated and imitated. Previous research has examined knowledge-intensive industries and studied firm performance and its association with attributes of knowledge such as its tacitness or codifiability (Cowan et al. 2000; Galunic and Simon 1998; Johnson et al. 2002; Kogut and Zander 1993). In contrast, this study examines the information complexity of newly introduced products and I would like to rule out alternative explanations.

\footnotetext{
${ }^{12}$ See Appendix for a detailed examination of the pre-history of signal processing as a scientific field and its technological evolution.
} 
The empirical setting of this study is formally referred to as the Digital Signal Processing (DSP) industry. Digital Signal Processors (DSPS) are physical devices or semiconductor "chips" that are used to digitally convert, transform and analyze audio, voice, image, video and other sensory signals from one form to another (Smith 1997). DSPs are essential components (Eyre and Bier 1998; Frantz 2000) used in a variety of consumer applications (cell phones, DVD players, stereos) and industrial solutions (telecommunications network switches, satellite transmission, global positioning). In 2007, worldwide DSP revenues were $\$ 27.2$ billion, representing about $10 \%$ of the total semiconductor industry revenue (Strauss 2007). The DSP industry and other algorithm-based industries exhibit a unique characteristic — their product introductions can be mapped to a finite set of algorithms of known or computable complexity (Deka 1995), which makes the proposed type of information-theoretic analysis possible.

Also, the algorithms underlying these product introductions are public knowledge and extensively codified. In fact, many of the algorithms first appeared in published academic research years, if not decades, before their actual implementation in the form of DSP products (Nebeker 1998a, b, c). Thus, there is a substantial common, codified, and cumulative base of knowledge available in the public domain to all firms that are current and prospective industry participants. Figure 2 shows historical knowledge production in the underlying scientific and engineering field of signal processing, measured in terms of the total annual number of patents granted and research papers published in academic journals. 
The generally low levels of tacitness of product knowledge for all firms in the DSP industry means that the process of "reverse engineering" of competitors' DSP products is not only feasible, it is a prevalent practice in the industry (Nelson and Winter 1982). The choice of the DSP industry ${ }^{13}$ effectively enables me to control for and minimize the potential for tacitness as a major source of competitive advantage and causal ambiguity (Reed and DeFillippi 1990) and focus on the inherent complexity of the products themselves as the primary simultaneous source of advantage and ambiguity.

\section{Data Sample and Data Collection Procedures}

In this study, I hand-assembled a comprehensive historical dataset of firmlevel and product-level market entry data and technical specifications for DSP chips from 1973 to 2009 (from industry inception to the most recent full year in which new product introduction data is available). I obtained the data from seven independent sources including: Berkeley Design Technology, Inc. (BDTI), Electronic Design News (EDN), Forward Concepts (FC), the Institute of Electrical and Electronics Engineers (IEEE) Signal Processing Society, the Smithsonian Institution's Chip Collection as well as information provided by the most active firms such as Analog Devices (AD) and Texas Instruments (TI).

I collected the firm-level and product-level data in the following manner.

First, I contacted representatives from BDTI, EDN, FC, the IEEE, the Smithsonian, AD and TI to obtain access to each organization's archives on the DSP industry. Next, I gathered and verified the firm-level and product-level data

\footnotetext{
${ }^{13}$ The first DSP product was introduced in 1973 (Strauss 2007), the year after the Gottschalk v. Benson case was decided by the SCOTUS (see Table 2). This also makes the DSP industry ideal for the study of the IP regime hypotheses $\mathrm{H} 4 \mathrm{a}, \mathrm{H} 4 \mathrm{~b}, \mathrm{H} 5 \mathrm{a}$, and $\mathrm{H} 5 \mathrm{~b}$ presented earlier.
} 
in each of the seven main datasets and then compared them to each other to generate a combined list of unique firms and products. Using this extensive archival data, I then validated the year that each product was introduced, the key technical characteristics of each product (architecture, generation of technology, performance specifications, etc.), and assigned each product to the firm that introduced it. In this combined list, firm and product names were normalized, duplicate firms and products were removed, and successor firms formed through mergers, acquisitions and spinoffs were identified and accounted for consistently. After completing this data consolidation effort, the combined sample was found to have 91 unique firms and a total of 853 new product introductions over a 37-year period. Each firm has at least one product introduction, and each product is assigned to only one firm. There are no jointly produced products in the sample. For firms with greater than 10 product introductions, the number of products and the approximate percentage of the sample that these products represent are shown in Table 3. The top 20 firms introduced 589 or $69.1 \%$ of the 853 products in the sample. The top 2 firms, AD and TI, accounted for $16.8 \%$ and $15.0 \%$, respectively, of all products introduced since industry inception.

The new product introductions span 8 generations (designated 0 through 7) of DSP technology as shown in Figure 3. Each successive generation of DSP technology incorporates architectural improvements which facilitate increasing levels of feasible complexity for DSPs. The value of the feasible complexity for each generation of technology is largely driven by Moore's Law, which states that the number of transistors which can be placed on an integrated circuit doubles 
every 18 to 24 months (Mollick 2006; Moore 1995). In this study, Moore's Law is used to extrapolate the theoretical upper bound of the overall level of complexity that is possible for all semiconductor products, including DSPs. Note that in Figure 3, the values of algorithmic and computational complexity as well as the value of the feasible complexity are base 10 logarithms of the actual values. Thus, a one unit increase on the $\mathrm{Y}$-axis corresponds to a $10 \mathrm{X}$ or one order of magnitude increase in algorithmic, computational, or feasible complexity. Each shift in the generation of DSP technology reflects one to two orders of magnitude or a $10 \mathrm{X}$ to $100 \mathrm{X}$ increase in the feasible complexity of DSP products. This indicates that dramatic increases in the level of algorithmic and computational complexity of DSP products are technologically possible for firms in this industry.

Table 4 summarizes the average levels of algorithmic and computational complexity and the maximum feasible complexity that is theoretically possible in each generation of technology. Nearly $51 \%$ or 434 products in the sample were introduced in the $6^{\text {th }}$ generation of DSP technology and about $25 \%$ or 209 products in the sample were introduced in the $7^{\text {th }}$ and most recent generation. In the $6^{\text {th }}$ generation of DSP technology, 134 (or $31 \%$ ) out of the 434 products introduced were made available through licensing. The 134 licensable products introduced in the $6^{\text {th }}$ generation of technology represent just over $71 \%$ of all of the licensable products introduced in the entire industry from inception to 2009 . In the $7^{\text {th }}$ generation, 31 (or 15\%) out of the 209 products introduced were made available through licensing. 


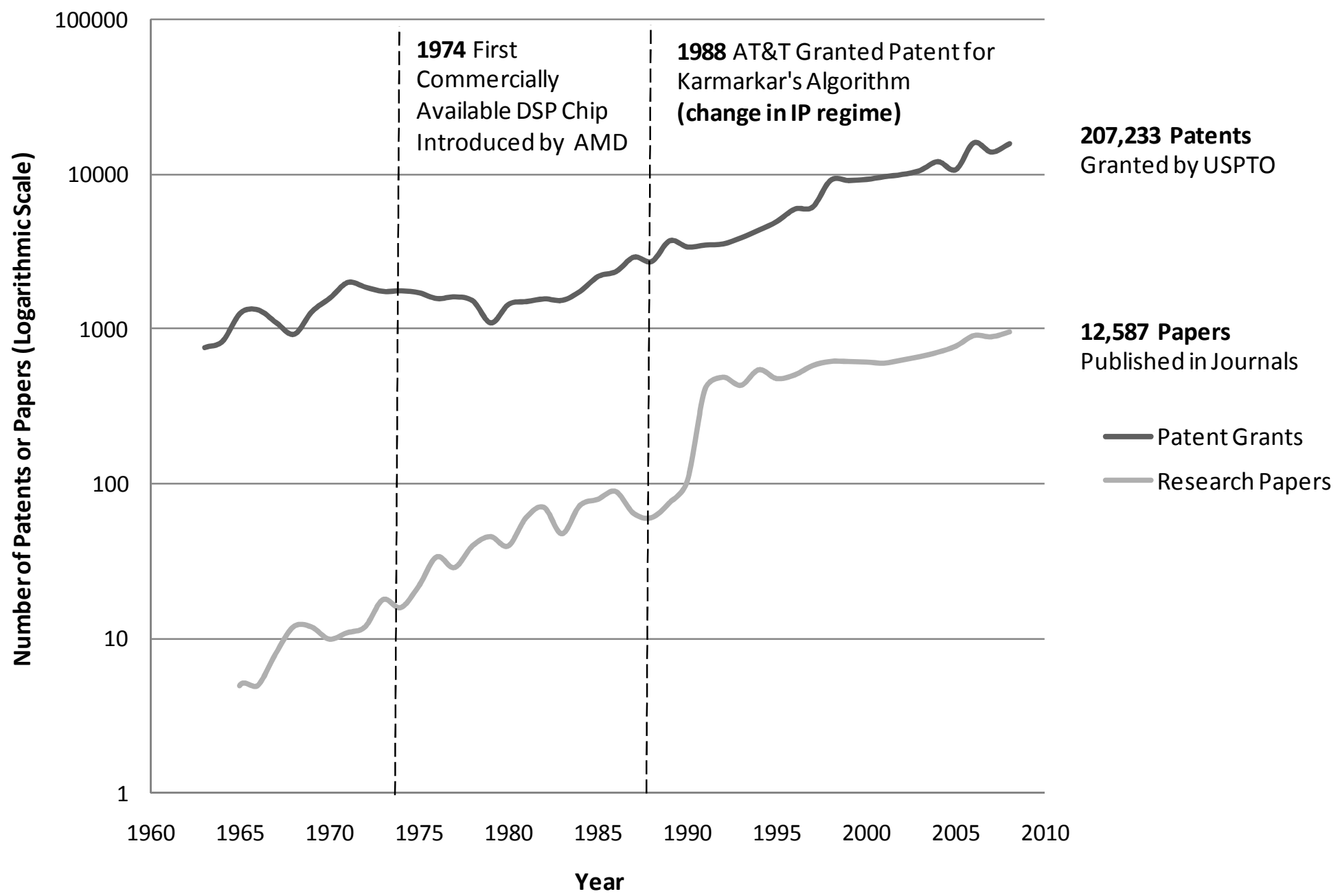

Figure 2. Knowledge Production and Key Milestones in Signal Processing, 1963-2008 
Table 3. Total Number of Product Introductions by Top 20 DSP Firms

\begin{tabular}{|c|c|c|c|c|}
\hline & & & Total Number of DSP & \\
\hline Rank & Firm Name & $\begin{array}{l}\text { Year of First DSP } \\
\text { Product Introduction }\end{array}$ & $\begin{array}{l}\text { Products Introduced by } \\
\text { Firm, 1973-2009 }\end{array}$ & $\begin{array}{l}\% \text { of } \\
\text { Total }\end{array}$ \\
\hline 1 & ANALOG DEVICES & 1986 & 143 & $16.8 \%$ \\
\hline 2 & TEXAS INSTRUMENTS & 1982 & 128 & $15.0 \%$ \\
\hline 3 & MOTOROLA & 1987 & 31 & $3.6 \%$ \\
\hline 4 & RENESAS & 2002 & 30 & $3.5 \%$ \\
\hline 5 & CEVA & 2002 & 24 & $2.8 \%$ \\
\hline 6 & LSI LOGIC & 1999 & 21 & $2.5 \%$ \\
\hline 7 & FREESCALE & 2003 & 20 & $2.3 \%$ \\
\hline 8 & ALTERA & 2004 & 18 & $2.1 \%$ \\
\hline 9 & HITACHI & 1982 & 18 & $2.1 \%$ \\
\hline 10 & NEC ELECTRONICS & 1980 & 18 & $2.1 \%$ \\
\hline 11 & ARC & 2001 & 16 & $1.9 \%$ \\
\hline 12 & ARM & 1998 & 16 & $1.9 \%$ \\
\hline 13 & AT\&T MICROELECTRONICS & 1984 & 16 & $1.9 \%$ \\
\hline 14 & MICROCHIP TECHNOLOGY & 1988 & 15 & $1.8 \%$ \\
\hline 15 & NXP SEMICONDUCTORS & 2006 & 15 & $1.8 \%$ \\
\hline 16 & DSP GROUP & 1993 & 13 & $1.5 \%$ \\
\hline 17 & VERISILICON & 2005 & 13 & $1.5 \%$ \\
\hline 18 & INFINEON TECHNOLOGIES & 1999 & 12 & $1.4 \%$ \\
\hline 19 & CIRRUS LOGIC & 2001 & 11 & $1.3 \%$ \\
\hline 20 & PHILIPS & 1987 & 11 & $1.3 \%$ \\
\hline & Subtotal for the Top & 20 DSP Firms in Sample & 589 & $69.1 \%$ \\
\hline & Subtotal for the other & 71 DSP Firms in Sample & 264 & $30.9 \%$ \\
\hline & & TOTAL & 853 & $100.0 \%$ \\
\hline
\end{tabular}




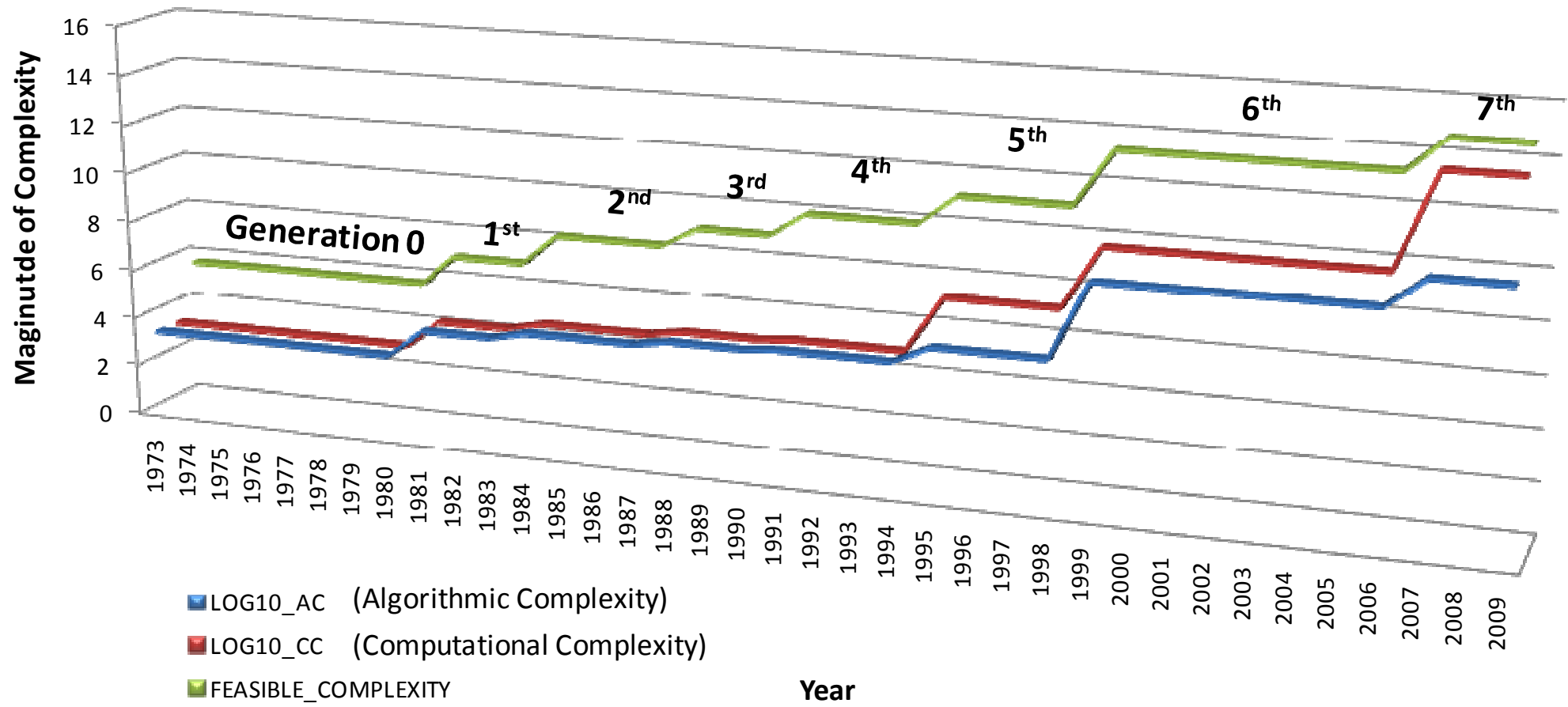

Figure 3. Feasible Complexity and Average Values of AC and CC for Each Generation of DSP Technology 
Table 4. New Production Introductions by Each Generation of DSP Technology

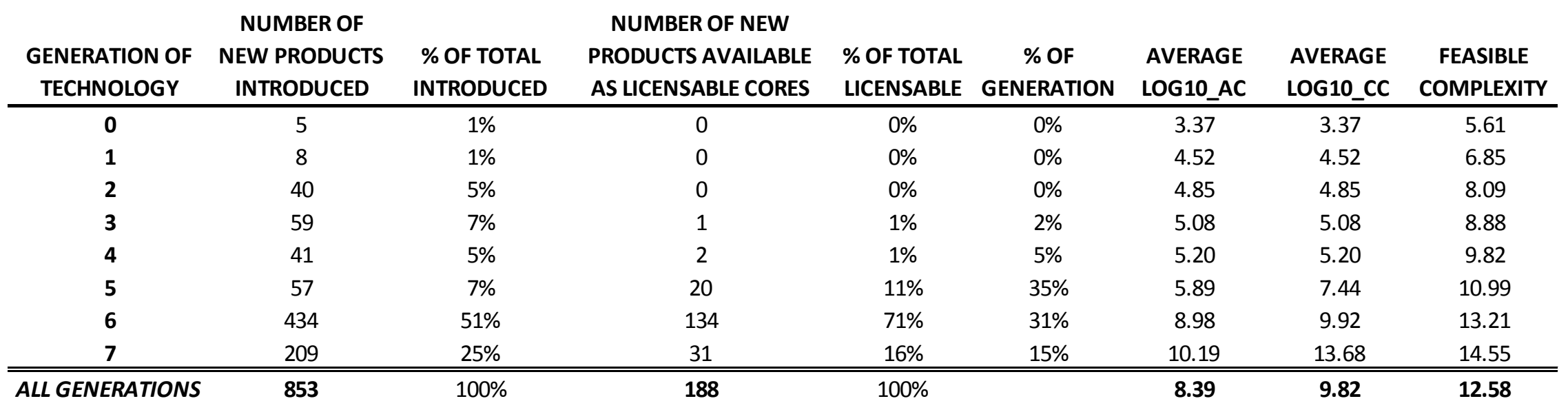

$\overrightarrow{0}$

For a summary of the specific technological changes and key market drivers associated with each generation of DSP technology listed above, see Table 22 in the Appendix. 


\section{Statistical Technique}

As described earlier, the research sample in this study consists of 853 products introduced by 91 firms over a 37-year period. Because my primary interest is in establishing the effect of the theoretical variables (algorithmic and computational complexity) at the product-level on the dependent variables, i.e., the likelihood of a product being replicated and imitated, across all of the products in the sample, I decided to use the generalized estimating equations (GEE) method (Nerkar 2003; Zeger and Liang 1986) to estimate the logistic regression model. The GEE framework is appropriate in this context for two main reasons: 1) the objective of the study is to estimate the average effect across the population as opposed to attributing heterogeneity to the clustering level, in this case the firm, as is typical in most firm-strategy research, 2) the sample of products is drawn from multiple firms and introduced over a large time window. The GEE logit framework estimates the same model as the standard logistic regression. The GEE logistic estimation differs from maximum-likelihood based logistic regression in that it allows for dependence within clusters, such as in longitudinal data (Diggle and Kenward 1994) and gives consistent estimates of the parameters and the standard errors by using a robust 'sandwich' estimator (Allison 2003; Hosmer and Lemeshow 2008).

\section{Variables and Measurement}

In this study, the dependent variables are the subsequent occurrences of replication or imitation of newly introduced products. The independent variables are information complexity measures (algorithmic and computational) and the 
change in IP regime. Note that an alternative to algorithmic and computational complexity is the use of an analytical technique called the design structure matrix (DSM), which captures the degree of modularity of a design (MacCormack et al. 2006). Measurement of inherent complexity using a DSM is not necessarily a meaningful predictor of replication and imitation for the DSP products in this study, because the degree of modularity does not vary much across architecturally similar products from the same generation of technology.

In addition to dummy variables for capturing firm fixed effects, the control variables include the geographic region in which the firm introducing the focal product is headquartered and the availability of the product through licensing. Lagged dependent variables (O'Brien 2003) control for possible unobserved heterogeneity at the product-level (Heckman et al. 1979) by taking into account the number of times a product has been previously replicated and imitated. I also control for the number of firms that have previously entered the market.

\section{Dependent Variables}

1. REPLICATED: This binary outcome variable indicates whether or not the focal product is subsequently replicated (copied by the same firm) within the same generation of technology. All 853 products are classified based on their technical features into one of eight mutually exclusive and collectively exhaustive categories representing each generation of DSP technology (Strauss 2007). If, for example, after its first product introduction, a firm later introduces a new product that is an extension of the original product (part of the same product line or product family) within the same generation of 
technology, then this is classified as the occurrence of a replication of the original product by the firm (REPLICATED $=1$ ). Note that later product introductions within the same product line or product family but not within the same generation of technology are not classified as the occurrence of a replication, because of the substantial technological differences between the products. I adopted this classification approach after extensive discussions with several DSP industry experts. For consistency and to ensure an independent and objective classification of the products grounded in industry practices, I followed the exact product categorizations standardized by EDN in their annual DSP industry directories and BDTI in their annual DSP chip benchmarking studies.

2. IMITATED: This binary outcome variable indicates whether or not the focal product is subsequently imitated (copied by competing firm(s)) within the same generation of technology. Similar to the approach described above for determining the subsequent occurrence of a replication, I followed a standardized process for determining the subsequent occurrence of an imitation. Based on the advice of my group of DSP industry experts, I relied solely on the available independent benchmarking studies from the archival sources described earlier. These annual studies compared the technical performance of a firm's newly introduced DSP chips with chips from its competitors and with previously introduced chips from all firms. If, for example, after the introduction of the focal product, a competitor later introduces a new product that closely matches the independently- 
benchmarked key technical features of the original product within the same generation of technology, then this is classified as the occurrence of a imitation of the original product by the competitor (IMITATED $=1$ ).

3. OUTCOME: The dependent variables REPLICATED and IMITATED are used in the initial set of binary logit regression analyses described in the Results section. As a further refinement of these analyses, an additional set of multinomial logit regression analyses are conducted by constructing a new categorical dependent variable, OUTCOME, directly from the variables REPLICATED and IMITATED. For each product in the sample, the variable OUTCOME is assigned a value of 0 , if the product is neither replicated nor imitated within the same generation of technology. A value of 1 is assigned if the product is replicated, but not imitated. A value of 2 is assigned if the product is imitated, but not replicated. Finally, a value of 3 is assigned if the product is replicated and imitated.

\section{Independent Variables}

1. LOG10_AC: This is the base 10 logarithm of the algorithmic complexity of the focal product. The value of the algorithmic complexity is estimated using the data width (in bits) of the product. For example, a data width of 16 bits equals a value of $2^{16}=65,536$ which is equivalent to a value of LOG10_AC $=4.816$. The rationale for using the data width of a DSP chip as an approximation for its algorithmic complexity is that the data width completely describes the maximum size of the data space for the operation of the DSP chip (Lee 1988). A larger data space requires a larger MDL for representing a product 
(MacKay 2003). Therefore, the value of the data width is proportional to the MDL of the product and may be suitable as a measure of algorithmic complexity (Grünwald 2007).

2. LOG10_CC: This is the base 10 logarithm of the computational complexity of the focal product. The value of the computational complexity is estimated using the instruction width (in bits) of the product. For example, an instruction width of 8 bits equals $2^{8}=256$ bits which is equivalent to a value of LOG10_CC $=2.408$. Similar to the logic for using the data width as an approximation of a DSP chip's algorithmic complexity, I use the instruction width as an approximation of its computational complexity. This is because the instruction width completely describes the maximum size of the instruction space for the operation of the DSP chip (Lyons 1997). A larger instruction space means that a larger set of instructions are required to represent a product (MacKay 2003; Zhao et al. 2002). Therefore, the value of the instruction width is proportional to the size of the instruction set of the product and may be useful as a measure of computational complexity (Goldreich 2008).

3. IP_REGIME: This binary variable is assigned a value of 1 only if the focal product was first introduced after the change in IP regime in 1988, the year the Karmarkar patent was granted by the USPTO (Stem 1991). Including this policy variable enables the analysis of a natural experiment of the effect of strengthening the patentability of algorithms on the likelihood of subsequent replication and imitation of algorithm-based products such as DSP chips. 


\section{Control Variables}

1. GEO_REGION: This categorical variable corresponds to the geographic region where the headquarters of the firm that produced the focal product is located. A value of $0=$ Asia-Pacific (Japan, China, Taiwan). A value of $1=$ Europe (Austria, Belgium, France, Germany, Netherlands, Poland, Russia, Switzerland, United Kingdom) and a value of $2=$ North America (Canada, United States). The speed and cost of innovation and the propensity to use technology replicated internally versus technology imitated from external sources may differ for firms headquartered in different geographic regions because of fundamental differences in managerial practices (Mansfield 1988).

2. LICENSABLE_CORE: This variable is assigned a value of 1 if the product is available as a licensable core, or $=0$ otherwise. DSPs available as licensable cores may be more likely to be imitated and less likely to be replicated than DSPs only available as chips (Grindley and Teece 1997).

3. DIVERSIFYING_ENTRANT: This variable is assigned a value of 1 if the firm that introduced the product is a diversifying entrant, or a value of 0 if it is a de novo entrant. Different types of entrants may have different strategies and incentives for engaging in outbound licensing (Motohashi 2008) versus integrated production (Arora and Fosfuri 2003). Products introduced by diversifying entrants may be more likely to be replicated and less likely to imitated than products introduced by diversifying entrants (Gallini 1984). ${ }^{14}$

\footnotetext{
${ }^{14}$ To avoid potential problems of multi-collinearity, DIVERSIFYING_ENTRANT is used in place of LICENSABLE_CORE in testing Hypotheses $\mathrm{H6a}$ and $\mathrm{H} 6 \mathrm{~b}$. The tests for all of the other hypotheses in this study use LICENSABLE_CORE.
} 
4. NREPLICATED_LAG1: This variable is a running count of the number of times a focal product has been previously replicated. Products that are in high demand may be frequently replicated (Winter and Szulanski 2001).

5. NIMITATED_LAG1: This variable is a running count of the number of times a focal product has been previously imitated. Products that are in high demand may be frequently imitated (Saviotti 2001).

6. NFIRMS_LAG1: This variable counts the total number of firms that entered the market in the previous year. Firm entry may indicate shifts in aggregate demand or technology and changes in barriers to imitation (Makadok 1998). 


\section{RESULTS}

\section{Descriptive Statistics and Correlations}

Table 5 presents descriptive statistics and a correlation matrix of the variables used in the analyses. REPLICATED and IMITATED are the dependent variables for the two separate sets of binary logit analyses for estimating the likelihood that a newly introduced product is subsequently replicated or imitated within the then current generation of technology. OUTCOME is the dependent variable used in the follow-on set of multinomial logit analyses. Of the 853 products introduced by DSP firms from 1974-2009, about $77 \%$ were replicated by the originating firm and about $45 \%$ were imitated by competitors. Thus, some products were both replicated and imitated. More precisely, as summarized in the bottom of Table 9, a mutually exclusive and collectively exhaustive breakdown of the possible product outcomes indicates the following. About $4 \%$ of products introduced by DSP firms are neither replicated nor imitated, 51\% are replicated but not imitated, $19 \%$ are imitated but not replicated, and the remaining $26 \%$ are replicated and imitated.

The mean values of algorithmic complexity (LOG10_AC) and computational complexity (LOG10_CC) for the 853 products in the sample are about 8.35 and 9.79, respectively, which correspond to bit values of approximately 27.7 bits and 32.5 bits, respectively. About $94 \%$ of all of the products in the sample were introduced after the change in IP regime 
(IP_REGIME=1) marked by the Karmarkar patent grant in 1988. In terms of the categorical control variable GEO_REGION, about $12 \%$ of the products are introduced by firms headquartered in the Asia-Pacific region, another $13 \%$ by firms based in Europe, and the remaining $75 \%$ by firms in North America. Over $22 \%$ of the products are available as licensable cores, as indicated by the control variable LICENSABLE_CORE. Diversifying entrants introduced $59 \%$ of the products. On average, about 4 DSP firms enter the market for the first time in the year preceding each new product introduction. The control variables for the running count of the number of times a product has been previously replicated or imitated, represented by lagged dependent variables NREPLICATED_LAG1 and NIMITATED_LAG1, respectively, are only used in separate sets of analyses, so the correlation of $r=0.281$ is not a concern. The highest correlation between any two independent variables is $r=-0.242(p<0.05)$ between LOG10_CC and GEO_REGION. This level of correlation indicates that there is little likelihood of multi-collinearity influencing the internal and external validity of the results. ${ }^{15}$

\section{Binary Logit Models for Replication}

Table 6 reports the results of the models examining how the values of algorithmic and computational complexity affect the likelihood that a newly introduced product is replicated within the then current generation of technology (Hypotheses H1a and H2a). Specifically, Model 1 represents a baseline specification comprised of all of the control variables. Models 2, 3, and 4 extend

\footnotetext{
${ }^{15}$ The correlation between DIVERSIFYING_ENTRANT and LICENSABLE_CORE is $r=-0.438$ $(p<0.05)$. To avoid potential problems associated with multi-collinearity, I use the variable LICENSABLE_CORE in testing all of the hypotheses, except for $\mathrm{H} 6 \mathrm{a}$ and $\mathrm{H} 6 \mathrm{~b}$. Because only $\mathrm{H} 6 \mathrm{a}$ and $\mathrm{H} 6 \mathrm{~b}$ make predictions based on the type of entrant, I replace LICENSABLE_CORE with DIVERSIFYING_ENTRANT in the tests of these hypotheses.
} 
this baseline model by separately adding the direct effects of algorithmic complexity, computational complexity, and the change in IP regime. Model 5 is the full model with all of the independent variables and controls included. All of the Models 1-5 include firm fixed effects. Across Models 1-5, all of the control variables are significant and are in the expected direction. All of the models are significant and the relative improvement in quasi likelihood associated with each model in comparison to the baseline model is shown at the bottom of Table 6 . This comparison indicates that Model 5 is the best fit model for estimating the likelihood that a product is replicated.

The coefficient of the independent variable LOG10_AC is negative and significant in both Model $2(\beta=-0.0188, p<0.1)$ and in Model $5(\beta=-0.0233$, $\mathrm{p}<0.05)$, which is the full model. This supports Hypothesis $\mathrm{H} 1 \mathrm{a}$, which predicts that the greater the algorithmic complexity of a newly introduced product, the lower the likelihood that it is subsequently replicated. The coefficient of the independent variable LOG10_CC is slightly positive but not significant in either Model 3 or Model 5. This does not support Hypothesis $\mathrm{H} 2 \mathrm{a}$, which predicts that the greater the computational complexity of a newly introduced product, the lower the likelihood that it is subsequently replicated. The coefficient of the independent variable IP_REGIME is positive and significant in both Model $4(\beta=0.9605$, $\mathrm{p}<0.01)$ and in Model $5(\beta=0.9729, p<0.01)$. This supports Hypothesis H4a, which predicts that after a legal precedent strengthening the patentability of algorithms, the likelihood that a product is subsequently replicated is higher in comparison to products introduced before the precedent. 
Table 5. Descriptive Statistics and Correlation Matrix

\begin{tabular}{|c|c|c|c|c|c|c|c|c|c|c|c|c|c|c|}
\hline Variable & Mean & Std. Dev. & 1 & 2 & 3 & 4 & 5 & 6 & 7 & 8 & 9 & 10 & 11 & 12 \\
\hline 1 REPLICATED & .77 & .42 & 1 & & & & & & & & & & & \\
\hline 2 IMITATED & .45 & .50 & $-.408^{* *}$ & 1 & & & & & & & & & & \\
\hline 3 OUTCOME & 1.67 & .91 & .014 & $.907^{* *}$ & 1 & & & & & & & & & \\
\hline 4 LOG10_AC & 8.35 & 7.30 & -.009 & -.005 & -.009 & 1 & & & & & & & & \\
\hline 5 LOG10_CC & 9.79 & 14.33 & .041 & $-.105^{\star \star}$ & $-.096^{* *}$ & $.110^{* *}$ & 1 & & & & & & & \\
\hline 6 IP_REGIME & .94 & .24 & $.173^{* *}$ & -.060 & .014 & $.130^{* *}$ & $.092^{* *}$ & 1 & & & & & & \\
\hline 7 GEO_REGION & 1.62 & .70 & $.162^{* *}$ & $-.095^{* *}$ & -.030 & -.025 & $-.242^{* *}$ & $.104^{* *}$ & 1 & & & & & \\
\hline 8 LICENSABLE_CORE & .22 & .41 & $-.110^{* *}$ & $.178^{* *}$ & $.145^{* *}$ & $.168^{* *}$ & -.022 & $.137^{* *}$ & $-.137^{* *}$ & 1 & & & & \\
\hline 9 DIVERSIFYING_ENTRANT & .59 & .49 & $.106^{* *}$ & $-.124^{* *}$ & $-.087^{*}$ & $-.252^{* *}$ & $-.121^{* *}$ & $-.165^{* *}$ & $.327^{* *}$ & $-.438^{* *}$ & 1 & & & \\
\hline 10 NFIRMS_LAG1 & 4.28 & 2.55 & $.193^{* *}$ & -.019 & $.068^{*}$ & $.148^{* *}$ & .032 & $.196^{* *}$ & .061 & .061 & $-.117^{* \star}$ & 1 & & \\
\hline 11 NREPLICATED_LAG1 & 5.39 & 10.80 & $.130^{* *}$ & $-.107^{\star *}$ & -.057 & -.001 & .023 & $.112^{* *}$ & $.192^{* *}$ & $-.129^{\star *}$ & $.255^{* *}$ & .000 & 1 & \\
\hline 12 NIMITATED_LAG1 & 17.17 & 27.29 & .010 & .056 & .066 & $-.154^{* *}$ & $-.135^{* *}$ & $.082^{*}$ & $.116^{* *}$ & $.078^{*}$ & -.037 & .049 & $281^{* *}$ & 1 \\
\hline
\end{tabular}


Table 6. Binary Logit Models of Likelihood that a Product is Replicated

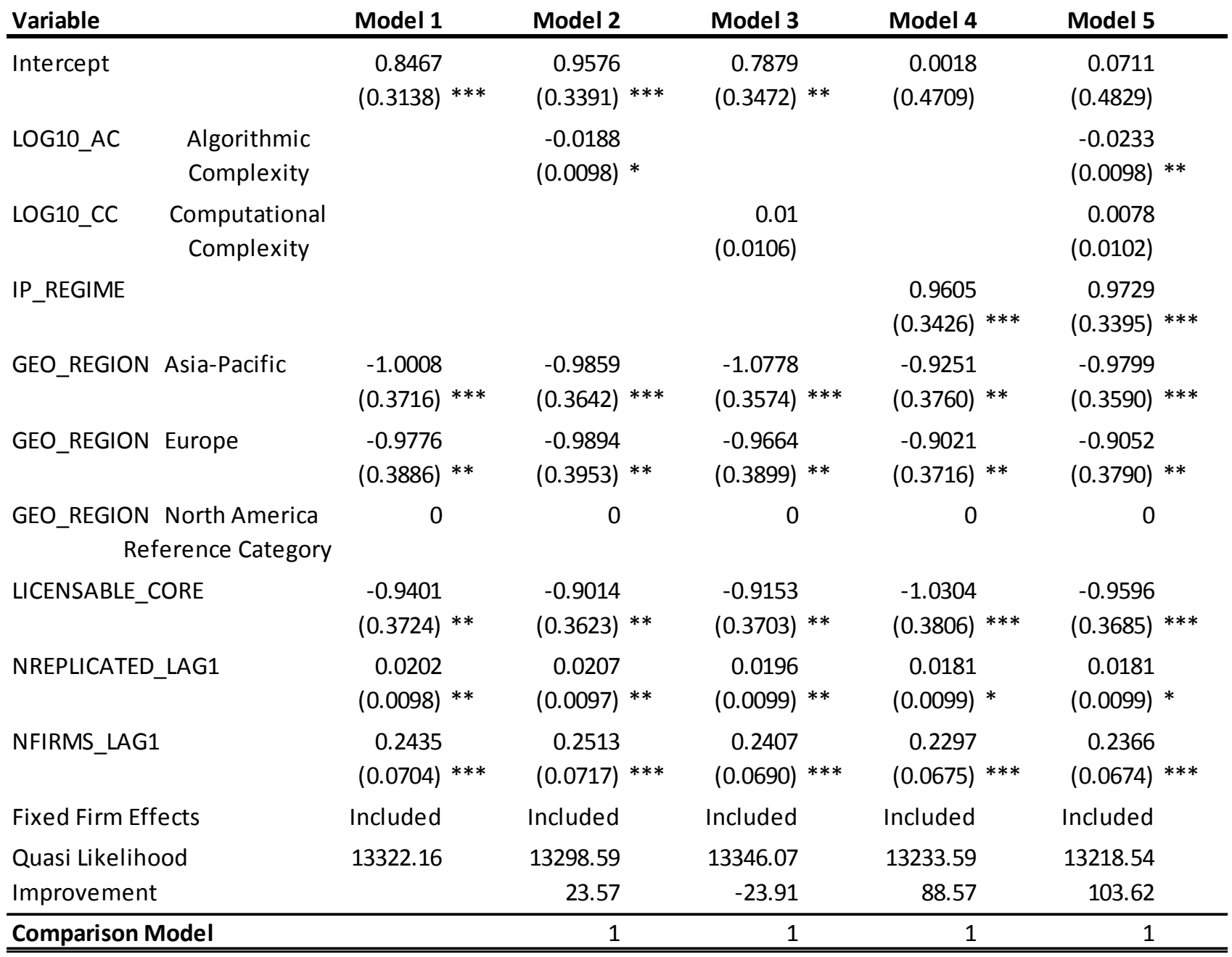

Values in parentheses represent robust standard errors clustered on firms.

All tests are two-tailed, ${ }^{* * *} p<0.01,{ }^{* *} p<0.05, * p<0.10$ 
Table 7. Binary Logit Models of Likelihood that a Product is Imitated

\begin{tabular}{|c|c|c|c|c|c|}
\hline Variable & Model 6 & Model 7 & Model 8 & Model 9 & Model 10 \\
\hline Intercept & $\begin{array}{c}-0.6792 \\
(0.2109) * * *\end{array}$ & $\begin{array}{c}-0.6676 \\
(0.2607) * *\end{array}$ & $\begin{array}{r}-0.3569 \\
(0.2213)\end{array}$ & $\begin{array}{l}-0.2436 \\
(0.2422)\end{array}$ & $\begin{array}{r}-0.1375 \\
(0.2518)\end{array}$ \\
\hline $\begin{array}{l}\text { Algorithmic } \\
\text { Complexity }\end{array}$ & & $\begin{array}{r}-0.0017 \\
(0.0142)\end{array}$ & & & $\begin{array}{r}0.0074 \\
(0.0150)\end{array}$ \\
\hline $\begin{array}{l}\text { Computational } \\
\text { Complexity }\end{array}$ & & & $\begin{array}{c}-0.04 \\
(0.0100) * * *\end{array}$ & & $\begin{array}{l}-0.0364 \\
(0.0114) * * *\end{array}$ \\
\hline IP_REGIME & & & & $\begin{array}{r}-0.4739 \\
(0.2905)\end{array}$ & $\begin{array}{r}-0.2928 \\
(0.2915)\end{array}$ \\
\hline GEO_REGION Asia-Pacific & $\begin{array}{c}0.8235 \\
(0.3407) * *\end{array}$ & $\begin{array}{c}0.8248 \\
(0.3392) * *\end{array}$ & $\begin{array}{r}1.0818 \\
(0.2519)\end{array}$ & $\begin{array}{c}0.7827 \\
(0.3350) * *\end{array}$ & $\begin{array}{r}1.0491 \\
(0.2417)\end{array}$ \\
\hline GEO_REGION Europe & $\begin{array}{c}0.9173 \\
(0.3776) * *\end{array}$ & $\begin{array}{c}0.9158 \\
(0.3811) * *\end{array}$ & $\begin{array}{c}0.8339 \\
(0.3700) * *\end{array}$ & $\begin{array}{c}0.8731 \\
(0.3538) * *\end{array}$ & $\begin{array}{c}0.8122 \\
(0.3554) * *\end{array}$ \\
\hline $\begin{array}{r}\text { GEO_REGION North America } \\
\text { Reference Category }\end{array}$ & 0 & 0 & 0 & 0 & 0 \\
\hline LICENSABLE_CORE & $\begin{array}{c}0.8899 \\
(0.2808) * * *\end{array}$ & $\begin{array}{c}0.8944 \\
(0.2594) * * *\end{array}$ & $\begin{array}{c}0.8301 \\
(0.2819) * * *\end{array}$ & $\begin{array}{c}0.9205 \\
(0.2880) * * *\end{array}$ & $\begin{array}{c}0.8293 \\
(0.2712) * * *\end{array}$ \\
\hline NIMITATED_LAG1 & $\begin{array}{r}0.0067 \\
(0.0053)\end{array}$ & $\begin{array}{r}0.0066 \\
(0.0057)\end{array}$ & $\begin{array}{r}0.0046 \\
(0.0052)\end{array}$ & $\begin{array}{r}0.0068 \\
(0.0053)\end{array}$ & $\begin{array}{r}0.0049 \\
(0.0054)\end{array}$ \\
\hline NFIRMS_LAG1 & $\begin{array}{r}-0.0423 \\
(0.0446)\end{array}$ & $\begin{array}{r}-0.0419 \\
(0.0469)\end{array}$ & $\begin{array}{r}-0.0322 \\
(0.0446)\end{array}$ & $\begin{array}{r}-0.0375 \\
(0.0447)\end{array}$ & $\begin{array}{r}-0.0308 \\
(0.0452)\end{array}$ \\
\hline Fixed Firm Effects & Included & Included & Included & Included & Included \\
\hline Quasi Likelihood & 20451.88 & 20504.07 & 20205.84 & 20425.79 & 20239.29 \\
\hline Improvement & & -52.19 & 246.04 & 26.09 & 212.59 \\
\hline Comparison Model & & 6 & 6 & 6 & 6 \\
\hline
\end{tabular}

Values in parentheses represent robust standard errors clustered on firms.

All tests are two-tailed, ${ }^{* * *} p<0.01,{ }^{* *} p<0.05,{ }^{*} p<0.10$ 
Table 8. Estimating the "Paradox of Replication"

\begin{tabular}{|c|c|c|c|c|c|c|c|c|c|c|c|c|}
\hline & Estima & ted & & & Estimated 0 & dds Ratio & s at Differe & nt Levels & of Overall C & omplexity & & \\
\hline & Odds $R$ & atios & LOV & & MODE & RATE & MODE & RATE & MODEI & RATE & HIG & \\
\hline CASE & FOR ALL C & CASES & CASE & & CASt & & CASE & & CASE 2 anc & d CASE 3 & $C A S$ & \\
\hline Value of AC & All Values & $S$ of $A C$ & LOW, AC & $<4.8165$ & LOW, AC & $<4.8165$ & $\mathrm{HIGH}, \mathrm{AC}>$ & $=4.8165$ & ALL VALUES & S IN CASE & $\mathrm{HIGH}, \mathrm{AC}>$ & $=4.8165$ \\
\hline Value of CC & All Value & $\mathrm{s}$ of $\mathrm{CC}$ & LOW, CC & 7.2247 & $\mathrm{HIGH}, \mathrm{CC}>$ & $=7.2247$ & LOW, CC & $<7.2247$ & 2 and $C$ & ASE 3 & $\mathrm{HIGH}, \mathrm{CC}>$ & $=7.2247$ \\
\hline Likelihood a Product is & REPLICATED & IMITATED & REPLICATED & IMITATED & REPLICATED & IMITATED & REPLICATED & IMITATED & REPLICATED & IMITATED & REPLICATED & IMITATED \\
\hline LOG10_AC & 0.977 & - & 1.684 & - & - & - & - & 1.107 & - & 1.074 & 0.975 & - \\
\hline LOG10_CC & - & 0.964 & - & - & 1.26 & 0.892 & - & 2.277 & 1.164 & - & - & 0.973 \\
\hline IP_REGIME & 2.646 & - & 2.227 & - & - & - & - & - & - & - & - & - \\
\hline $\begin{array}{r}\text { GEO_REGION Asia-Pacific } \\
\text { vs. North America }\end{array}$ & 0.375 & - & 0.524 & 2.592 & - & - & 0.066 & 7.182 & 0.175 & 4.631 & 0.33 & 2.363 \\
\hline $\begin{array}{l}\text { GEO_REGION Europe } \\
\text { vs. North America }\end{array}$ & 0.404 & 2.253 & 0.313 & 3.038 & 0.301 & - & - & 0.405 & - & - & 0.429 & 6.547 \\
\hline LICENSABLE_CORE & 0.383 & 2.292 & 0.355 & 2.437 & 0.031 & 2.321 & 0.113 & - & 0.091 & 2.24 & - & 1.839 \\
\hline NREPLICATED_LAG1 & 1.018 & - & 1.065 & - & 0.963 & - & - & - & 0.971 & - & 1.05 & - \\
\hline NIMITATED_LAG1 & - & - & - & 0.996 & - & 1.047 & - & 1.25 & - & 1.076 & - & 1.009 \\
\hline NFIRMS_LAG1 & 1.267 & - & 1.078 & - & 1.643 & 0.911 & 1.81 & 1.699 & 1.751 & 0.876 & 1.205 & 1.065 \\
\hline Percent Concordant & 77.4 & 65.9 & 76.2 & 63.1 & 88.1 & 74.3 & 86.2 & 81 & 87.5 & 73 & 72.6 & 67 \\
\hline Somers' D & 0.553 & 0.329 & 0.533 & 0.295 & 0.777 & 0.511 & 0.75 & 0.672 & 0.762 & 0.479 & 0.459 & 0.36 \\
\hline Number of Products & 853 & & 33. & & 12 & & $12 \varepsilon$ & & 25 & & 26 & \\
\hline Mean Value of AC & 8.35 & & 4.7 & & 4.6 & & 10.0 & & 7.4 & & 13.7 & \\
\hline Mean Value of CC & $9.7 \mathrm{~s}$ & & 4.9 & & 15.0 & & 5.3 & & 10.1 & & 15.5 & \\
\hline $\begin{array}{l}\text { Estimated Size of the } \\
\text { "Wedge" Between } \\
\text { Replication and Imitation }\end{array}$ & $-2.3 \%$ & $\begin{array}{l}-3.6 \% \\
\end{array}$ & $68.4 \%$ & - & $26.0 \%$ & $\begin{array}{l}-10.8 \% \\
\%\end{array}$ & - & $127.7 \%$ & $16.4 \%$ & $7.4 \%$ & $-2.5 \%$ & $-2.7 \%$ \\
\hline
\end{tabular}

Note: Only the estimated Odds Ratios associated with parameters that are significant at the $p<0.10$ level or better in each model are shown 
Table 9. Multinomial Logit Models of Likelihood of Product Outcomes

\section{Estimated Odds Ratios for Comparisons of Outcomes}

\begin{tabular}{lcccccc} 
Variable & $\mathbf{1}$ vs. 0 & $\mathbf{2 ~ v s . 0}$ & $\mathbf{3}$ vs. 0 & $\mathbf{2 ~ v s . ~ 1}$ & $\mathbf{3}$ vs. 1 & $\mathbf{3}$ vs. 2 \\
\hline LOG10_AC & 0.963 & - & 0.971 & 1.019 & - & - \\
LOG10_CC & - & 0.939 & 0.915 & 0.975 & 0.958 & - \\
IP_REGIME & 2.848 & - & 3.341 & 0.364 & - & 3.064 \\
$\begin{array}{l}\text { GEO_REGION Asia-Pacific } \\
\text { vs. North America }\end{array}$ & 0.432 & 1.804 & - & 3.583 & 2.225 & 0.529 \\
$\begin{array}{l}\text { GEO_REGION Europe } \\
\text { vs. North America }\end{array}$ & - & 1.884 & - & 3.199 & 1.521 & 0.42 \\
$\begin{array}{l}\text { LICENSABLE_CORE } \\
\text { NREPLICATED_LAG1 }\end{array}$ & 0.454 & - & - & 3.717 & 1.81 & 0.496 \\
NFIRMS_LAG1 & - & 0.981 & - & 0.972 & - & 1.025 \\
\hline \hline
\end{tabular}

Note: Only the estimated Odds Ratios associated with parameters

that are significant at the $p<0.10$ level or better in each model are shown

Coding of Possible Outcomes:

$\%$ of Outcomes

$0=$ Product is Not Replicated and is Not Imitated within the current generation of technology

$4.0 \%$

$1=$ Product is Replicated, but is Not Imitated within the current generation of technology

$51.0 \%$

$2=$ Product is Imitated, but is Not Replicated within the current generation of technology

$18.8 \%$

$3=$ Product is Replicated and is Imitated within the current generation of technology

$26.3 \%$

TOTAL $\quad 100.0 \%$ 


\section{Binary Logit Models for Imitation}

Table 7 reports the results of the models examining how the values of algorithmic and computational complexity affect the likelihood that a newly introduced product is imitated within the then current generation of technology (Hypotheses H1b and H2b). Specifically, Model 6 represents a baseline specification comprised of all of the control variables. Models 7, 8 , and 9 augment this baseline model by separately adding the direct effects of algorithmic complexity, computational complexity, and the change in IP regime. Model 10 is the full model with all of the independent variables and controls included. Consistent with the previously described Models 1-5 for examining the likelihood of replication, Models 6-10 for examining imitation include firm fixed effects. Across Models 6-10, all of the control variables are in the expected direction, but only the coefficients of the variables for GEO_REGION and LICENSABLE_CORE are significant. All of the models are significant and the relative improvement in quasi likelihood associated with each model in comparison to the baseline model is shown at the bottom of Table 7. This comparison indicates that Model 8 is the best fit for estimating the likelihood that a product is imitated.

The coefficient of the independent variable LOG10_AC is not significant in either Model 7 or in Model 10, which is the full model. This does not support Hypothesis $\mathrm{H} 1 \mathrm{~b}$, which predicts that the greater the algorithmic complexity of a newly introduced product, the lower the likelihood that it is subsequently imitated. The coefficient of LOG10_CC is negative and significant in Model 8 ( $\beta=-0.04$, 
$p<0.01)$ and Model $10(\beta=-0.0364, p<0.01)$. This supports Hypothesis H2b, which predicts that the greater the computational complexity of a newly introduced product, the lower the likelihood that it is subsequently imitated. The coefficient of IP_REGIME is negative (its expected direction), but not significant in either Model 9 or in Model 10. This does not support Hypothesis H4b, which predicts that after a legal precedent strengthening the patentability of algorithms, the likelihood that a product is subsequently imitated is lower in comparison to products introduced before the precedent.

As a next step, I compute the odds ratios associated with the coefficients that are significant in the full models for replication (Model 5) and imitation (Model 10). These values are shown in Table 8 in the column labeled "Estimated Odds Ratios - For All Cases". Since the values I used for the algorithmic and computational complexity are base 10 logarithms, a unit increase in LOG10_AC or LOG10_CC corresponds to a 10X increase in the measure.

Note that it is entirely possible for a $10 \mathrm{X}$ increase in the algorithmic and computational complexity of DSPs to occur in only a few years' time, since Moore's Law implies that the overall feasible complexity of such chips doubles every 18 to 24 months (Mollick 2006). A10X increase in the algorithmic complexity of a newly introduced product reduces the odds that the product is replicated by $-2.3 \%$. Similarly, a $10 \mathrm{X}$ increase in the computational complexity of a newly introduced product reduces the odds that the product is imitated by $3.6 \%$. In terms of estimating the size of the "wedge" between ease of replication and difficulty of imitation (Rivkin 2001), the net difference between the odds of 
replication and the odds of imitation is $1.3 \%$ for all 853 DSP products in the sample.

In addition, the change in IP regime appears to have a significant effect on the likelihood that a product is replicated, but no significant effect on the likelihood that a product is imitated. For products introduced after the change in IP regime, the odds of subsequently being replicated are 2.65 times higher than for products introduced before the change in IP regime. Note that the coefficient of the control variable LICENSABLE_CORE is in the expected direction and significant $(p<0.01)$ in all of the Models $1-10$ for replication and imitation shown in Table 6 and Table 7. In Model 5, the full model for replication, the coefficient of LICENSABLE_CORE is negative $(\beta=-0.9596, p<0.01)$. In Model 10 , the full model for imitation, the coefficient of LICENSABLE_CORE is positive $(\beta=0.8293$, $\mathrm{p}<0.01)$. This supports Hypotheses $\mathrm{H} 5 \mathrm{a}$ and $\mathrm{H} 5 \mathrm{~b}$, which predict that making a product available through outbound technology licensing decreases the likelihood of replication and increases the likelihood of imitation.

For DSPs available as licensable cores, the odds of subsequently being replicated are $62 \%$ lower, while the odds of subsequently being imitated are $129 \%$ higher than for DSPs that are not available via licensing. A one product increase in the number of times that a product is previously replicated (NREPLICATED_LAG1) increases the odds of subsequent replication by $1.8 \%$. In contrast, a one product increase in the number of times that a product is previously imitated (NIMITATED_LAG1) does not appear to have a significant effect on the odds of subsequent imitation. 


\section{Sub-Sample Analyses for Different Levels of Complexity}

As a refinement of the previously described analyses, I repeat the binary logistic regressions for replication (Model 5) and imitation (Model 10) on 4 distinct sub-samples of the 853 DSP products in the total sample. Each sub-sample corresponds to a separate case which represents a different level of information complexity. Classification in the appropriate sub-sample is determined by computing the median values of LOG10_AC (4.8165) and LOG10_CC (7.2247) respectively. Case 1 represents low overall information complexity and the 332 products in this sub-sample all have a value of LOG10_AC and LOG10_CC below their respective median values. Case 2 represents one of two possible scenarios for moderate overall complexity, while Case 3 represents the other. In Case 2, all of the 125 products in this sub-sample have a value of LOG10_AC that is below the median and a value of LOG10_CC that is above the median. Case 3 is exactly the opposite of Case 2. In Case 3 , all of the 128 products in this sub-sample have a value of LOG10_AC that is above the median and a value of LOG10_CC that is below the median. Case 4 represents high overall information complexity and the 268 products in this sub-sample all have a value of LOG10_AC and LOG10_CC above their respective median values.

For comparison purposes, an additional case, which combines Case 2 and Case 3 is also shown. At moderate levels of overall information complexity (Case 2 and Case 3 combined), a 10X increase in algorithmic complexity increases the odds that a product will be replicated by $16.4 \%$, while a $10 \mathrm{X}$ increase in computational complexity increases the odds that a product will be 
imitated by $7.4 \%$. In terms of estimating the size of the "wedge" between ease of replication and difficulty of imitation (Rivkin 2001), the net difference between the odds of replication and the odds of imitation is $9.0 \%$ for the 253 DSP products in the combined sub-sample for moderate levels of overall information complexity.

Decomposing the moderate complexity case further, the size of the "wedge" appears to be largest for the 125 products in Case 2, where algorithmic complexity is below its median value and computational complexity is above its median value. For Case 2, a 10X increase in computational complexity increases the odds that a product will be replicated by $26.0 \%$ and simultaneously decreases the odds that a product will be imitated by $-10.8 \%$. The net difference of $36.8 \%$ between the odds of replication and the odds of imitation for Case 2 is the largest of any of the 4 cases. In comparison, for Case 4 , the net difference between the odds of replication and the odds of imitation is only $0.2 \%$.

A meaningful direct comparison to Case 1 is not possible because neither algorithmic nor computational complexity appear to have a significant effect on imitation in Case 1. For the products in Case 1, geographic region and the availability of a product as a licensable core appear to have a significant effect on the likelihood that a product is imitated. For each of the cases shown, the closer that the percent of observations concordant with predictions are to $100 \%$ and the higher that the values of Somer's $D$ are above 0.5 , the better the models fit with the observed data (Hosmer and Lemeshow 2008). Note that the proposed models have the largest percent concordance and highest values of Somer's D for Case 2 and Case 3, which represent moderate complexity. Based on these 
results, Hypothesis $\mathrm{H} 3 a$ is not supported, but Hypothesis $\mathrm{H} 3 \mathrm{~b}$ is supported. The difference between the likelihood that a product is replicated and the likelihood that is it is imitated appears to be greater at moderate levels of complexity, in comparison to high levels of complexity.

\section{Multinomial Logit Models for Product Outcomes}

As the next step in my analyses, I reformulate the model as a multinomial logit model which incorporates the four possible product outcomes as shown in Table 9. The comparison shown in the column labeled " 3 vs. 0" shows the odds of the outcome that a product is replicated and imitated (OUTCOME=3) versus the outcome that a product is neither replicated nor imitated (OUTCOME=0). A 10X increase in algorithmic complexity reduces the odds of the outcome that a product is replicated and imitated by $-2.9 \%$, in comparison to the outcome that the product is neither replicated nor imitated. A 10X increase in computational complexity reduces the odds of the outcome that a product is replicated and imitated by $-8.5 \%$, in comparison to the outcome that the product is neither replicated nor imitated. The comparison shown in the column labeled "3 vs. 1" shows the odds of the outcome that a product is replicated and imitated (OUTCOME $=3$ ) versus the outcome that a product is replicated but not imitated (OUTCOME=1). A 10X increase in computational complexity reduces the odds of the outcome that a product is replicated and imitated by $-4.2 \%$, in comparison to the outcome that the product is replicated but not imitated. Thus far, Hypotheses

$\mathrm{H} 1 \mathrm{a}, \mathrm{H} 2 \mathrm{~b}, \mathrm{H} 3 \mathrm{~b}, \mathrm{H} 4 \mathrm{a}, \mathrm{H} 5 \mathrm{a}$ and $\mathrm{H} 5 \mathrm{~b}$ are supported. In the next section I test the remaining hypotheses, $\mathrm{H} 6 \mathrm{a}$ and $\mathrm{H} 6 \mathrm{~b}$. 


\section{Analyses for Different Types of Entrants}

Hypothesis $\mathrm{H} 6 \mathrm{a}$ predicts that the likelihood that a newly introduced product is replicated is lower for de novo entrants than for diversifying entrants. Hypothesis $\mathrm{H} 6 \mathrm{~b}$ predicts that the likelihood that a newly introduced product is imitated is higher for de novo entrants than for diversifying entrants. To evaluate hypotheses $\mathrm{H} 6 \mathrm{a}$ and $\mathrm{H} 6 \mathrm{~b}$, I replace the variable LICENSABLE_CORE with DIVERSIFYING_ENTRANT and conduct additional analyses as described below.

First, I construct the series of contingency tables shown in Table 10. I compute the odds ratios (all are significant at the $p<0.01$ level) for each set of contingency tables and observe the following:

1. The odds that a product is replicated are $39.7 \%$ lower for de novo entrants than diversifying entrants.

2. The odds that a product is imitated are $66.2 \%$ higher for de novo entrants than diversifying entrants.

3. The odds that a product is replicated are $44.3 \%$ lower for products that are available as licensable cores than for products not available via licensing.

4. The odds that a product is imitated are $139 \%$ higher for products that are available as licensable cores than for products not available via licensing.

5. The odds that a product is available as a licensable core are 10.46 times greater for de novo entrants than for diversifying entrants.

The baseline observations listed above suggest that de novo entrants in the DSP industry have a greater propensity to make their newly introduced products available as licensable cores and, as a consequence, these products 
are more likely to be imitated than products introduced by diversifying entrants. This supports Hypothesis $\mathrm{H} 6 \mathrm{a}$ and $\mathrm{H} 6 \mathrm{~b}$ but further support is needed using models which include the full set of explanatory variables, beyond the $2 \times 2$ contingency tables and computed odds ratios shown in Table 10.

Next, I repeat the sub-sample analyses for different levels of complexity following the same steps as before (see page 68), except that I now replace the variable LICENSABLE_CORE with DIVERSIFYING_ENTRANT. ${ }^{16}$ I control for all of the same factors as before. The results of these sub-sample analyses are shown in Table 11 (see the column labeled "Estimated Odds Ratios - For All Cases"). Overall, the odds that a newly introduced product is replicated are 99.5\% higher for diversifying entrants than for de novo entrants. Also, overall, the odds that a product is imitated are $36.2 \%$ lower for a diversifying entrant than for a de novo entrant. These results are consistent with the observations obtained earlier from computing the odds ratios from the contingency tables in Table 10 and lend additional support to Hypothesis $\mathrm{H} 6 \mathrm{a}$ and $\mathrm{H} 6 \mathrm{~b}$.

Note that a 10X increase in algorithmic complexity decreases the odds that a product is replicated by $2.2 \%$, but appears to have no significant effect on the odds that a product is imitated. A 10X increase in computational complexity, increases the odds that a product is replicated by $1.4 \%$ and decreases the odds that it is imitated by $-3.9 \%$. Thus, as a function of computational complexity, the size of the "wedge " in terms of the relative difference between ease of replication and ease of imitation is $5.3 \%$ for all products.

\footnotetext{
${ }^{16}$ Including both variables, LICENSABLE_CORE and DIVERSIFYING_ENTRANT could increase the potential for problems associated with multi-collinearity. The odds ratios computed for the observations listed on the previous page provide support for making this variable substitution.
} 
Table 10. Contingency Tables and Odds Ratios

CONTINGENCY TABLE FOR ENTRANT TYPE - NUMBER OF PRODUCTS IN EACH CATEGORY ARE SHOWN OUTCOMES

OUTCOMES

\begin{tabular}{|c|c|c|c|c|c|c|c|}
\hline ENTRANT TYPE & REPLICATED & NOT REPLICATED & TOTALS & IMITATED & NOT IMITATED & TOTALS & $\%$ OF TOTAL \\
\hline DE NOVO & 251 & 98 & 349 & 183 & 166 & 349 & $41 \%$ \\
\hline DIVERSIFYING & 408 & 96 & 504 & 201 & 303 & 504 & $59 \%$ \\
\hline TOTALS & 659 & 194 & 853 & 384 & 469 & 853 & $100 \%$ \\
\hline \multirow[t]{2}{*}{$\%$ OF TOTAL } & $77 \%$ & $23 \%$ & $100 \%$ & $45 \%$ & $55 \%$ & $100 \%$ & \\
\hline & \multicolumn{2}{|c|}{ Odds Ratio = 0.603} & \multicolumn{3}{|c|}{ Odds Ratio = 1.662} & & \\
\hline
\end{tabular}

CONTINGENCY TABLE FOR TECHNOLOGY LICENSING - NUMBER OF PRODUCTS IN EACH CATEGORY ARE SHOWN OUTCOMES OUTCOMES

\begin{tabular}{|c|c|c|c|c|c|c|c|}
\hline LICENSABLE CORE & REPLICATED & NOT REPLICATED & TOTALS & IMITATED & NOT IMITATED & TOTALS & $\%$ OF TOTAL \\
\hline YES & 129 & 59 & 188 & 116 & 72 & 188 & $22 \%$ \\
\hline NO & 530 & 135 & 665 & 268 & 397 & 665 & $78 \%$ \\
\hline TOTALS & 659 & 194 & 853 & 384 & 469 & 853 & $100 \%$ \\
\hline \multirow[t]{2}{*}{$\%$ OF TOTAL } & $77 \%$ & $23 \%$ & \multirow[t]{2}{*}{$100 \%$} & $45 \%$ & $55 \%$ & \multirow[t]{2}{*}{$100 \%$} & \\
\hline & \multicolumn{2}{|c|}{ Odds Ratio $=0.557$} & & \multicolumn{2}{|c|}{ Odds Ratio $=2.387$} & & \\
\hline
\end{tabular}

CONTINGENCY TABLE FOR ENTRANT TYPE AND TECHNOLOGY LICENSING - NUMBER OF PRODUCTS IN EACH CATEGORY ARE SHOWN LICENSABLE CORE

\begin{tabular}{rcccc} 
ENTRANT TYPE & YES & NO & TOTALS & \% OF TOTAL \\
\hline DE NOVO & 153 & 196 & 349 & $41 \%$ \\
\hline \hline DIVERSIFYING & 35 & 469 & 504 & $59 \%$ \\
\hline TOTALS & $\mathbf{1 8 8}$ & 665 & $\mathbf{8 5 3}$ & $100 \%$ \\
\% OF TOTAL & $22 \%$ & $78 \%$ & $100 \%$ & \\
\cline { 2 - 3 } & Odds Ratio = $\mathbf{1 0 . 4 6 0}$ & &
\end{tabular}

The computed Odds Ratios shown in all of the tables above are significant $(p<0.01)$ 
Table 11. Estimating the "Paradox of Replication" for Diversifying vs. De Novo Entrants Estimated Estimated Odds Ratios at Different Levels of Overall Complexity

\begin{tabular}{|c|c|c|c|c|c|c|c|c|c|c|c|c|}
\hline & \multicolumn{2}{|c|}{ Odds Ratios } & \multicolumn{2}{|c|}{ LOW } & \multicolumn{2}{|c|}{ MODERATE } & \multicolumn{2}{|c|}{ MODERATE } & \multicolumn{2}{|c|}{ MODERATE } & \multicolumn{2}{|c|}{$\mathrm{HIGH}$} \\
\hline CASE & FOR ALL & CASES & CAS & & $C A S$ & & CASE & & CASE 2 anc & dCASE 3 & CASE & \\
\hline Value of $A C$ & All Value & es of $A C$ & LOW, AC & $<4.8165$ & LOW, AC & $<4.8165$ & $\mathrm{HIGH}, \mathrm{AC}$ & $>=4.8165$ & ALL VALUES & S IN CASE & $\mathrm{HIGH}, \mathrm{AC}>$ & $>=4.8165$ \\
\hline Value of CC & All Value & es of CC & LOW, CC & $<7.2247$ & $\mathrm{HIGH}, \mathrm{CC}$ & $>=7.2247$ & LOW, CC & $<7.2247$ & 2 and $C$ & ASE 3 & $\mathrm{HIGH}, \mathrm{CC}>$ & $=7.2247$ \\
\hline Likelihood a Product is & REPLICATED & IMITATED & REPLICATED & IMITATED & REPLICATED & IMITATED & REPLICATED & IMITATED & REPLICATED & IMITATED & REPLICATED & IMITATED \\
\hline LOG10_AC & 0.978 & - & 1.907 & - & - & - & - & 1.14 & - & 1.076 & 0.981 & - \\
\hline LOG10_CC & 1.014 & 0.961 & - & 1.93 & 1.195 & 0.894 & 0.485 & 2.392 & 1.138 & - & 1.012 & 0.966 \\
\hline IP_REGIME & 2.491 & - & 2.049 & - & - & - & - & - & - & - & - & - \\
\hline $\begin{array}{r}\text { GEO_REGION Asia-Pacific } \\
\text { vs. North America }\end{array}$ & 0.373 & - & - & 2.685 & 0.251 & 4.414 & 0.088 & 5.675 & 0.094 & 6.075 & 0.479 & 2.073 \\
\hline $\begin{array}{l}\text { GEO_REGION Europe } \\
\text { vs. North America }\end{array}$ & 0.466 & 2.066 & 0.314 & 2.971 & 0.473 & - & 3.534 & 0.311 & - & - & 0.455 & 5.821 \\
\hline DIVERSIFYING_ENTRANT & 1.995 & 0.638 & 2.042 & - & - & - & - & - & - & - & 2.372 & 0.48 \\
\hline NREPLICATED_LAG1 & 1.018 & - & 1.066 & - & 0.974 & - & - & - & 0.98 & - & 1.043 & - \\
\hline NIMITATED_LAG1 & - & - & - & 0.996 & - & 1.05 & - & 1.224 & - & 1.077 & - & 1.009 \\
\hline NFIRMS_LAG1 & 1.281 & - & 1.094 & - & 1.641 & 0.904 & 1.476 & 1.661 & 1.701 & 0.871 & 1.222 & 1.061 \\
\hline Percent Concordant & 76.1 & 65.5 & 75.4 & 63.8 & 84.9 & 73.7 & 84.7 & 80.3 & 85.3 & 72.7 & 74 & 68.2 \\
\hline Somers' D & 0.529 & 0.322 & 0.519 & 0.304 & 0.713 & 0.496 & 0.712 & 0.656 & 0.715 & 0.473 & 0.488 & 0.385 \\
\hline Number of Products & 85 & & 33 & & 12 & & 12 & & 253 & & 268 & \\
\hline Mean Value of $A C$ & 8.3 & & 4.7 & & 4.6 & & 10. & & 7.4 & & 13.7 & \\
\hline Mean Value of CC & 9.7 & & 4.9 & & 15. & & 5.3 & & 10.1 & & 15.5 & \\
\hline $\begin{array}{l}\text { Estimated Size of the } \\
\text { "Wedge" Between } \\
\text { Replication and Imitation }\end{array}$ & $\begin{array}{r}1.4 \% \\
5.3 \%\end{array}$ & 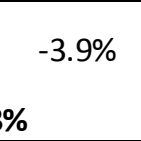 & $\begin{array}{l}90.7 \% \\
-2.3\end{array}$ & $\begin{array}{l}93.0 \% \\
3 \%\end{array}$ & $\begin{array}{r}19.5 \% \\
30.1\end{array}$ & $\begin{array}{l}-10.6 \% \\
1 \%\end{array}$ & $\begin{array}{r}-51.5 \% \\
-190\end{array}$ & $\begin{array}{l}139.2 \% \\
7 \%\end{array}$ & $\begin{array}{r}13.8 \% \\
6.2 \%\end{array}$ & $\begin{array}{l}\quad 7.6 \% \\
\% \quad\end{array}$ & $\begin{array}{r}1.2 \% \\
4.6 \%\end{array}$ & $\begin{array}{l}-3.4 \% \\
\%\end{array}$ \\
\hline
\end{tabular}

Note: Only the estimated Odds Ratios associated with parameters that are significant at the $\mathrm{p}<0.10$ level or better in each model are shown 
Table 12. Multinomial Logit Model of Likelihood of Product Outcomes for Diversifying vs. De Novo Entrants

Estimated Odds Ratios for Comparisons of Outcomes

\begin{tabular}{|c|c|c|c|c|c|c|}
\hline Variable & 1 vs. 0 & 2 vs. 0 & 3 vs. 0 & 2 vs. 1 & 3 vs. 1 & 3 vs. 2 \\
\hline LOG10_AC & 0.959 & - & 0.969 & 1.021 & - & - \\
\hline LOG10_CC & - & 0.953 & 0.917 & 0.969 & 0.956 & - \\
\hline IP_REGIME & 2.303 & - & 3.047 & 0.395 & - & 3.16 \\
\hline $\begin{array}{l}\text { GEO_REGION Asia-Pacific } \\
\text { vs. North America }\end{array}$ & 0.288 & - & - & 3.576 & 2.768 & 0.598 \\
\hline $\begin{array}{l}\text { GEO_REGION Europe } \\
\text { vs. North America }\end{array}$ & - & 2.718 & - & 2.578 & 1.436 & 0.414 \\
\hline DIVERSIFYING_ENTRANT & - & 0.398 & - & 0.464 & - & 2.448 \\
\hline NREPLICATED_LAG1 & - & 1.048 & - & 0.971 & - & 1.021 \\
\hline NFIRMS_LAG1 & 1.467 & 1.114 & 1.451 & 0.807 & - & 1.247 \\
\hline
\end{tabular}

Note: Only the estimated Odds Ratios associated with parameters

that are significant at the $p<0.10$ level or better in each model are shown

Coding of Possible Outcomes:

$\%$ of Outcomes

$0=$ Product is Not Replicated and is Not Imitated within the current generation of technology

$4.0 \%$

$1=$ Product is Replicated, but is Not Imitated within the current generation of technology

$51.0 \%$

$2=$ Product is Imitated, but is Not Replicated within the current generation of technology

$18.8 \%$

$3=$ Product is Replicated and is Imitated within the current generation of technology

$26.3 \%$

TOTAL $\quad 100.0 \%$ 
Table 13. Summary of Results for Hypothesized Differences in Products, Levels of Complexity, and Entrants

\begin{tabular}{|c|c|c|c|}
\hline Hypothesis & Variable(s) of Interest & Model(s) & Results \\
\hline H1a & $\begin{array}{l}\text { Algorithmic Complexity, } \\
\text { REPLICATED }\end{array}$ & $\begin{array}{l}\text { Binary Logit for } \\
\text { Replication }\end{array}$ & $\begin{array}{l}\text { SUPPORTED, coefficient of LOG10_AC is negative and significant } \\
(p<0.05)\end{array}$ \\
\hline H1b & $\begin{array}{l}\text { Algorithmic Complexity, } \\
\text { IMITATED }\end{array}$ & $\begin{array}{l}\text { Binary Logit for } \\
\text { Imitation }\end{array}$ & NOT SUPPORTED, coefficient of LOG10_AC is not significant \\
\hline $\mathrm{H} 2 \mathrm{a}$ & $\begin{array}{l}\text { Computational Complexity, } \\
\text { REPLICATED }\end{array}$ & $\begin{array}{l}\text { Binary Logit for } \\
\text { Replication }\end{array}$ & NOT SUPPORTED, coefficient of LOG10_CC is not significant \\
\hline H2b & $\begin{array}{l}\text { Computational Complexity, } \\
\text { IMITATED }\end{array}$ & $\begin{array}{l}\text { Binary Logit for } \\
\text { Imitation }\end{array}$ & $\begin{array}{l}\text { SUPPORTED, coefficient of LOG10_CC is negative and significant } \\
(p<0.05)\end{array}$ \\
\hline H3a & $\begin{array}{l}\text { Moderate vs. Low Levels } \\
\text { of Information Complexity, } \\
\text { REPLICATED, IMITATED }\end{array}$ & Sub-Sample Analyses & $\begin{array}{l}\text { NOT SUPPORTED, coefficient values in low complexity case are not } \\
\text { significant, does not allow a meaningful comparison to moderate } \\
\text { complexity case }\end{array}$ \\
\hline H3b & $\begin{array}{l}\text { Moderate vs. High Levels } \\
\text { of Information Complexity, } \\
\text { REPLICATED, IMITATED }\end{array}$ & Sub-Sample Analyses & $\begin{array}{l}\text { SUPPORTED, size of the "wedge" is the greatest at moderate levels of } \\
\text { complexity }(9.0 \%) \text { in comparison to high levels of complexity }(0.2 \%)^{17}\end{array}$ \\
\hline $\mathrm{H} 4 \mathrm{a}$ & $\begin{array}{l}\text { IP Regime Change, } \\
\text { REPLICATED }\end{array}$ & $\begin{array}{l}\text { Binary Logit for } \\
\text { Replication }\end{array}$ & $\begin{array}{l}\text { SUPPORTED, coefficient of IP_REGIME is positive and significant } \\
(p<0.01)\end{array}$ \\
\hline H4b & $\begin{array}{l}\text { IP Regime Change, } \\
\text { IMITATED }\end{array}$ & $\begin{array}{l}\text { Binary Logit for } \\
\text { Imitation }\end{array}$ & $\begin{array}{l}\text { NOT SUPPORTED, coefficient of IP_REGIME is negative (its expected } \\
\text { direction) but not significant }\end{array}$ \\
\hline H5a & $\begin{array}{l}\text { Technology Licensing, } \\
\text { REPLICATED }\end{array}$ & $\begin{array}{l}\text { Binary Logit for } \\
\text { Replication }\end{array}$ & $\begin{array}{l}\text { SUPPORTED, coefficient of LICENSABLE_CORE is negative and } \\
\text { significant }(p<0.01)\end{array}$ \\
\hline H5b & $\begin{array}{l}\text { Technology Licensing, } \\
\text { IMITATED }\end{array}$ & $\begin{array}{l}\text { Binary Logit for } \\
\text { Imitation }\end{array}$ & $\begin{array}{l}\text { SUPPORTED, coefficient of LICENSABLE_CORE is positive and } \\
\text { significant }(\mathrm{p}<0.01)\end{array}$ \\
\hline \multirow[t]{3}{*}{ H6a } & \multirow{3}{*}{$\begin{array}{l}\text { Diversifying Entrants vs. } \\
\text { De Novo Entrants, } \\
\text { REPLICATED }\end{array}$} & Contingency Tables & SUPPORTED, odds of replication $-39.7 \%$ for de novo entrants $(p<0.01)$ \\
\hline & & Sub-Sample Analyses & SUPPORTED, odds of replication $+99.5 \%$ for diversifying entrants $(p<0.1)$ \\
\hline & & $\begin{array}{l}\text { Multinomial Logit for } \\
\text { Product Outcomes }\end{array}$ & $\begin{array}{l}\text { SUPPORTED, odds of outcome " } 3 \text { vs. } 2 \text { " }+245 \% \text { for diversifying entrants } \\
(p<0.1)\end{array}$ \\
\hline \multirow[t]{3}{*}{ H6b } & \multirow{3}{*}{$\begin{array}{l}\text { Diversifying Entrants vs. } \\
\text { De Novo Entrants, } \\
\text { IMITATED }\end{array}$} & Contingency Tables & SUPPORTED, odds of imitation $+66.2 \%$ for de novo entrants $(p<0.01)$ \\
\hline & & Sub-Sample Analyses & SUPPORTED, odds of imitation $-36.2 \%$ for diversifying entrants $(p<0.1)$ \\
\hline & & $\begin{array}{l}\text { Multinomial Logit for } \\
\text { Product Outcomes }\end{array}$ & $\begin{array}{l}\text { SUPPORTED, odds of outcome " } 2 \text { vs. } 1 \text { " }-53.6 \% \text { for diversifying entrants } \\
(p<0.1)\end{array}$ \\
\hline
\end{tabular}

\footnotetext{
${ }^{17}$ When the variable LICENSABLE_CORE is replaced with DIVERSIFYING_ENTRANT, this result holds and the size of the "wedge" at moderate complexity is $6.2 \%$ in comparison to $4.6 \%$ at high levels of complexity.
} 
At low levels of information complexity (Case 1), the odds that a product is replicated are $104 \%$ higher for diversifying entrants than for de novo entrants. However, at these low levels of information complexity, the type of entrant does not appear to have a significant effect on the odds that a product is imitated. At moderate levels of information complexity (Case 2, Case 3, and Case 2 and 3 combined), the type of entrant does not appear to have any significant effect on the odds that a product is replicated or on the odds that it is imitated. In contrast, at high levels of information complexity (Case 4), the type of entrant does appear to have a significant effect on the odds that a product is replicated and on the odds that it is imitated. At these high levels of information complexity, the odds that a product is replicated are $137 \%$ higher for diversifying entrants than for de novo entrants. The odds that a product is imitated are $52 \%$ lower for diversifying entrants than for de novo entrants.

As a final step in the analyses of the effect of the type of entrant on the likelihood of replication and imitation, I repeat the multinomial logit analyses following the same steps as before (see page 70). As explained in the previous set of sub-sample analyses, I again replace the variable LICENSABLE_CORE with DIVERSIFYING_ENTRANT and I control for all of the same factors as before. The results are shown in Table 12.

The comparison shown in the column labeled "2 vs. 0" shows the odds of the outcome that a product is imitated but not replicated (OUTCOME=2) versus the outcome that a product is replicated nor imitated (OUTCOME=0). These results indicate that the odds of outcome "2 vs. 0" occurring are $61.2 \%$ lower for 
diversifying entrants than for de novo entrants, which suggests that products introduced by diversifying entrants are less likely to be imitated. This lends further support to Hypothesis H6b.

The comparison shown in the column labeled " 2 vs. 1 " shows the odds of the outcome that a product is imitated but not replicated (OUTCOME=2) versus the outcome that a product is replicated but not imitated (OUTCOME=1). These results indicate that the odds of outcome "2 vs. 1" occurring are $53.6 \%$ lower for diversifying entrants than for de novo entrants, which also suggests that products introduced by diversifying entrants are less likely to be imitated. Again, this lends further support to Hypothesis H6b.

The comparison shown in the column labeled " 3 vs. 2 " shows the odds of the outcome that a product is replicated and imitated (OUTCOME=3) versus the odds of the outcome that a product is imitated but not replicated (OUTCOME=2). These results indicate that the odds of outcome " 3 vs. 2" occurring are $245 \%$ higher for diversifying entrants than for de novo entrants, which suggests that products introduced by diversifying entrants are more likely to be replicated. This lends further support to Hypothesis $\mathrm{H} 6 \mathrm{a}$.

Evaluated separately and collectively, the preceding analyses of contingency tables, sub-samples at different levels of complexity, and the multinomial logit model all consistently support Hypotheses $\mathrm{H} 6 \mathrm{a}$ and H6b. Overall, for the 853 products introduced by the 91 firms in the sample, the likelihood that a product is replicated is lower for de novo entrants than for diversifying entrants, which supports Hypothesis H6a. Also for all of these 
products and firms, the likelihood that a product is imitated is higher for de novo entrants than for diversifying entrants, which supports Hypothesis H6b. The "wedge" between ease of replication and ease of imitation appears to be greatest for diversifying entrants at high levels of information complexity. However, at moderate levels of information complexity, there does not appear to be a significant size "wedge" difference between diversifying and de novo entrants.

Overall, eight out of the twelve proposed hypotheses are supported (Hypotheses H1a, H2b, H3b, H4a, H5a, H5b, H6a and H6b). A summary of the results is presented in Table 13. The contributions, implications, limitations and future research directions related to all of the findings presented in this chapter are discussed in detail in the next chapter. 


\section{DISCUSSION AND CONCLUSION}

Based on the preceding results, for the 91 DSP firms and 853 products in the sample, information complexity appears to be a meaningful predictor of the likelihood that a newly introduced product is replicated, imitated, or both. In general, increases in algorithmic complexity appear to decrease the likelihood that a product is replicated, while increases in computational complexity appear to decrease the likelihood that a product is imitated. However, the direction and significance of the effects of algorithmic and computational complexity appear to vary at different levels of overall information complexity and in the presence of the full set of control variables. Consistent with predictions of past simulation studies reported in the literature, there appears to be a "wedge" between the ease of replication and the difficulty of imitation, and the size of this "wedge" seems to be the greatest at moderate levels of complexity. At high levels of overall information complexity, in particular, the size of the wedge is comparatively smaller than at moderate levels of complexity.

In addition, an IP regime change which strengthens the patentability of algorithms appears to significantly increase the likelihood that a newly introduced product is subsequently replicated but does not significantly decrease the likelihood that the product is imitated. In contrast, under IP regimes which facilitate the formation of a market for technology, outbound licensing of a newly introduced product appears to significantly decrease the likelihood that the 
product is replicated, while significantly increasing the likelihood that the product is imitated. Products introduced by de novo entrants are less likely to be replicated and more likely to be imitated than products introduced by diversifying entrants. Diversifying entrants appear to have the greatest advantage over de novo entrants at high and low levels of information complexity. Neither diversifying entrants nor de novo entrants appear to have a significant relative advantage over the other at moderate levels of complexity.

\section{Contributions}

In terms of theory, this study contributes to the broader strategy and entrepreneurship literature by introducing a model and methods for estimating the inherent complexity of any product, when the product is represented in the form of an algorithm. I integrate research streams from information theory with research streams on the KBV of the firm to formulate a methodology for evaluating the relationship between information complexity and firm-level product replication and imitation processes. I extend earlier work on relational complexity and strategy based on NK models in a new direction by developing measures for information complexity based on the underlying information-theoretic concepts of algorithmic and computational complexity.

I also develop and test a method for mapping new product introductions to a finite set of algorithms of known or computable complexity. I apply this method to empirically test a generalized model of information complexity in the context of the process of entrepreneurial discovery in knowledge-intensive industries. I not only demonstrate "proof of concept" that the method works, I also obtain 
empirical evidence to support largely untested predictions from prior simulationbased studies on knowledge replication and imitation processes. Specifically, I introduce an information-theoretic approach to quantifying the extent to which the "paradox of replication" (Kogut and Zander 1992) or the "wedge" between the ease of replication and the difficulty of imitation (Rivkin 2001) affects the reproduction of newly introduced products as units of knowledge.

The generalized model of information complexity may be applied to the analysis of a broad range of knowledge-intensive industries that are growing in their economic and technological importance, and where products may be represented in the form of an algorithm. This empirically testable model may be especially useful in industry contexts where the values of $N$ and $K$ or the degree of modularity does not vary substantially across products and relational complexity is therefore not a meaningful predictor of product replication or imitation (Solow et al. 1999). For researchers, managers, and policymakers involved in analyzing or making decisions related to $R \& D$, product management, and technology strategy, this study outlines a practical tool for estimating how much the inherent complexity (Wilson and Latombe 1994) of a product affects a firm's ability to replicate the product and its competitors' abilities to imitate the product.

\section{Implications}

My methodology for examining information complexity, replication, and imitation suggests several important theoretical, managerial, and policy implications, as described below. For strategy and entrepreneurship scholars 
who seek to understand the antecedents and consequences of knowledge reproduction processes within firms, this methodology offers a means to analyze not only products, but any unit of knowledge that can be represented as an algorithm. For example, codifiable organizational routines may be represented in algorithmic form as a complete and finite set of information and instructions for completing a specified task (Dosi 2000; Grant 1996b; Lillrank 2003; Nelson and Winter 1982; Winter and Szulanski 2001). Codified organizational processes, procedures, mindsets, dominant logics, and strategic logics that undergird the rules and heuristics for making decisions (Bettis and Prahalad 1995; Bingham et al. 2007; Pentland and Feldman 2005; Pentland and Rueter 1994; Tollin 2008) may be analyzed in terms of their algorithmic and computational complexity in a similar manner to the analyses conducted in this study. ${ }^{18}$

Because the concepts of algorithmic and computational complexity are grounded in the fundamental principles of information theory, any algorithmic representation of the information associated with a unit of knowledge can be analyzed quantitatively. However, producing algorithmically and computationally complex products may not necessarily require that a firm's strategies, routines, and processes of firms also be algorithmically and computationally complex (Baldwin and Clark 2000; Beinhocker 2006; Davis et al. 2009). In fact, as Eisenhardt and Sull (2001) explain, "When the business landscape was simple, companies could afford to have complex strategies. But now that business is so

\footnotetext{
18 "Organizational routines can be conceptualized as generative systems with internal structures and dynamics ... For some questions, routines can be taken as a unit of analysis without considering their internal structure, but there are many research questions for which it is useful to consider the parts of routines either separately or as they interact" (Pentland and Feldman 2005).
} 
complex, they need to simplify. Smart companies have done just that with a new approach: a few straightforward, hard-and-fast rules that define direction without confining it" (Eisenhardt and Sull 2001).

A further implication of this study may be the need to broaden complexityrelated research in strategic management and entrepreneurship beyond the concept of relational complexity or interdependence implicit in the use of NK models. In particular, this study demonstrates the potential value of developing new, empirically testable models and measures for other dimensions of complexity such as information (Boisot 2000; Boisot and Canals 2004; Boisot et al. 2007; Sorenson 2005). While this study focused on the effects of differences in products, IP regimes, and the type of entrant on knowledge replication and imitation, this study also highlights the need for further research at multiple levels of analysis. For example, conceptual and experimental research on managerial cognition may help uncover the possible relationship between information complexity and the individual and collective decision-making processes of managers and management teams (Simon 1959).

For managers in knowledge-intensive industries who seek to build competitive advantage for their firms, different types of information complexity may have a different direction and magnitude of effect on the likelihood that a product is replicated or imitated. For example, in the DSP industry setting of this study, at moderate levels of overall information complexity, simultaneously increasing algorithmic and computational complexity results in the greatest size "wedge" between the likelihood of replication and imitation. However, in the same 
industry setting, but at high levels of overall information complexity, simultaneously increasing algorithmic and computational complexity results in a much smaller "wedge" between the likelihood of replication and imitation. These empirical findings support and extend the propositions and predictions of previous conceptual work (Bharadwaj et al. 1993; Reed and DeFillippi 1990) and simulation studies (Rivkin 2000, 2001). These results suggest that the type of information complexity (algorithmic or computational), and the level of overall information complexity (low, moderate, or high), may matter a great deal in terms of the relative ease or difficulty of replication and imitation. Maximizing the size of the "wedge" at any given level of overall information complexity requires managers to understand how high-level product design choices (Hobday 1998; Hobday et al. 2000; Novak and Eppinger 2001; Sanchez and Mahoney 1996) and development paths (Baldwin and Clark 2000; Clark and Fujimoto 1991; Millson et al. 1992; Rothaermel and Deeds 2004) drive the different types of information complexity, and in turn how information complexity drives replication and imitation processes.

In addition, when operating at the same overall level of information complexity and when subject to the same IP regime, managers of different types of entrants (diversifying and de novo), may make different optimal decisions for their respective firms regarding outbound licensing and product strategy. Based on the empirical results obtained from the DSP industry, diversifying entrants have the greatest competitive advantage over de novo entrants at low and at high levels of complexity but no significant advantage at moderate levels of 
complexity. Thus, when faced with a large number of de novo entrants as potential competitors, diversifying entrants should focus on introducing products of either low or high information complexity. In contrast, when faced with a large number of diversifying entrants as potential competitors, de novo entrants should focus on introducing products of moderate information complexity. Furthermore, to maximize its competitive advantage at moderate levels of complexity, a de novo entrant should, whenever possible, pursue a replicator strategy and opt to be an Integrated Producer rather than an Outbound Licensor of its products.

For policymakers in regulatory agencies and positions of authority who seek to encourage innovation in knowledge-intensive industries in a procompetitive manner, providing institutional frameworks and legal precedents which reinforce the patentability of algorithms may be a vital policy tool. This study indicates that products introduced by DSP firms headquartered in the AsiaPacific and European regions are substantially less likely to be replicated and substantially more likely to be imitated than products introduced by firms headquartered in North America. A change in IP regime in the U.S. which strengthens the patentability of algorithms appears to enhance the incentives for firms headquartered in North America to focus on replicating their own products. With stronger government assurances that their intellectual property rights for algorithms will be protected, North American firms may expect greater economic rents from replication (Hall and Ziedonis 2001; Jaffe 2000; Kortum and Lerner 1998; Schoemaker 1990). As a potential policy tool, supporting the patentability of algorithms may promote product replication, but may not necessarily deter 
imitation. This is because imitation deterrence is often driven by the expected costs and benefits of future patent litigation (Lanjouw and Schankerman 2001; Somaya 2003) rather than the existence of past legal precedents.

IP regime changes which facilitate the formation of markets for technology may dramatically alter the competitive landscape by shifting the strategic incentives for firms to engage in outbound licensing or integrated production. If IP regime changes allow and approve of knowledge-sharing arrangements such as cross-licensing agreements (Grindley and Teece 1997; Hall and Ziedonis 2001; Shapiro 2000), patent pools (Gilbert 2004; Joshi and Nerkar 2011; Lerner 2002; Merges 2001) and R\&D consortia (Branstetter and Sakakibara 2002; Grossman and Shapiro 1986; Sakakibara 2002), then these arrangements may also shift the incentives for firms to pursue a replicator or an imitator strategy. Beyond the information complexity of products themselves, the structural complexity of the IP regime (Alter and Meunier 2009; Coriat and Orsi 2002; Helfer 2009; Jaffe 2000; Malerba and Orsenigo 1993) under which these products are introduced may be a critical factor in determining the likelihood of replication and imitation.

Using the empirical results obtained from my analyses of the DSP industry, I compiled a list of questions and answers for researchers, managers, and policymakers to use when estimating the likelihood of replication and imitation of products introduced by different firms. This list is intended to serve as a set of "rules of thumb" for making "optimally imperfect decisions" (Baumol and Quandt 1964) based on whether a product is more or less likely to be replicated or imitated (see Table 14). 


\section{Table 14. "Rules of Thumb" for Estimating Replication and Imitation ${ }^{19}$}

\begin{tabular}{|c|c|c|}
\hline Main Question & Follow-up Question & Answers Based on This Study \\
\hline $\begin{array}{l}\text { Which product, } A \text { or } B \text {, is } \\
\text { more likely to be } \\
\text { replicated? }\end{array}$ & $\begin{array}{l}\text { What is the algorithmic } \\
\text { complexity of each product? }\end{array}$ & $\begin{array}{l}\text { The product with the greater algorithmic } \\
\text { complexity is less likely to be replicated. } \\
\text { If the algorithmic complexity is the same for both } \\
\text { products, then the products are equally likely to } \\
\text { be replicated. }\end{array}$ \\
\hline $\begin{array}{l}\text { Which product, } \mathrm{A} \text { or } \mathrm{B} \text {, is } \\
\text { more likely to be } \\
\text { imitated? }\end{array}$ & $\begin{array}{l}\text { What is the computational } \\
\text { complexity of each product? }\end{array}$ & $\begin{array}{l}\text { The product with the greater computational } \\
\text { complexity is less likely to be imitated. } \\
\text { If the computational complexity is the same for } \\
\text { both products, then the products are equally } \\
\text { likely to be imitated. }\end{array}$ \\
\hline $\begin{array}{l}\text { Should the respective } \\
\text { firms that introduced } \\
\text { product } A \text { and product B, } \\
\text { pursue a replicator or an } \\
\text { imitator strategy? }\end{array}$ & $\begin{array}{l}\text { What is the overall level of } \\
\text { information complexity of } \\
\text { each product? } \\
\text { LOW, MODERATE, or HIGH }\end{array}$ & $\begin{array}{l}\text { At moderate levels of information complexity, } \\
\text { replicators have the greatest advantage over } \\
\text { imitators. Therefore, the firm introducing the } \\
\text { product should pursue a replicator strategy. } \\
\text { At low and high levels of information complexity, } \\
\text { replicators have the smallest advantage over } \\
\text { imitators. Therefore, the firm introducing the } \\
\text { product should pursue either strategy without } \\
\text { significantly affecting how likely the product is to } \\
\text { be replicated or imitated. }\end{array}$ \\
\hline $\begin{array}{l}\text { How does a change in IP } \\
\text { regime affect whether a } \\
\text { product more or less } \\
\text { likely to be replicated or } \\
\text { imitated? }\end{array}$ & $\begin{array}{l}\text { Does the new IP regime } \\
\text { support the patentability of } \\
\text { algorithms? } \\
\text { YES or NO }\end{array}$ & $\begin{array}{l}\text { If the IP regime supports the patentability of } \\
\text { algorithms, then the product is more likely to } \\
\text { replicated but not necessarily less likely to be } \\
\text { imitated. }\end{array}$ \\
\hline $\begin{array}{l}\text { How does technology } \\
\text { licensing affect whether } \\
\text { a product more or less } \\
\text { likely to be replicated or } \\
\text { imitated? }\end{array}$ & $\begin{array}{l}\text { Is the product available via } \\
\text { outbound licensing? } \\
\text { YES or NO }\end{array}$ & $\begin{array}{l}\text { If the product is available via outbound licensing, } \\
\text { then the product is less likely to be replicated } \\
\text { and more likely to be imitated. }\end{array}$ \\
\hline $\begin{array}{l}\text { How does the type of } \\
\text { firm affect whether a } \\
\text { product more or less } \\
\text { likely to be replicated or } \\
\text { imitated? }\end{array}$ & $\begin{array}{l}\text { Is the firm that introduced } \\
\text { the product a diversifying } \\
\text { entrant (established firm) or } \\
\text { a de novo entrant (startup or } \\
\text { spinoff)? }\end{array}$ & $\begin{array}{l}\text { At low and high levels of information complexity, } \\
\text { a product introduced by a diversifying entrant is } \\
\text { more likely to be replicated and less likely to be } \\
\text { imitated that a product introduced by a de novo } \\
\text { entrant. } \\
\text { At moderate levels of information complexity, } \\
\text { there is no significant difference between } \\
\text { diversifying and de novo entrants in terms of } \\
\text { how likely a product is to be replicated or } \\
\text { imitated. }\end{array}$ \\
\hline
\end{tabular}

${ }^{19}$ Baumol and Quandt (1964) define a rule of thumb to be a set of rules describing a decision procedure with the following characteristics:

(a) The variables which are employed in the decision criteria are objectively measurable;

(b) The decision criteria are objectively communicable, and decisions do not depend on the judgment of individual decision-makers;

(c) As a corollary to (b), every logically possible configuration of variables corresponds to a (usually unique) determinate decision;

(d) The calculation of the appropriate decision is simple, inexpensive, and well suited for frequent repetition and for spot checking by management in higher echelons.

A decision process with these characteristics seems to be designed as the instrument par excellence of optimally imperfect decision-making for routine and recurrent problems. 


\section{Limitations and Future Directions for Research}

While this study contributes to the existing strategy and entrepreneurship literature and offers important implications for theory, practice, and policy, there are some limitations that future extensions could address. First and foremost, the fundamental assumption that makes my methodology analytically tractable and empirically testable — that units of knowledge such as products can be represented as algorithms — may not apply to a number of knowledge-based products such creative, cultural or entertainment goods (Caves 2000; Cunningham 2002; Hirsch 1972). That said, as described earlier, there are a number of industries in which products may be represented as algorithms. This study focuses on one industry in particular, DSP, and the findings in terms of the direction and magnitude of the effects of algorithmic and computational complexity on the likelihood of replication and imitation may differ across industries.

One of the limitations of this single-industry study is that it is not possible to completely discern the extent to which technological, financial, and temporal constraints determine the feasible set of design choices which firms face prior to making decisions to replicate or imitate earlier products (Gonzalez-Zugasti et al. 2000; Pate-Cornell and Dillon 1998; 2001). These high-level design choices may directly drive the level and type of complexity associated with a newly introduced product and the related information processing activities of the organization introducing the product (Novak and Eppinger 2001; Sosa et al. 2004). Furthermore, these choices may change dramatically during generational shifts 
in technology (Bass and Christensen 2002). For example, a generational shift in technology such as a new system architecture may reduce or even remove some critical technical, economic, and timing constraints for all firms while increasing or adding new constraints (Malerba and Orsenigo 1993). Changes in any of these constraints may enable the formation of new firms and the exploitation of new markets through replication and/or imitation (Shane 2001).

I speculate that one of the possible reasons why Hypotheses $\mathrm{H} 1 \mathrm{~b}, \mathrm{H} 2 \mathrm{a}$, $\mathrm{H} 3 \mathrm{a}$, and $\mathrm{H} 4 \mathrm{~b}$ are not supported by the results of this study is because of the nature and duration of the eight distinct generational shifts in DSP technology which occurred from 1973 to $2009 .{ }^{20}$ For example, in the initial stages and early generations of DSP technology, increases in algorithmic complexity may have been far more feasible than increases in computational complexity. Therefore, early on, copying data may have been easier than copying instructions, which makes replication somewhat easier and imitation slightly more difficult (this supports $\mathrm{H} 1 \mathrm{a}$, but not $\mathrm{H} 1 \mathrm{~b})$. In contrast, in the mid-to-later generations of DSP technology, increases in computational complexity may have been much more feasible than increases in algorithmic complexity. ${ }^{21}$ Therefore, later on, copying data may have been harder than copying instructions, which makes replication somewhat more difficult and imitation slightly easier (this supports $\mathrm{H} 2 \mathrm{~b}$, but not $\mathrm{H} 2 \mathrm{a})$. Because the earlier generations of DSP technology are on average shorter

\footnotetext{
${ }^{20}$ The recombination and rediscovery of mathematical, architectural, and material innovations may have had a profound effect on the technological evolution of the DSP industry. These factors are analyzed and discussed in detail from a historical perspective in the Appendix. Mathematical innovations in particular may have had a greater impact on the feasible level of computational complexity than on the feasible level of algorithmic complexity.

${ }^{21}$ See Figure 3 for a graph of the feasible complexity for each generation of DSP technology.
} 
in duration with fewer products introduced than in the later generations, a meaningful comparison between moderate and low levels of complexity is not possible (this supports $\mathrm{H} 3 \mathrm{~b}$, but not $\mathrm{H} 3 \mathrm{a}$ ). ${ }^{22}$ In the case of a change in IP regime which strengthens the patentability of algorithms, this study found a positive and significant effect on the likelihood of replication and a negative but not significant effect on the likelihood of imitation (this supports $\mathrm{H} 4 \mathrm{a}$, but not $\mathrm{H} 4 \mathrm{~b}$ ). The existence of a substantial common, codified, and cumulative base of knowledge available in the public domain may help explain why firms appear to be able to invent around (Samuelson and Scotchmer 2002) patented algorithms and imitate these algorithms without infringing on the IP rights of the original inventors, even when those rights are strengthened by an IP regime change.

Further empirical work is needed to refine and validate the model and findings presented here. Future work could expand the methodology to the analysis of the replication and imitation of new products in a diverse array of industries that are based on fundamental innovations in algorithms (Berlinski 2001). A multi-industry study comparing product introductions across a range of knowledge-intensive industries, or a single-industry study comparing product introductions based on different technologies may shed light on the extent to which the likelihood of replication and imitation varies as a function of industry and technology characteristics including technological, financial, and temporal constraints.

\footnotetext{
${ }^{22}$ Recall from Figure 3 and Table 4 that only a small number of low complexity products were introduced in the earlier stages of the DSP industry. In fact, about $71 \%$ of all of the product introductions occurred in the last two generations of DSP technology. These products had, on average, higher levels of algorithmic and computational complexity than the products introduced in the preceding generations of DSP technology.
} 
In this study, I control for firm effects by using robust standard errors that are clustered at the firm-level and this approach accounts for firm-level heterogeneity. If correlations exist between the complexity measures I examined and the unobserved attributes of products, the coefficients obtained will be overstated (Allison 2003; Hosmer and Lemeshow 2008). Research that controls for additional firm-level heterogeneity can improve the precision of the estimates of the effect of algorithmic and computational complexity on the likelihood that a newly introduced product is replicated or imitated. Despite these limitations, this research provides strong evidence that the likelihood of a product being replicated or imitated is associated with measurable dimensions of information complexity. In addition, there may be factors in the competitive environment that influence the likelihood that a product is subsequently replicated or imitated. Although I have attempted to control for these factors in my models, there may be some unobserved factors that are not fully captured in these models.

Future research could build on the model, methods, and results presented here in a number of potentially promising areas. One important area for future research may be the development of more precise measures for algorithmic and computational complexity. In this study, I use the data width and instruction width of a DSP product as proportional approximations of the algorithmic and computational complexity of the product (Goldreich 2008; Grünwald 2007). This approach may result in extremely conservative estimates which are only rough approximations of the respective quantities of interest. More advanced information-theoretic models and techniques may enable much more precise 
measurement of information complexity in a variety of settings ( $\mathrm{Li}$ and Vitányi 2008; MacKay 2003).

Another important area for future work may be investigating the error rates of replication and imitation associated with the processing of complex information. For tractability, this study assumed that error rates of replication and imitation were constant for each firm. However, these error rates may themselves be algorithmically and computationally complex functions of a wide range of explanatory variables (Anderson 1999) ${ }^{23}$ including parameters associated with the breadth and depth of firm search patterns (Gavetti and Levinthal 2000; Siggelkow and Rivkin 2005), the level of pre-entry experience (Ganco and Agarawal 2009; Ganco and Hoetker 2009), and the degree of knowledge simplification implied by the use of managerial heuristics (Baumol and Quandt 1964; Davis et al. 2009). Furthermore, if errors occasionally generate beneficial mutations (Axelrod and Cohen 1999; McKelvey 1999; Mitleton-Kelly 2003) when copying knowledge, then under certain conditions, higher error rates may actually increase the chances of successfully exploiting the information obtained through entrepreneurial discovery processes.

Yet another important area for future research may be examining how firms produce complex products by cooperating with other firms including current and prospective competitors in innovation networks within industries and across industries. A firm's structural position as well as its degree of embeddedness in an innovation network (Granovetter 1985; Gulati et al. 2000; Henderson and

\footnotetext{
${ }^{23}$ As Anderson (1999) points out, "It is usually impossible to forecast the exact value of a chaotic system in nature, because small measurement errors between two apparently identical values at time $t$ can lead to large differences at time $t+1$."
} 
Clark 1990) may enable it to absorb and handle differing amounts of information complexity. In addition, the underlying deep structure (Ackerman et al. 2008; Barley 1986; DeSanctis and Poole 1994; Orlikowski 1992) of the information obtained via participation in an innovation network may vary in ways not fully captured by the measurement of algorithmic and computational complexity.

Although the methodology developed in this study is primarily used to examine the replication and imitation of products as a unit of knowledge, other aspects of organizations may also be represented as algorithms. Quoting Winter (1986), Grant (1996b) defines an organizational routine as a "relatively complex pattern of behavior ... triggered by a relatively small number of initiating signals or choices and functioning as a recognizable unit in a relatively automatic fashion." This definition of an organizational routine is congruent with the conceptualization of algorithms upon which this entire study is based. Embracing the methodology presented here may open up intriguing new possibilities for research on the quantitative measurement of information complexity and the replication and imitation of units of knowledge such as organizational routines, processes, procedures, decision-making rules and heuristics. Beyond entrepreneurial discovery in knowledge-intensive industries, information complexity may be a useful concept for understanding how the inherent structure of units of knowledge affects strategic decisions at the firm-level. In sum, I believe that extending this methodology to other aspects of organizational strategy as well as overcoming the previously described limitations of this study offer promising new directions for future research. 


\title{
APPENDIX: INDUSTRY SETTING AND HISTORICAL CONTEXT
}

\author{
Mixed Signals: How the Recombination and Rediscovery of \\ Mathematical, Material, and Architectural Innovations \\ Shaped the Signal Processing Industry, 1948-2008 ${ }^{24}$
}

\section{The Science of Signal Processing}

Signal processing is the science of identifying, analyzing, manipulating, and extracting physical signals such as audio, video, images and sensory data in real-time. Digital Signal Processors (DSPs) are semiconductor chips which are the core engines of a diverse array of products including cell phones, digital cameras, high-definition televisions, network equipment, global-positioning systems, and communications satellites. DSPs account for $\$ 27$ billion or $10 \%$ of global semiconductor revenues (Strauss 2008). Although DSPs are technologically and economically significant, the evolution of innovation in the signal processing industry is relatively unexplored.

In this appendix, I trace the commercialization of signal processing since its inception in 1948, when the following three breakthrough innovations occurred. Information theory, a mathematical innovation, introduced a conceptual foundation for designing DSPs. Transistors, a material innovation, provided the

\footnotetext{
${ }^{24} \mathrm{~A}$ an earlier version of the material contained in this appendix was summarized and presented at the Business History Conference (BHC) Annual Meeting on the "The Business History of Everything" held March 25-27, 2010 in Athens, GA and was nominated for the K. Austin Kerr Prize for Best Ph.D. Student Paper. Parts of this appendix were also presented in a talk entitled "An Analysis of the Evolution of the Digital Signal Processing Industry as a Global Market for Technology, 1986-2008," at the Industry Studies Association (ISA) Conference, held at the University of Illinois-Chicago, May 6, 2010.
} 
physical building blocks for creating DSPs. Stored-program computing, an architectural innovation, offered an integrated framework for recombining mathematical and material innovations to produce functional DSPs. An analysis of sixty years of subsequent innovation in DSPs reveals that: (1) some fundamental mathematical innovations are actually rediscoveries of earlier inventions; (2) architectural innovations often lag mathematical innovations by decades due to the technological constraints of material innovations; and (3) architectural innovations frequently reconfigure industry alliances and open new markets. The unintentional loss and rediscovery of mathematical innovations, the unanticipated lag between architectural and mathematical innovations, and the unexpected rearrangement of firm alliances are all possible sources of surprising new entrepreneurial opportunities to be discovered and exploited by firms in the signal processing industry.

Within the domain of science, the discipline of signal processing has been described as a remarkable success story that has resulted in the tangible creation of a multitude of useful "products that have changed the way we live" (Chiariglione 1997). From a cell phone in a caller's hand to a communications satellite in Earth's orbit, and from local wireless networks for Internet connectivity to global positioning systems (GPS) for vehicle navigation - and nearly everything digital in between — signal processing is a fundamental, enabling technology which makes all of these products possible. Although most people are aware of the many end products resulting from signal processing research 
and development, few people are aware of the existence of the underlying scientific field of signal processing itself.

As Leah H. Jamieson ${ }^{25}$, 2007 President and CEO of the Institute of Electrical and Electronics Engineers (IEEE) ${ }^{26}$ observed regarding signal processing's lack of visibility as an engineering endeavor, "it often seems that only the people who actually work in signal processing think about who we are and what we do" (Nebeker 1998a).

The purpose of this appendix is to broaden and deepen our understanding of the origins, historical evolution, technological importance, and economic significance of the "numerous innovations in theory, algorithms, and implementation" (Hu 1997) in signal processing from 1948 to 2008. From a Schumpeterian perspective, the most essential aspect of innovation is "carrying out new combinations" to generate inventions which may include "discovery scientifically new and can also exist in a new way of handling a commodity commercially" (Schumpeter 1934). I examine how the recombination and rediscovery of three types of innovations — mathematical, material, and architectural — generated surprises and impacted the commercialization of signal processing.

This appendix is organized in the following manner. First, I briefly describe the early origins of signal processing and discuss the earliest known digital

\footnotetext{
${ }^{25}$ August 2009. Biosketch of Leah H. Jamieson.

${ }^{26}$ The IEEE is the world's largest technical society. By 2008, IEEE had 375,000 members in 160 countries, with $43 \%$ outside of the United States, where it was founded in 1884 as the American Institute of Electrical Engineers (AIEE). IEEE includes 38 societies in various specialties and serves its members with 130 journals, transactions and magazines; more 300 conferences annually; and 900 active standards. See A Brief History of the IEEE.
} 
representation of a signal. I also define the basic terminology used throughout the study. Next, I outline the growth of modern signal processing as a formalized field of research from its birth in 1948, to the introduction of the first digital signal processor chip in 1974; I highlight relevant and inter-related innovations in information theory, transistors, and computing. Then, I analyze the emergence and structure of digital signal processing as a global high-technology industry from 1974 to 2008, with an emphasis on exploring the role of innovation in reshaping inter-firm alliances and driving new opportunities. Finally, I summarize the main findings of this historical analysis and assess their potential implications for innovation in other knowledge-intensive industries. Based on these findings and implications, I evaluate recent speculation on the future of signal processing.

\section{The Early Origins of Signal Processing, c. 2500 B.C.}

\section{The "Palermo Stone" and Nilometers}

Possibly the first known application of signal processing may be traced back to approximately 2500 B.C., when the ancient Egyptians used the "Palermo Stone" (St. John 2003; Wilkinson 2000) and a series of measuring stations called "nilometers" (Ardagh 1889; Manoug 1889) along the banks of the Nile River to measure seasonal water levels in an attempt to predict future flooding (Eltahir and Wang 1999; Jarvis 1964). In this C. 2500 B.C. example, the signal, or physical quantity sampled, was the water level of the Nile, and the processing, or codification of the signal, was the regular and periodic inscription of the corresponding hieroglyphs into stone by human hands (Prandoni and Vetterli 2008). 


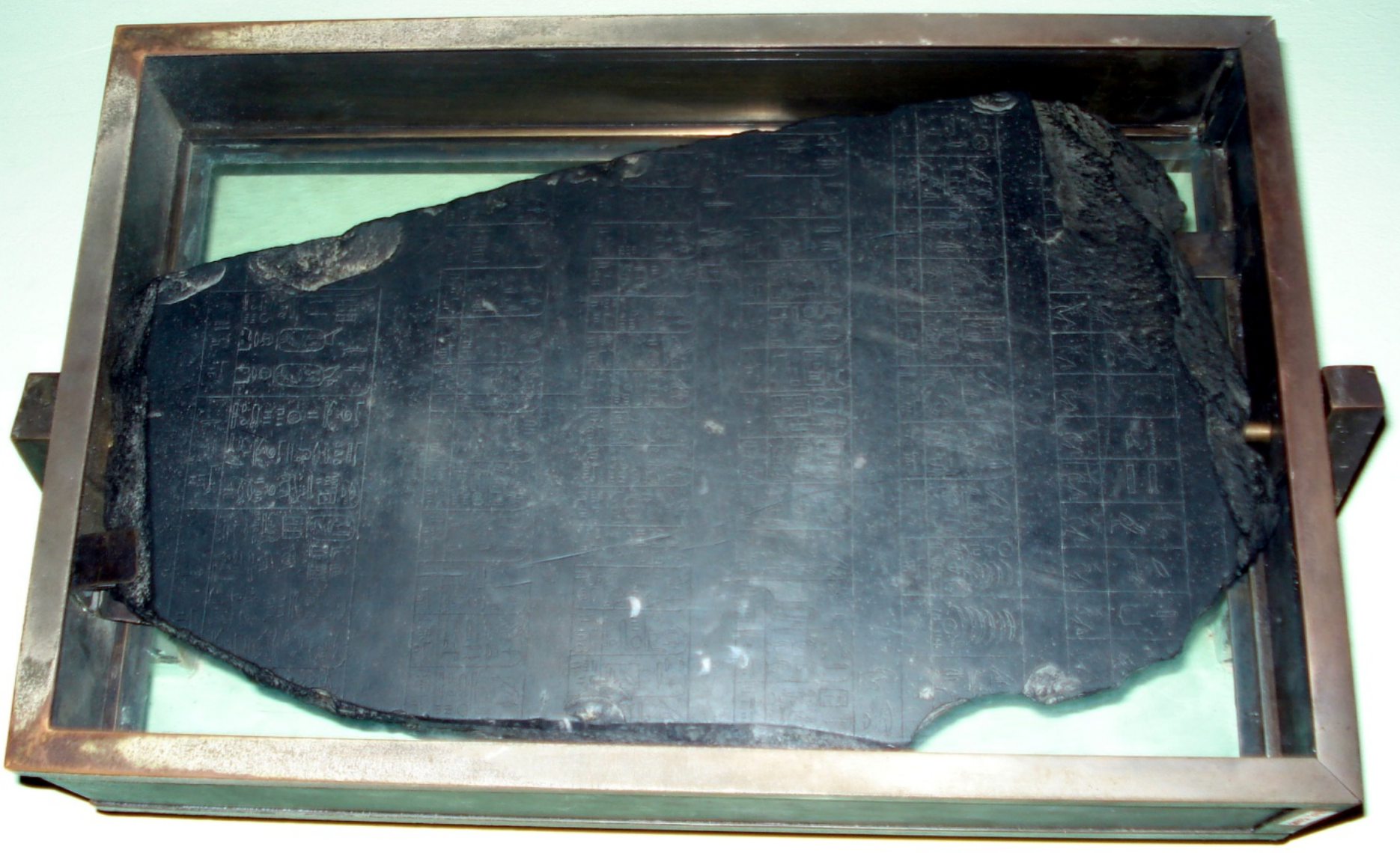

Figure 4. Photograph of a Large Fragment of the "Palermo Stone"

(On display in the Regional Archeological Museum in Palermo, Italy. Source: Wikimedia Commons) 


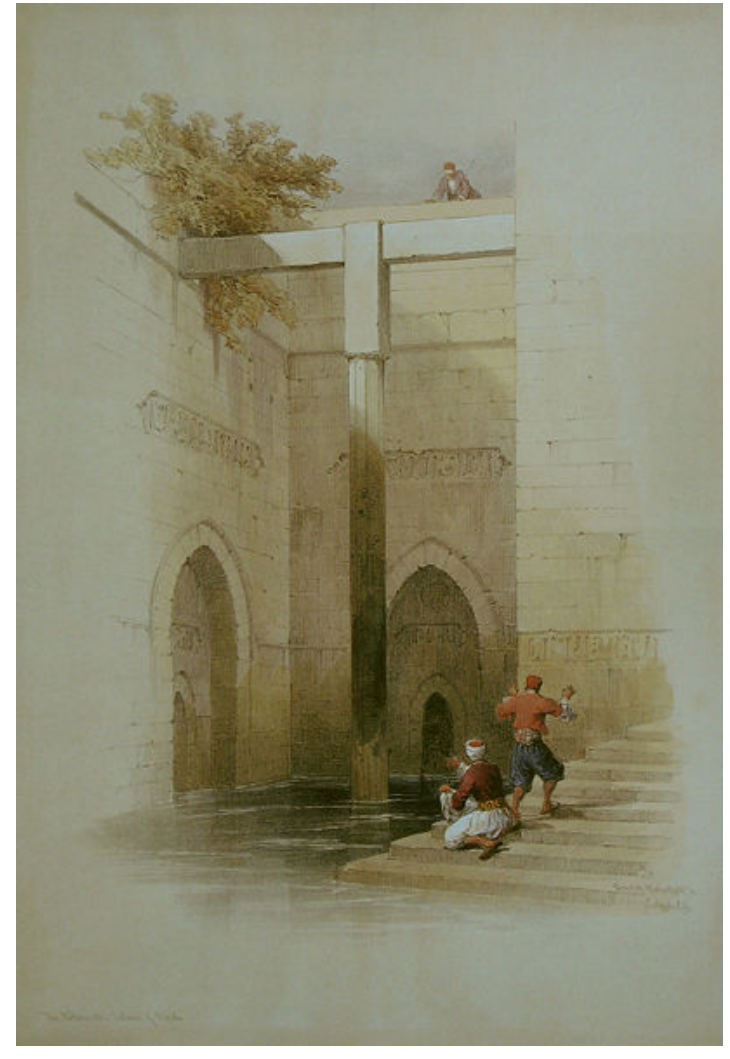

Figure 5. Illustration of the Nilometer on the Isle of Rhoda, Cairo

David Roberts (1796-1864).

Source: Wikimedia Commons

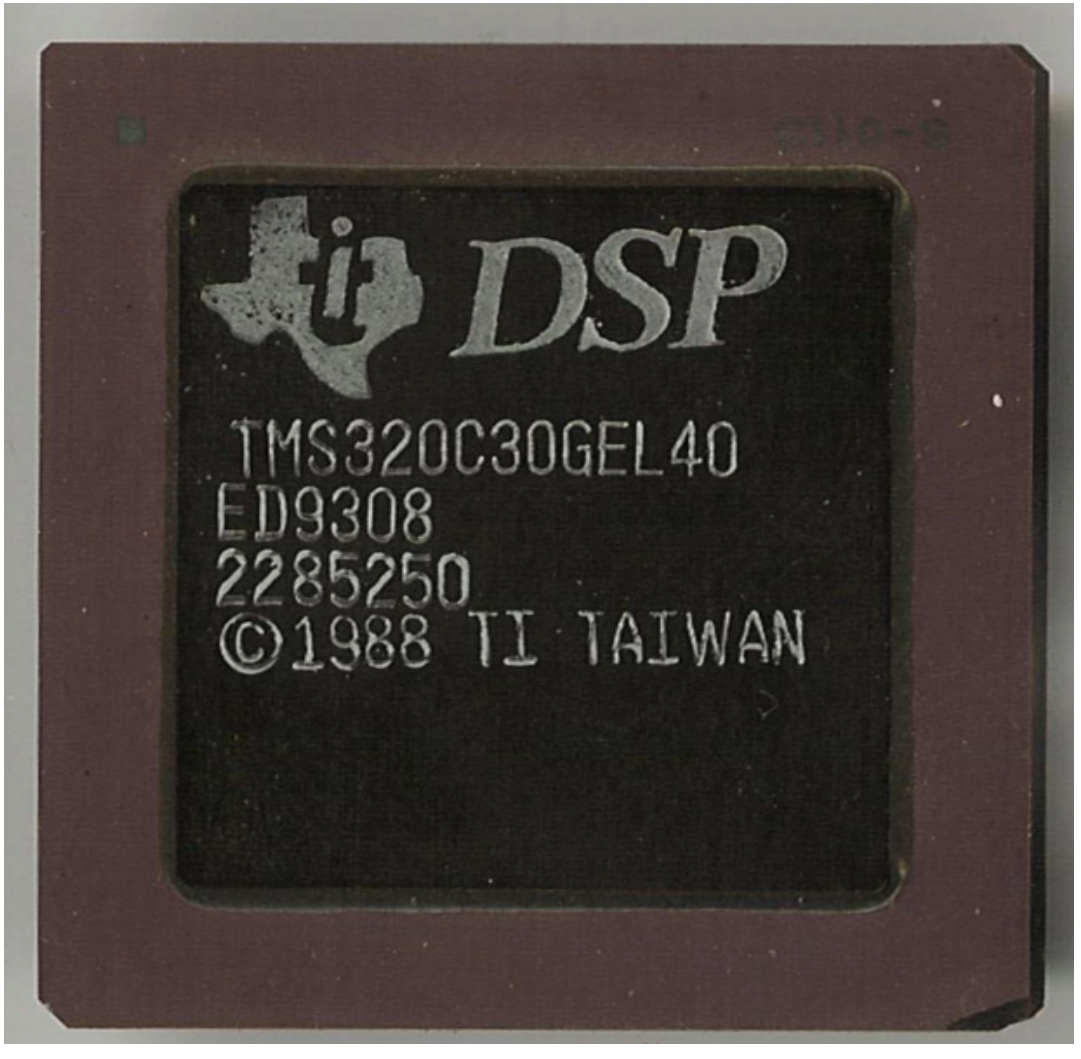

Figure 6. Photograph of a Modern DSP Chip Manufactured by Texas Instruments, 1988

Source: Wikimedia Commons 
Table 15. Type of Innovation in Primitive DSP System and Modern DSP Chips

\begin{tabular}{|c|c|c|c|c|}
\hline $\begin{array}{l}\text { Type of } \\
\text { Innovation }\end{array}$ & $\begin{array}{c}\text { Primitive } \\
\text { DSP System }\end{array}$ & $\begin{array}{c}\text { Modern } \\
\text { DSP Chips }\end{array}$ & $\begin{array}{c}\text { Potential } \\
\text { Impact on Field }\end{array}$ & $\begin{array}{c}\text { Relevant Previous } \\
\text { Findings }\end{array}$ \\
\hline Mathematical & $\begin{array}{l}\text { Egyptian calendar, } \\
\text { writing system, \& } \\
\text { numerals (Gardiner } \\
\text { and Gauthier- } \\
\text { Laurent } 1927 \text { ) }\end{array}$ & $\begin{array}{l}\text { Information } \\
\text { theory \& } \\
\text { numerical } \\
\text { analysis }\end{array}$ & $\begin{array}{l}\text { The "formalization" and } \\
\text { "axiomization" of a } \\
\text { mathematical theory will } \\
\text { facilitate its wider use (Glas } \\
\text { 1999). }\end{array}$ & $\begin{array}{l}\text { Both "thought experiments" and } \\
\text { "numerical experiments" contribute to } \\
\text { knowledge and are essential to the } \\
\text { process of conceptual reform and } \\
\text { mathematical innovation (Stoltzner 2003). }\end{array}$ \\
\hline Material & $\begin{array}{l}\text { Stones and the } \\
\text { tools for carving \& } \\
\text { transport (Lucas } \\
\text { and Harris 1962) }\end{array}$ & $\begin{array}{l}\text { Transistors } \\
\text { and the tools } \\
\text { for design \& } \\
\text { manufacture }\end{array}$ & $\begin{array}{l}\text { Technical benchmarks (such } \\
\text { as Moore's Law }{ }^{27} \text { ) are a self- } \\
\text { fulfilling prophecy; } \\
\text { technologies will evolve in } \\
\text { ways not predicted by and } \\
\text { even contradictory to } \\
\text { established benchmarks } \\
\text { (Tuomi 2002). }\end{array}$ & $\begin{array}{l}\text { The entry of global competitors and the } \\
\text { adoption of industry standards increase } \\
\text { the diversity and rate of material } \\
\text { innovation, thereby enabling organizations } \\
\text { to overcome the performance barriers } \\
\text { implicit in technical benchmarks (Mollick } \\
\text { 2006). }\end{array}$ \\
\hline Architectural & $\begin{array}{l}\text { Construction of } \\
\text { nilometers (Clarke } \\
\text { and Engelbach } \\
1990 \text { ) }\end{array}$ & $\begin{array}{l}\text { Construction of } \\
\text { stored- } \\
\text { program } \\
\text { computer }\end{array}$ & $\begin{array}{l}\text { Architectural innovation will be } \\
\text { "initiated by new entrants and } \\
\text { will lead to the failure of } \\
\text { incumbents in a product class" } \\
\text { (Tushman and Nelson 1990). }{ }^{28}\end{array}$ & $\begin{array}{l}\text { Architectural innovation leads to "the } \\
\text { failure of incumbents and the rise of new } \\
\text { organizations; this process recurs over } \\
\text { successive generations of architectural } \\
\text { innovations" (Tushman and Nelson 1990). }\end{array}$ \\
\hline
\end{tabular}

\footnotetext{
${ }^{27}$ Moore's Law characterizes an empirically observed relationship indicating that the number of transistors on an integrated circuit has doubled approximately every 18-24 months, over the history of computing. The Law is named in honor of Intel Co-Founder Gordon Moore. For Moore's original article, see (Moore 1998). For Moore's own updated perspective, see (Moore 1995).

${ }^{28}$ Quote is from page 3 of (Tushman and Nelson 1990) The referenced quote summarizes the original longitudinal study by Henderson and Clark of the photolithography industry from 1962 to 1986 appearing in the same issue. See (Henderson and Clark 1990). See also (Christensen 1992) For related work on recombinant innovation see (Galunic and Eisenhardt 2001).
} 
Restated in more specific, $21^{\text {st }}$ century A.D. technical terms, signals are analog or digital electrical representations of time-varying or spatial-varying physical quantities (Oppenheim and Schafer 1975). Signal processing is the science of identifying, analyzing, manipulating, and extracting signals in real-time (Lyons 1997). Digital Signal Processing (DSP) "is the mathematics, the algorithms, and the techniques used to manipulate these signals after they have been converted into a digital form" (Smith 1997). Digital Signal Processors $(D S P S)^{29}$ are physical devices or semiconductor chips that are used to digitally convert, transform and analyze audio, voice, image, video and other sensory signals from one form to another (Eyre and Bier 1998; Eyre 2000).

Thus, now expressed in modern parlance, the "Palermo Stone", "nilometers", and human stone carvers can be regarded as the essential components of a primitive DSP system which was used to capture the measurement of Nile's water level as a discrete-time digitally-sampled physical signal and manually convert it into the form of pictorial images (St. John 2003).

\section{Innovation in Primitive DSP System and Modern DSP Chips}

Because its hieroglyphically-encoded digital data is still used in contemporary hydrological (Atiya et al. 1999) and statistical (St. John 2003) research, the Palermo Stone is "arguably the first recorded digital signal which is still of relevance today" (Prandoni and Vetterli 2008). In the preceding example, the creation of a primitive stone-based DSP system was made possible by the

\footnotetext{
${ }^{29}$ Within the industry and academia, the term "DSP" is commonly used to mean both "Digital Signal Processing" and "Digital Signal Processor," the singular form of "Digital Signal Processors." To avoid confusion, in this study, the term "DSP" is used specifically to refer to the science, while the terms "DSP chips" and "DSPs" are used to refer specifically to the chips.
} 
earlier mathematical, material, and architectural innovations summarized in Table 15. As will be discussed in the next section, the development of modern silicon-based DSP chips was also made possible by significant advances within each type of innovation. The potential impact and relevant previous findings for each of these types of innovation are also shown in Table 15.

\section{Modern Signal Processing as a Formalized Field of Research, 1948-1973}

The story of modern signal processing begins in 1948 and continues to the present day. Three major research breakthroughs appeared in 1948: the introduction of information theory, the invention of the transistor, and the demonstration of the first stored-program computer (Nebeker 1998c). Understanding the emergence of these three distinct, yet highly complementary research areas is critical for analyzing the evolution of signal processing as a general purpose technology (GPT). General purpose technologies (GPTs) are defined as enabling technologies, which "open up new opportunities, rather than offering complete, final solutions" (Bresnahan and Trajtenberg 1995).

A GPT is a type of "drastic innovation" which has "the potential for pervasive use in a wider range of sectors in ways that drastically change their modes of operation" (Helpman 1998). GPTs have four essential features: "(1) much scope for improvement initially, (2) many varied uses, (3) applicability across large parts of the economy, and (4) strong complementarities with other technologies" (Lipsey et al. 2005). Although prior studies have examined the evolution of related GPTs such as the electric dynamo and the personal computer (David 1990), as well as microprocessors (Grindley and Teece 1997; 
Hall and Ziedonis 2001; Linden 2003), the current study is perhaps among the first to analyze the evolution of signal processing as a GPT from the perspective of economic history and Schumpeterian innovation (Nebeker 1998a, b, c). Information Theory in 1948: The Mathematical Logic for Designing DSPS

The year 1948 is generally considered to be the starting point for signal processing as a formalized field of research. The seminal event which launched the field was the publication of Claude Elwood Shannon's (1948) paper entitled "A mathematical theory of communication" in which he laid out the foundations of information theory. According to Shannon (1948), "the fundamental problem of communication is that of reproducing at one point, either exactly or approximately, a message selected at another point." Shannon first introduced and defined the smallest unit of information to be a bit, which is a simple binary representation of a 0 or 1 value (Waldrop 2001). Shannon published his work in the Bell System Technical Journal and the core ideas in his paper were heavily influenced by the earlier work of Bell Labs researchers including Harry Nyquist and Ralph Hartley. While at Bell Labs, Shannon also briefly worked with Alan Turing as part of a joint cryptographic research project (Aspray 1985) with the British military during World War II and with John von Neumann and Norbert Weiner at Princeton's Institute for Advanced Study (Kahn 1967).

Earlier, in 1924, Nyquist published "Certain factors affecting telegraph speed" in the Bell System Technical Journal, in which he formulated a theory describing bandwidth requirements for accurate and reliable information transmission (Maliniak 2005). In 1928, Hartley published "Transmission of 
information," in the same journal and for the first time introduced "a quantitative measure by which the capacities of various systems to transmit information may be compared" (Hartley 1970). Hartley's work was published shortly after the first successful transatlantic transmission of a television program (Burns et al. 1998) from London to Hartsdale, New York and he discussed "its application to systems of telegraphy, telephony, picture transmission and television over both wire and radio paths" (Hartley 1970). Nyquist's and Hartley's research can be further traced back to the even more fundamental physics concepts of energy and entropy and the principles of thermodynamics and statistical mechanics first proposed by Ludwig Boltzmann in 1877 and later refined in 1901 by Willard Gibbs and Max Planck (Gibbs et al. 1906; Planck 1901).

It is important to note that Shannon, Nyquist, and Hartley all developed their ideas while employed at Bell Labs (or its precursor research center at the Western Electric Company) and they all published their findings in the Bell System Technical Journal. Thus, if the birth of modern signal processing can be traced back to a single organization, it is Bell Labs. Another significant contribution which Shannon made in 1948 in collaboration with colleagues at Bell Labs was the enhancement of Pulse Code Modulation (PCM) which was originally invented independently by Paul Rainey in 1926 and Alan Reeves in 1937 (Nebeker 1998c). Shannon along with Bernard Oliver and John Pierce described the underlying theory of a new method for digitally converting and quantizing signals into an efficient binary format that is the basis for audio and video coding schemes widely used in digital telephone and multimedia systems 
even to this day (Verdu 1998). In 1948, Shannon's fellow Bell Labs scientist and research collaborator, Richard Hamming developed an error-correction code for binary transmission which greatly improved the reliability of signal processing and today bears his name as "the Hamming code" (MacKay 2003). Also in 1948, the work of British statistician Maurice Bartlett on time-series analysis advanced mathematical techniques for spectrum estimation (Nebeker 1998c) which is critical for signal processing applications.

Why did so many important information-theoretic breakthroughs related to signal processing emerge around 1948? Norbert Weiner, generally regarded as the "father of cybernetics" speculated that "Largely because of the impetus gained during the World War II, communication and control engineering have reached a very high level of development today. Many perhaps do not realize that the present age is ready for a significant turn in the development toward far greater heights than we have ever anticipated" (Wiener 1949). Military investment in research and development for applications such as communications, cryptography, and radar appears to be the primary catalyst for early advances in signal processing (Walker 2003) and Claude Shannon, Norbert Wiener, Warren McCulloch, Walter Pitts, Alan Turing, and John Von Neumann emerged as the scientific leaders of the post-war research program to build a unified information theory from multi-disciplinary fields (Aspray 1985).

\section{Transistors in 1948: The Physical Materials for Building DSPS}

In 1948, another critical event which contributed to the birth of modern signal processing was the announcement of the invention of the transistor by Bell 
Labs researchers John Bardeen, Walter Brattain, and William Shockley (Riordan and Hoddeson 1998). The original design of the transistor was actually begun by Bardeen and Brattain in 1947 and subsequently improved by William Shockley in 1948, who prototyped earlier field effect transistor designs (Clements 2007) that were patented by Julius Lilienfeld in Canada in 1927 and 1928 and by Oskar Heil in Germany in 1934 (Hutcheson 2005; Kleint and Lilienfeld 1998). The trio of Bardeen, Brittain, and Shockley was awarded the Nobel Prize in Physics in 1956 and a description of their invention is included below.

The transistor is a three terminal, solid state electronic device. In a three terminal device we can control electric current or voltage between two of the terminals by applying an electric current or voltage to the third terminal. This three terminal character of the transistor is what allows us to make an amplifier for electrical signals, like the one in our radio. With the three-terminal transistor we can also make an electric switch, which can be controlled by another electrical switch. By cascading these switches (switches that control switches that control switches, etc.) we can build up very complicated logic circuits. ${ }^{30}$

The invention of the transistor revolutionized the electronics industry. Expensive and energy-consuming vacuum tubes could be replaced with cheaper, lower-power and more reliable transistors which could perform the same amplification and switching functions essential for signal processing with much more efficiency (Riordan and Hoddeson 1998). It is interesting to note that the name "transistor" was actually coined by John Pierce, who was one of Claude Shannon's original collaborators along with Bernard Oliver on PCM. Pierce supervised Bardeen, Brattain, and Shockley's series of experiments on the development of the transistor. Bell Labs served as the intellectual nexus for the information theorists and transistor physicists whose collective work in

${ }^{30}$ Description of the Transistor. Source: http://www.nobelprize.org 
establishing a formal and axiomatic foundation for signal processing would soon radically shape its evolution.

Stored-Program Computing in 1948: The System Architecture for Implementing

$\underline{D S P S}$

In addition to the multiple breakthroughs in information theory and the invention of the transistor which occurred at Bell Labs in 1948, the third major area of innovation which catalyzed the formation of signal processing as a field of research was the demonstration of the first stored-program computer by Frederick Williams and Tom Kilburn at the University of Manchester in England (Nebeker 1998a). As first published in Nature (Lavington 1993), the Small-Scale Experimental Machine (SSEM), nicknamed the "Baby", was designed and built at the University of Manchester, and made its first successful run of a program on June 21, 1948 (Williams and Kilburn 1948). The SSEM was the first computer that could store not only data but any user program in electronic memory and process it at electronic speed (Williams and Kilburn 1949).

Table 16. Functional Specifications of the Small-Scale Experimental Machine (SSEM)

\section{SSEM Functionality}

32-bit word length

Serial binary arithmetic using 2's complement integers A single address format order code

A random access main store of 32 words, extendable up to 8192 words A computing speed of around 1.2 milliseconds per instruction

The SSEM functioned according to the specifications shown in Table 16. Although these specifications would appear to be extremely primitive and 
painfully slow by modern computing standards, they were unprecedented at the time. A replica of the SSEM was built in 1998 in commemoration of the $50^{\text {th }}$ anniversary of its invention and a picture is shown in Figure 7.

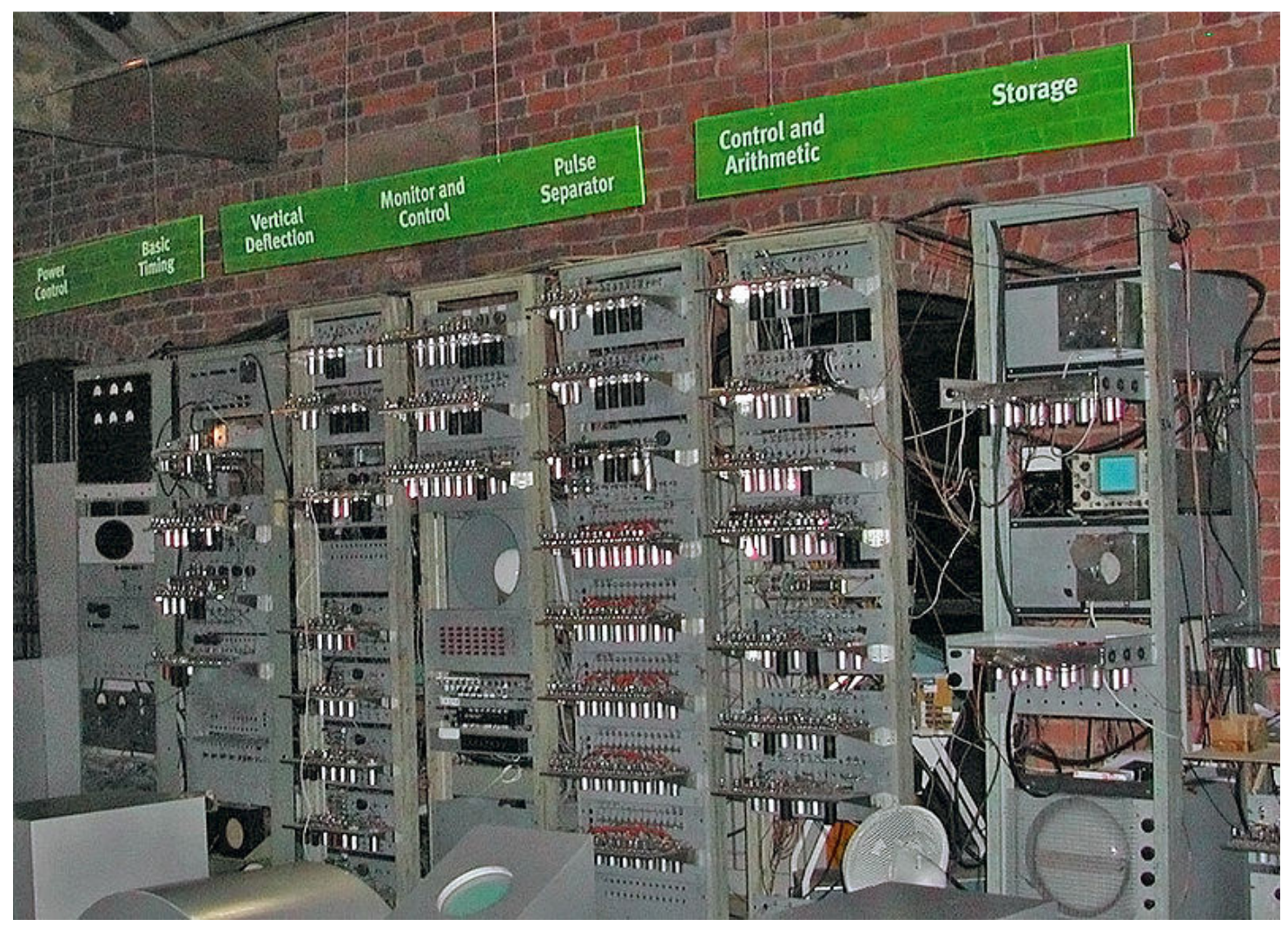

Figure 7. Photograph of a Replica of the SSEM, The World's First StoredProgram Computer

(On Display at the Museum of Science and Industry in Manchester, England) Source: Wikimedia Commons

Williams and Kilburn along with other colleagues at the University of Manchester were later instrumental in producing the world's first transistor computer in 1953. This transistor computer was built using 200 contact point transistors and performed arithmetic operations at 125,000 calculations per second. ${ }^{31}$ In comparison, 55 years later, in 2008, Intel announced the world's

${ }^{31}$ Source: University of Manchester Computer Science Archives 
first computer with over 2 billion transistors on a single chip and which operates at clock speeds between 1.2 to $2 \mathrm{GHz}{ }^{32}$

Thus, in 55 years, the number of transistors which may be incorporated into a single computer has increased by a factor of 10 million, a remarkable rate of advance that has led to the rapid evolution of signal processing as a GPT. This rate of technical advance is even more astounding when one compares the processing speed of single-chip DSPs to microcontrollers, a specialized form of microprocessor-based computer on a single chip (Nebeker 1998c). From 1980 to 1995 , the performance of single-chip DSPs increased by about three orders of magnitude (a factor of improvement of nearly 1,000 times) in comparison to the performance of microcontrollers (Frantz and Papamichalis 1996). The remarkable and unprecedented rate of technological advancement in signal processing may account for the occurrence of substantial errors in threat perception and opportunity recognition among firms in the industry. These errors in assessing threats and opportunities may, in turn, contribute the magnitude and direction of the numerous surprises encountered by firms in the industry.

Timeline and Milestones in Modern Signal Processing, 1948-1974

Although the critical technologies which led to the formalization of the field of signal processing first emerged in 1948, it was not until 26 years later that the first commercially available digital signal processing (DSP) chips were actually produced. In 1973, TRW produced the first "DSP engine" which was designed for classified U.S. military applications and was not commercially available. The first commercially available off-the-shelf DSP chips were introduced the next year

${ }^{32}$ Sources: Intel and Physorg http://www.physorg.com/news121350597.html 
in 1974 by Advanced Micro Devices as the Am2901 family of discrete logic chips (Strauss 2007). In the period from 1948 to 1974, a number of unexpected or surprising technical advances occurred in information theory, transistors, and computing which were essential to the development of the first DSP chips.

These advances and related market events such as the entry of new companies and products are summarized chronologically in Tables 17,18, 19, and 20, with major developments impacting signal processing highlighted (see shaded blocks) throughout.

Table 17. Timeline of Events in the Field of Signal Processing, ${ }^{33} 1948-1949$

\begin{tabular}{|c|c|c|c|}
\hline Year & Information Theory & Transistors & Computing \\
\hline 1948 & $\begin{array}{l}\text { At Bell Labs in the U.S., } \\
\text { Claude Shannon publishes } \\
\text { foundations of information } \\
\text { theory. } \\
\text { Claude Shannon, Bernard } \\
\text { Oliver and John Pierce publish } \\
\text { fundamentals of Pulse Code } \\
\text { Modulation (PCM). } \\
\text { Richard Hamming introduces } \\
\text { error correction codes } \\
\text { Maurice Bartlett introduces } \\
\text { statistical techniques for } \\
\text { spectrum estimation. }\end{array}$ & $\begin{array}{l}\text { Bell Labs announces the } \\
\text { invention of the transistor by } \\
\text { researchers John Bardeen, } \\
\text { Walter Brattain and William } \\
\text { Shockley. } \\
\text { Raytheon CK703 is first } \\
\text { commercially available } \\
\text { transistor. } \\
\text { Junction transistor theory } \\
\text { developed by William } \\
\text { Shockley at Bell Labs. }\end{array}$ & $\begin{array}{l}\text { At the University of } \\
\text { Manchester in England, } \\
\text { Frederic Williams and Tom } \\
\text { Kilburn demonstrate the } \\
\text { Small-Scale Experimental } \\
\text { Machine (SSEM), the first } \\
\text { stored-program computer. }\end{array}$ \\
\hline 1949 & $\begin{array}{l}\text { - Shannon's Communication } \\
\text { Theory of Secrecy Systems is } \\
\text { declassified. } \\
\text { - Marcel J. E. Golay introduces } \\
\text { Golay codes for forward error } \\
\text { correction. } \\
\text { John Tukey introduces } \\
\text { statistical techniques for the } \\
\text { spectral analysis of random } \\
\text { processes. }\end{array}$ & $\begin{array}{l}\text { "Type A" point contact } \\
\text { transistor enters limited } \\
\text { production at Bell Labs. } \\
\text { W. MacWilliams builds } \\
\text { the Transistor Gating } \\
\text { Matrix at Bell Labs, using } \\
40 \text { "Type A" transistors; } \\
\text { this is the first functional } \\
\text { transistor application. }\end{array}$ & $\begin{array}{l}\text { - BINAC, the Binary Automatic } \\
\text { Computer, is designed for } \\
\text { Northrop Aircraft Company by } \\
\text { the Eckert-Mauchly Computer } \\
\text { Corporation (EMCC), which } \\
\text { was the first computer } \\
\text { company. BINAC was the first } \\
\text { stored-program computer in } \\
\text { the US, and the world's first } \\
\text { commercial digital computer. }\end{array}$ \\
\hline
\end{tabular}

${ }^{33}$ I compiled this set of tables (Table 17-20) from multiple sources, including Nebeker (1998a, b, c) and Verdu (1998). For additional details and more in-depth timelines for information theory, transistors and computing, see also http://www.historyofscience.com, http://www.intel.com/museum/online/hist_micro/hof/, http://www.sciencetimeline.net, and http://www.asc-cybernetics.org/foundations/timeline.htm. 
Table 18. Timeline of Events in the Field of Signal Processing, 1950-1959

\begin{tabular}{|c|c|c|c|}
\hline Year & Information Theory & Transistors & Computing \\
\hline $\begin{array}{l}1950- \\
1959\end{array}$ & $\begin{array}{l}\text { 1951 } \\
\text { David A. Huffman invents } \\
\text { Huffman encoding, a method } \\
\text { of finding optimal prefix codes } \\
\text { for lossless data compression } \\
\text { for any set of symbols; the } \\
\text { algorithm is eventually used } \\
\text { for compressing data in } \\
\text { everything from compact discs } \\
\text { to interplanetary spacecraft } \\
\text { (Waldrop, 2001). } \\
\text { 1955 } \\
\text { Peter Elias introduces } \\
\text { convolutional codes. } \\
\text { 1956 } \\
\text { - Noam Chomsky publishes } \\
\text { "Three Models for the } \\
\text { Description of Language" and } \\
\text { introduces two key concepts: } \\
\text { the hierarchy of syntactic } \\
\text { forms, and transformational- } \\
\text { generative grammar theory; } \\
\text { Chomsky expands on these } \\
\text { ideas in Syntactic Structures } \\
\text { (1957). } \\
\text { - Norbert Wiener publishes The } \\
\text { Human Use of Human Beings. } \\
\text { - Raj Chandra Bose and } \\
\text { Dwijendra Kumar Ray- } \\
\text { Chaudhuri, and independently } \\
\text { the next year Alexis } \\
\text { Hocquenghem, present BCH } \\
\text { codes. } \\
\text { 1957 production to Cybernetics. } \\
\text { Eugene Prange first discusses } \\
\text { cyclic redundancy codes. } \\
\text { A joint United States and } \\
\text { European committee is } \\
\text { formed to create a universal } \\
\text { programming language, } \\
\text { 'Algorithmic Language,' or } \\
\text { 'Algol.' the precursor of } \\
\text { 'Pascal.; In the course of } \\
\text { creating Algol, John Backus } \\
\text { and Peter Naur invented } \\
\text { 'Backus-Naur notation' for } \\
\text { a programming language. } \\
\text { - }\end{array}$ & 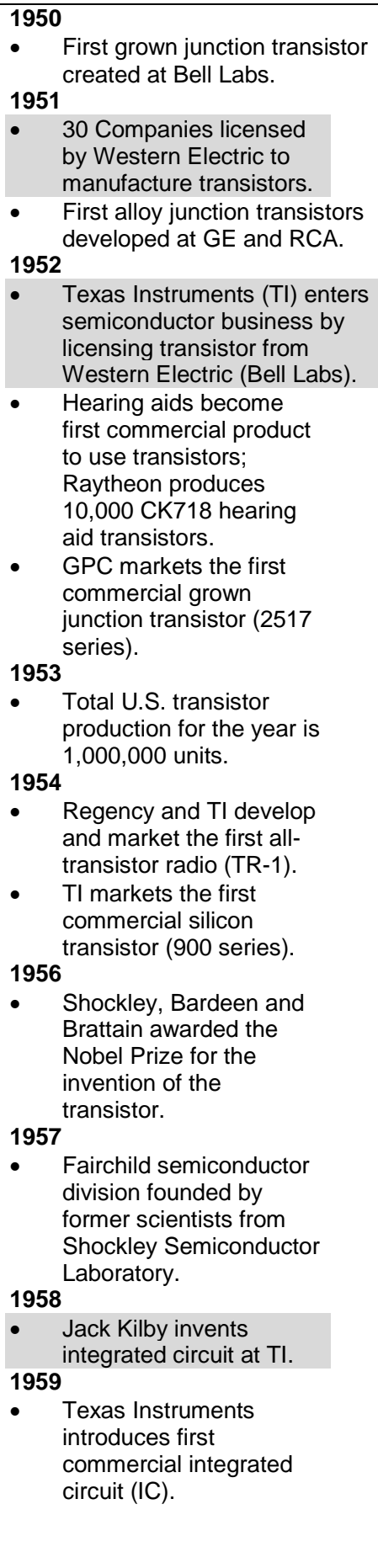 & 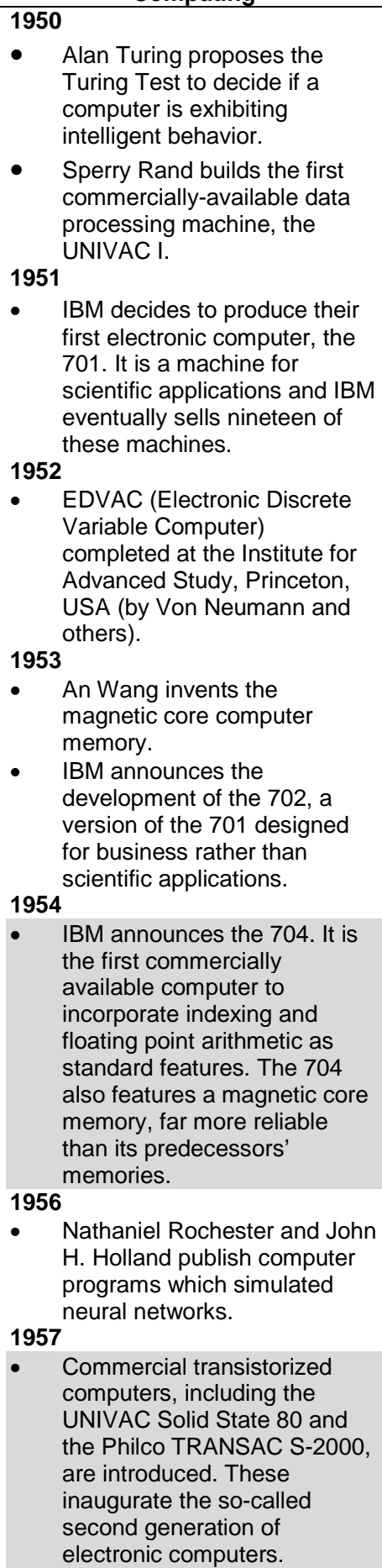 \\
\hline
\end{tabular}


Table 19. Timeline of Events in the Field of Signal Processing, 1960-1969

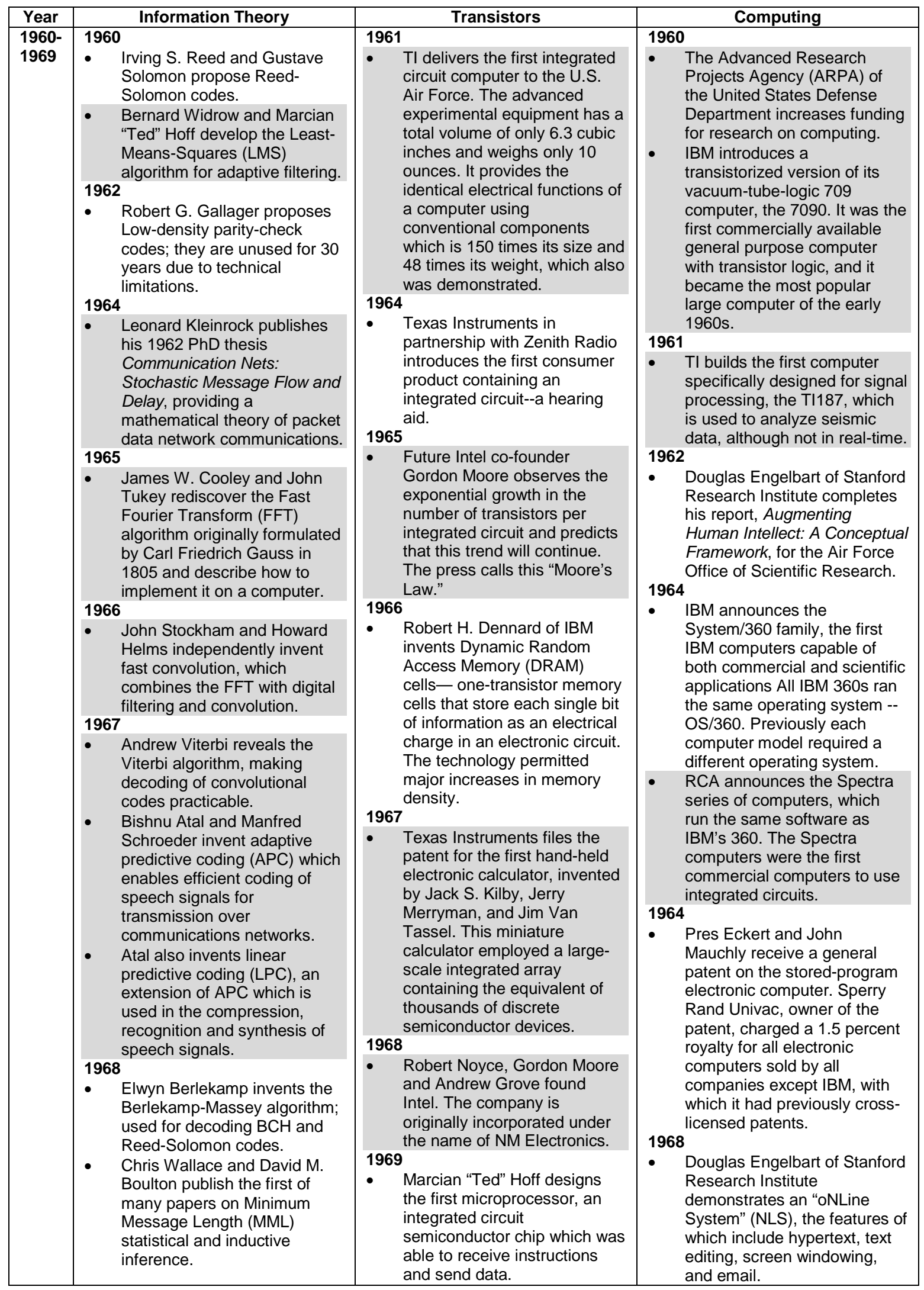


Table 20. Timeline of Events in the Field of Signal Processing, 1970-1974

\begin{tabular}{|c|c|c|c|}
\hline Year & Information Theory & Transistors & Computing \\
\hline $\begin{array}{l}1970- \\
1974\end{array}$ & $\begin{array}{l}\text { 1970 } \\
\text { - Valerii Denisovich Goppa } \\
\text { introduces Goppa codes, A } \\
\text { new class of linear correcting } \\
\text { codes. } \\
\text { 1971 } \\
\text { Thomas Kailath and Enders } \\
\text { Robinson publish a number of } \\
\text { papers on statistical } \\
\text { techniques for optimal design } \\
\text { of filters and systems for } \\
\text { reducing noise in signal } \\
\text { transmissions. } \\
\text { 1972 } \\
\text { Thomas Parks and James } \\
\text { McClellan and introduce the } \\
\text { Parks-McClellan algorithm for } \\
\text { designing and implementing } \\
\text { efficient and optimal finite } \\
\text { impulse response FIR filters. } \\
\text { James K. Baker and Fred } \\
\text { Jelinek introduce statistical } \\
\text { techniques which enable } \\
\text { speech recognition by } \\
\text { automated systems. } \\
\text { Franklin Cooper introduces } \\
\text { new techniques for analyzing } \\
\text { speech patterns and } \\
\text { synthesizing speech signals } \\
\text { discover and prove the } \\
\text { Slepian-Wolf coding limits for } \\
\text { distributed source coding. } \\
\text { acoustics and human auditory } \\
\text { perception. } \\
\text { J. Justesen proposes } \\
\text { Justesen codes, an } \\
\text { improvement of Reed- } \\
\text { Solomon codes. } \\
\text { James Flanagan proposes } \\
\text { adaptive differential pulse } \\
\text { code modulation (ADPCM), } \\
\text { which exploited the fact that a } \\
\text { small sample of speech can } \\
\text { be predicted fairly accurately } \\
\text { from preceding samples. } \\
\text { new standard for encoding } \\
\text { - }\end{array}$ & $\begin{array}{l}\text { 1970 } \\
\text { Gilbert Hyatt files a patent } \\
\text { application entitled Single } \\
\text { Chip Integrated Circuit } \\
\text { Computer Architecture based } \\
\text { on work begun in } 1968 \text {. This } \\
\text { was the first general patent on } \\
\text { the microprocessor. Twenty } \\
\text { years later in 1990, the U.S. } \\
\text { Patent Office awarded the } \\
\text { patent, but was overturned in } \\
\text { 1995. } \\
\text { Intel announces the Intel } \\
\text { 1103, the world's first } \\
\text { commercially available } \\
\text { Dynamic Random Access } \\
\text { Memory (DRAM) chip (1K bit } \\
\text { pMOS dynamic RAM ICs). } \\
\text { 1971 } \\
\text { TI announces a new standard } \\
\text { one-chip MOS/LSI calculator } \\
\text { logic circuit to make full } \\
\text { electronic calculators } \\
\text { available for the mass } \\
\text { consumer market. } \\
\text { The chip incorporates all of } \\
\text { the logic and memory circuits } \\
\text { to perform complete 8-digit } 3- \\
\text { register calculator functions, } \\
\text { including full precision add, } \\
\text { subtract, multiply, and divide } \\
\text { operations. The chip was } \\
\text { priced at less than } \$ 20 . \\
\text { Intel announces the first } \\
\text { microprocessor, the 4-bit } \\
\text { Intel announces the } 8080 \\
\text { eight-bit microprocessor. It will } \\
\text { power the MITS Altair } 8800 \\
\text { designed by H. Edward } \\
\text { Roberts, the first truly } \\
\text { inexpensive personal } \\
\text { computer. Within a year the } \\
\text { 8800 will be designed into } \\
\text { hundreds of different } \\
\text { products. }\end{array}$ & $\begin{array}{l}1970 \\
\text { MIT Lincoln Labs develops } \\
\text { the Fast Digital Processor } \\
\text { (FDP), the first real-time DSP } \\
\text { computer, which performed } \\
\text { signal processing tasks about } \\
100 \text { time faster than the } \\
\text { general-purpose computers of } \\
\text { the era. A more powerful } \\
\text { version was introduced in } \\
\text { 1974 for speech processing. } \\
\text { 1971 } \\
\text { C. Gordon Bell and Allen } \\
\text { Newell publish Computer } \\
\text { Structures: Readings and } \\
\text { Examples, a systematized } \\
\text { presentation of the principles } \\
\text { governing the design of } \\
\text { computer systems. } \\
\text { IBM's first operational } \\
\text { application of speech } \\
\text { recognition enables customer } \\
\text { engineers servicing } \\
\text { equipment to "talk" to and } \\
\text { receive "spoken" answers } \\
\text { from a computer that can } \\
\text { recognize about } 5,000 \text { words. } \\
1973 \\
\text { The Alto computer system is } \\
\text { operational at Xerox PARC. } \\
\text { Conceptually the first personal } \\
\text { computer system, it eventually } \\
\text { featured the first WYSYWG } \\
\text { (What You See is What You } \\
\text { Get) editor, a graphic user } \\
\text { interface (GUI), networking } \\
\text { through Ethernet, and a } \\
\text { mouse. } \\
\text { IBM builds the first prototype } \\
\text { computer (the } 801 \text { ) employing } \\
\text { RISC (Reduced Instruction } \\
\text { Set Computer) architecture. } \\
\text { Based on an invention by } \\
\text { John Cocke, RISC simplified } \\
\text { the instructions given to run } \\
\text { computers, making them } \\
\text { faster and more powerful. }\end{array}$ \\
\hline
\end{tabular}


The Role of Computational Complexity in Driving Technological Adoption

A careful review of the preceding timeline of events impacting signal processing offers some valuable insights regarding the largely unpredictable and surprising evolution of DSP as a GPT. Advances in information theory sometimes led directly to improvements in computing architectures, which were then quickly implemented in commercial products made possible by the latest transistor devices. However, this process was rarely linear or as straightforward as it might appear from the retrospective summary (Tables 17-20) compiled in this study. For example, some innovations such as David Huffman's 1951 invention of Huffman coding for lossless data compression were quickly adopted and remain in use even today (Huffman 2006). However, Peter Elias' 1955 more computationally complex invention of convolutional codes (Elias 1955) was not practical to implement until 12 years later with Andrew Viterbi's 1967 development of the Viterbi algorithm for decoding (Viterbi 1967). In a more extreme case, Robert Gallager's 1962 invention of low-density parity-check codes was not usable until 30 years later due to technical limitations and computational complexity (Richardson and Urbanke 2003).

In addition, some innovations were actually rediscoveries of earlier inventions. In these situations, the source of the surprise was that information was unintentionally lost and then found. Perhaps the most notable of example of rediscovery in signal processing is James Cooley's and John Tukey's (1965) formulation of the Fast Fourier Transform (FFT) which was originally discovered by Carl Friedrich Gauss over one hundred and sixty years earlier c.1805 
(Heideman et al. 1985) ${ }^{34}$ What made Cooley's and Tukey's version of the FFT spread so quickly was the ease of implementation in the computers available at the time (Cooley 1992). The FFT, which enables the frequency domain processing of the time domain representation of physical signals (Cooley 1987; Cooley and Tukey 1965) in real-time, is absolutely fundamental to all signal processing applications in use today (Rader and Brenner 1976).

Figure 8 below utilizes a brief numerical example to illustrate the significance of the FFT as a mathematical innovation. ${ }^{35}$

Figure 8. The Computational Complexity of Fast Fourier Transform (FFT) in Comparison to the Discrete Fourier Transform (DFT)

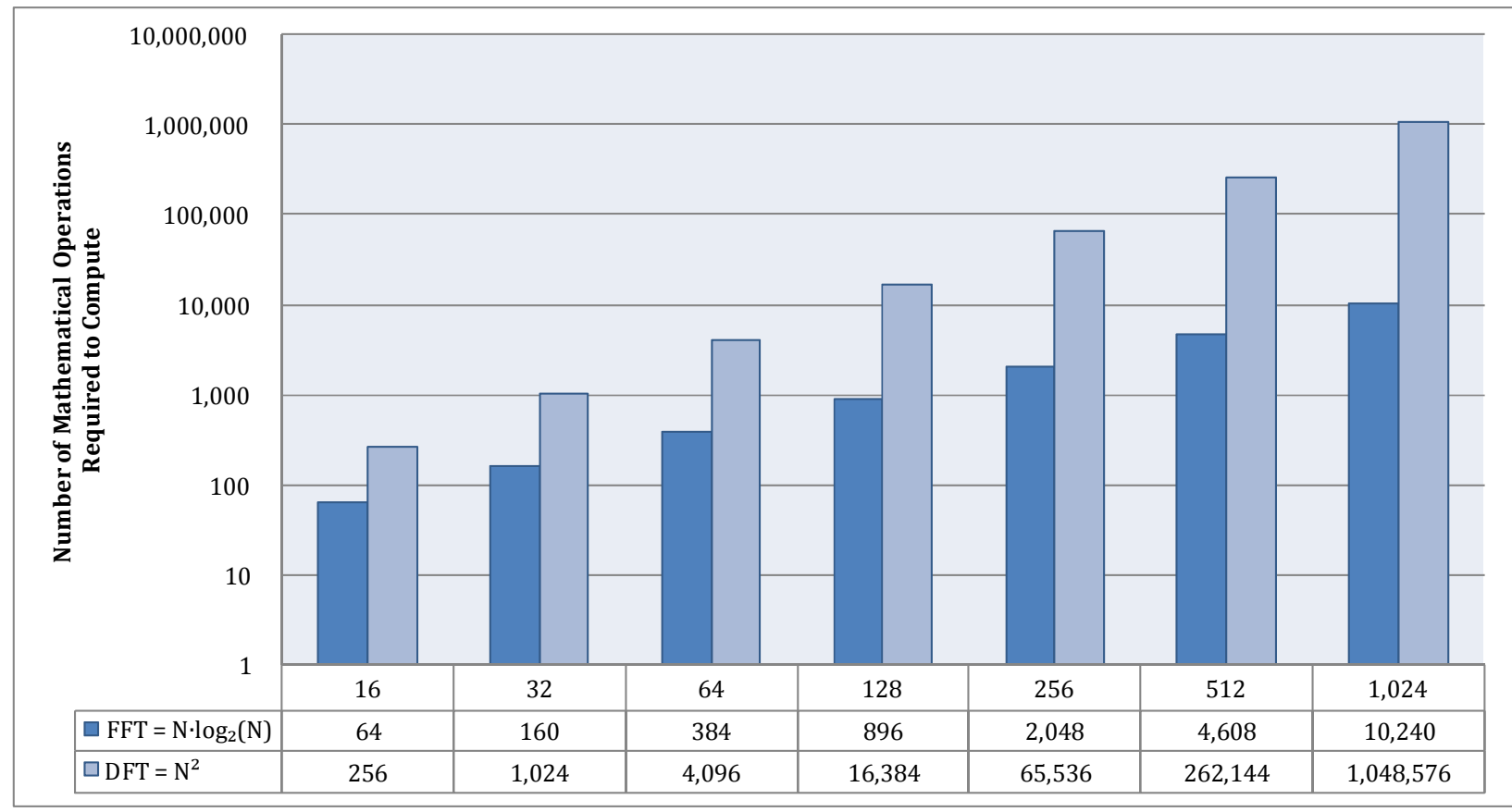

\footnotetext{
${ }^{34}$ (Heideman et al. 1985) According to the authors, the treatise of interest was entitled "Theoria Interpolationis Methodo Nova Tractata". It was published only posthumously in Volume 3 of the collected works of Gauss in 1866, but was originally written, most likely, in 1805.

${ }^{35}$ Note that scale on the $\mathrm{Y}$-axis is logarithmic, each increment is an increase in order of magnitude (a factor of 10).
} 
Prior to the discovery of the FFT, the Discrete Fourier Transform (DFT) was the best known method for generating a frequency-domain representation of a sampled signal. Here, the variable $N$ corresponds to the length of the sampled signal; the greater the length, the higher the value of $N$. As the value of $N$ on the $\mathrm{X}$-axis (in the figure below) increases from $N=16$ to $N=1024$ (corresponding to an increase the sample length), the number of mathematical operations (multiplications and additions) required to compute the FFT increases from 64 to a value of 10,240 (an increase by a factor of 160 times). In comparison, the number of mathematical operations required to compute the DFT increases from 256 to $1,048,576$ (an increase by a factor of 4,096 times). The net result is that for a sample length of $\mathrm{N}=1024$, the DFT is exactly 102.4 times more computationally complex than the FFT. ${ }^{36}$

Thus, as shown in the preceding numerical example, the impact of the FFT as a mathematical innovation was a dramatic reduction in the computational complexity of the most fundamental algorithm required for every signal processing application. The "thought experiments" that were previously only possible on paper could actually be tested and validated through "numerical experiments" by efficiently programming the available computing power (Cooley 1992). This enabled scientists and engineers to prototype and implement a variety applications in fields ranging from sonar systems for underwater navigation to seismic monitoring systems for oil exploration. Perhaps the most surprising and fascinating aspect about the FFT is that it was rediscovered multiple times and in multiple forms by a number of scientists working in different

${ }^{36}$ Obtained by dividing $1,048,576$ by 10,240 . 
disciplines. Table 21 below summarizes the known instances of the initial discovery computationally efficient alternatives to the DFT.

Table 21. Discovery and Rediscovery of Computationally Efficient Alternatives to the $\mathrm{DFT}^{37}$

\begin{tabular}{|lll|} 
Generalizability & $\begin{array}{l}\text { Input Sequence Lengths } \\
\text { (Acceptable Values of } M\end{array}$ & $\begin{array}{l}\text { Researcher(s) and } \\
\text { Year of Initial Discovery }\end{array}$ \\
\hline \multirow{3}{*}{ Most General } & Any composite integer & $\begin{array}{l}\text { Gauss }-1805, \text { Cooley \& Tukey - } \\
1965(\mathrm{FFT})\end{array}$ \\
\cline { 2 - 3 } & $\begin{array}{l}\text { Any integer with relatively } \\
\text { prime factors }\end{array}$ & $\begin{array}{l}\text { Thomas }-1948, \text { Good }-1958, \\
\text { Winograd }-1976\end{array}$ \\
\cline { 2 - 3 } $2^{n} \cdot \mathrm{K}, 3^{n} \cdot \mathrm{K}$ & Stumpff -1939 \\
\cline { 2 - 3 } Least General & $2^{n} \cdot \mathrm{K}$ & Runge -1903 \\
\cline { 2 - 3 } $2^{n}$ & Danielson \& Lanczos -1942 \\
\cline { 2 - 3 } & $4,8,16,32$ & Smith -1846 \\
\cline { 2 - 3 } & 12 & Carlini -1828, Everett -1923 \\
\hline
\end{tabular}

Remarkably, over a 160 year span of time, from 1805 to 1965 , at least 7 different alternatives to the DFT were discovered by 11 different researchers or pairs of researchers. The most generalizable approach, the FFT, which was developed by Cooley and Tukey in 1965, was actually a rediscovery of the comparable work of Gauss from 1805 (Cooley 1987). The unintentional loss and rediscovery of this vital know-how may have contributed to errors in threat perception and opportunity recognition among potential developers of signal processing technology and may account for the occurrence of surprises during the course of the emergence of the scientific field and industry.

\footnotetext{
${ }^{37}$ I modified the original table entitled "Principal Discoveries of Efficient Methods of Computing the DFT" on page 272 of (Heideman et al. 1985) The modified table indicates the overall generalizability of each alternative in terms of the allowed values for the input sequence lengths.
} 
The Role of Key Inventors in Generating More than One Type of Innovation

In addition to the rediscovery of the FFT, the original contributions of a select group of researchers who spanned two or more areas of innovation (mathematical, material, and/or architectural) were also significant in the evolution of signal processing. For example, in 1960, Marcian "Ted" Hoff developed the Least-Means-Squares (LMS) algorithm (Widrow and Stearns 1985) with his doctoral advisor, Bernard Widrow, as part of his Ph.D. dissertation (Hoff 1962). The LMS algorithm is perhaps second only to the FFT in terms of its widespread use in signal processing applications as an adaptive filtering mechanism (Widrow and Haykin 2003). Later, in 1969, Hoff was an early employee at Intel as is credited with co-inventing the microprocessor with Frederico Faggin and Stan Mazor. ${ }^{38}$ Hoff contributed to key developments in both information theory and transistors and it is impossible to discern how much influence his invention in one domain had on his subsequent invention in another related domain. Similarly, at Bell Labs in 1948, John Pierce developed the methodology of pulse code modulation (PCM) with Bernard Oliver and Claude Shannon while also managing the team of John Bardeen, Walter Brattain and William Shockley when they conducted the series of experiments that led to the invention of the transistor. Based on the analysis presented thus far on the unpredictable evolutionary path of signal processing, the description below appears to appropriately characterize mathematical, material, and architectural innovation in this field.

${ }^{38}$ Source: Intel Corporation, http://inventors.about.com/od/mstartinventions/a/microprocessor.htm 
Models that depict innovation as a smooth, well-behaved linear process badly mis-specify the nature and direction of the causal factors at work. Innovation is complex, uncertain, somewhat disorderly, and subject to changes of many sorts. (Kline and Rosenberg 1986)

Furthermore, as Stephen Kline and Nathan Rosenberg explain, "The process of innovation must be viewed as a series of changes in a complete system not only of hardware but also of market environment, production facilities and knowledge, and the social contexts of the innovation organization"(Kline and Rosenberg 1986). In Kline and Rosenberg's (1986) framework, "Commercial innovation is controlled by two distinct sets of forces that interact with one another in subtle and unpredictable ways." The two sets of forces are market forces and technological forces and they are closely interconnected on multiple levels. Thus, understanding the evolution of signal processing as a GPT also requires the careful measurement and analysis of the interaction of market forces and technological forces over time. The non-deterministic nature of this interaction may generate errors in organizational beliefs about the field of signal processing and these errors may produce surprise in less resilient organizations. In the next section, I examine both sets of forces and their effect on the emergence and growth of DSP firms and the DSP industry as a whole.

\section{DSP as a Global High-Technology Industry, 1974-2008}

As described earlier, the field of signal processing has its roots in the breakthroughs in information theory, transistors and computing which occurred in 1948. Over 26 years passed before the first commercially available off-the-shelf DSP chips were introduced in 1974 by Advanced Micro Devices as the Am2901 family of discrete logic chips; in the 34 subsequent years that passed from the 
introduction of the first off-the-shelf DSP chips, the total size of the DSP industry grew from virtually zero to over $\$ 27$ billion in total revenues in 2008 (Strauss 2008). ${ }^{39}$

\section{Initial Generation of Commercial DSP}

In the period from 1974-2008, DSP technology underwent six major changes in technology regimes, represented by six new generations of technology. After Advanced Micro Devices' introduction of the Am2901 family of DSP chips in 1974, the next major milestone was the introduction of the Speak and Spell ${ }^{\mathrm{TM}}$ educational toy by Texas Instruments (TI) in 1978 (Frantz 1982). Market and technological forces interacted synergistically, demonstrating that DSP could be used to create a new class of consumer products that would eventually transform the way we live. The Speak and Spell ${ }^{\mathrm{TM}}$ incorporated the non-programmable TMS280, the first single-chip implementation of a DSP algorithm and was the first widely used mass market consumer product to utilize DSP technology (Strauss 2007). ${ }^{40}$ The introduction of the Speak and Spell ${ }^{\mathrm{TM}}$ surprised $\mathrm{TI}$ and its competitors in the emerging DSP industry by demonstrating that consumer applications of signal processing could be enormously profitable for firms even in comparison to military applications of the technology. In the same year, 1978, AMI Semiconductor announced the first programmable DSP, the S2811 (Strauss 2007), but was beaten to the market by Intel, which introduced the 2920 DSP chip which was designed by Marcian "Ted" Hoff (the

\footnotetext{
${ }^{39}$ Estimates are for all DSP silicon, which includes general purpose programmable DSP chips and embedded DSP chips. See Appendix for Profiles and a Comparison of DSP Firms.

${ }^{40}$ According to Strauss (2007), prior to the introduction of the TMS280, all DSP algorithms required multiple chips for implementation.
} 
co-inventor of the LMS algorithm for adaptive filtering in 1960 and the Intel 4004, the first microprocessor in 1969).

1st Generation of Commercial DSP

After the introduction of these early single-chip DSPs by TI, AMI, and Intel, the first major shift in DSP technology occurred in 1980 with the introduction $\mu$ PD7720 by NEC and the DSP-1 by AT\&T (Lee 1988, 1989). The significance of both chips is that they were the first DSPs based on the Harvard architecture, a computer architecture which separates data and memory buses for real-time operation. ${ }^{41}$ The result of adopting this architecture is that both chips were sufficiently powerful for real-time processing of audio signals. Because AT\&T's DSP-1 chip was only available for internal use until 1985, NEC's $\mu$ PD7720 was the first practical off-the-shelf DSP chip for use in real-time audio applications (Strauss 2007).

\section{2nd Generation of Commercial DSP}

The second substantial improvement in DSP chip technology occurred during 1983-1987 when Texas Instruments, Toshiba, Fujitsu, Matsushita and AT\&T all introduced DSP chips which incorporated the single-cycle multiplieraccumulator (MAC) function, which effectively doubled the bandwidth of these DSPs versus previous chips (Lee 1988, 1989). The AT\&T DSP32 which was introduced internally in 1984 and externally in 1986 had the added distinction of being the first floating-point DSP chip available in the commercial market. ${ }^{42}$

\footnotetext{
${ }^{41} \mathrm{http} / / /$ www.pic24micro.com/harvard_vs_von_neumann.html

${ }^{42}$ Source: AT\&T, Lucent, and Agere company historical timelines
} 


\section{Subsequent Generations of Commercial DSP}

The third wave of technological change in DSP chip technology occurred in the years 1987-1990, when a number of vendors, most notably Zoran and Analog Devices introduced DSP chips featuring reconfigurable memory, increased parallelism, and expanded instruction sets, all of which improved the overall flexibility of the DSP chips. (Strauss 2007). These chips were primarily used for military applications. Vendors also focused on optimizing their earlier first-generation floating-point chip designs. The fourth wave of DSP technology from 1990-1994 was marked by the introduction of integer operational capabilities, optimization of chips for commonly used algorithms, smaller chip sizes and faster processing speeds. ${ }^{43}$ Several vendors introduced their secondgeneration of floating point DSP chips and their second-generation of integer DSP chips. The fifth wave of DSP technology from 1994-1998 featured the inclusion and of numerous functions which optimized DSPs for use in cell phones and wireless infrastructure.

The sixth and most recent wave of DSP technology from 1999-2006 was characterized by a fundamental change in chip architecture, the first DSP chips based on VLIW (Very Large Instruction Word) and superscalar architectures were introduced. ${ }^{44}$ The benefit of this new architecture was the ability to efficiently handle more complex algorithms for a variety of signal processing

\footnotetext{
${ }^{43}$ Source: Motorola's DSP56156 product data sheet.

${ }^{44}$ Source: ZSP, LSI Logic.
} 
applications in audio, video, wireless and multimedia products. ${ }^{45}$ The current generation of DSP products reflects continued improvement in increasing the processing speed, flexibility and capabilities of fixed-point, floating-point, and integer DSPs over time along with the density improvements expected with Moore's Law and the fabrication cost increases expected with Moore's Second Law (discussed in the next section). Table 22 below summarizes the six generations of DSP technology and key market drivers during the commercialization phase of the industry from 1974-2008.

Table 22. Generations of DSP Technology and Market Drivers ${ }^{46}$

\begin{tabular}{|c|c|c|c|}
\hline Years & Generation & Technological Changes & Market Drivers \\
\hline $\begin{array}{l}1974- \\
1980\end{array}$ & 0 & $\begin{array}{l}\text { First single-chip implementation of a } \\
\text { DSP algorithm }\end{array}$ & $\begin{array}{l}\text { Military applications, } \\
\text { Consumer applications- } \\
\text { Speak and Spell }\end{array}$ \\
\hline $\begin{array}{l}1980- \\
1983\end{array}$ & 1 & $\begin{array}{l}\text { First DSPs based on the Harvard } \\
\text { architecture }\end{array}$ & Audio applications \\
\hline $\begin{array}{l}1983- \\
1987\end{array}$ & 2 & $\begin{array}{l}\text { Doubled bandwidth; } \\
\text { First floating-point DSP } \\
\end{array}$ & $\begin{array}{l}\text { Audio and communications } \\
\text { applications }\end{array}$ \\
\hline $\begin{array}{l}1987- \\
1990\end{array}$ & 3 & $\begin{array}{l}\text { Reconfigurable memory, increased } \\
\text { parallelism, and expanded instruction } \\
\text { sets, all of which improved the } \\
\text { overall flexibility }\end{array}$ & $\begin{array}{l}\text { Military applications, } \\
\text { imaging }\end{array}$ \\
\hline $\begin{array}{l}1990- \\
1994\end{array}$ & 4 & $\begin{array}{l}\text { Integer operational capabilities, } \\
\text { optimization of chips for commonly } \\
\text { used algorithms, smaller chip sizes } \\
\text { and faster processing speeds }\end{array}$ & $\begin{array}{l}\text { Communications } \\
\text { applications }\end{array}$ \\
\hline $\begin{array}{l}1994- \\
1998\end{array}$ & 5 & $\begin{array}{l}\text { Optimized for use in cell phones and } \\
\text { wireless communications } \\
\text { infrastructure. }\end{array}$ & Wireless applications \\
\hline $\begin{array}{l}1998- \\
2006\end{array}$ & 6 & $\begin{array}{l}\text { First VLIW and superscalar } \\
\text { architectures for efficiently handling } \\
\text { complex algorithms }\end{array}$ & $\begin{array}{l}\text { Wireless and multimedia } \\
\text { applications }\end{array}$ \\
\hline 2006- & Current & $\begin{array}{l}\text { Continued improvement in } \\
\text { processing speed, flexibility, } \\
\text { capabilities, and density }\end{array}$ & $\begin{array}{l}\text { Audio, video, wireless and } \\
\text { multimedia applications }\end{array}$ \\
\hline
\end{tabular}

${ }^{45}$ Source: Discussion with former members of the technical staff at ZSP Corporation.

${ }^{46}$ For details on each generation of DSP technology, see Strauss (2007). 
As shown in Table 22, the nature of the technological changes and the key market drivers were different from one generation of DSP to another. Architectural improvements over six generations of technology have facilitated the opening of new markets for a broad range of DSP applications. Although a consumer application, Speak and Spell ${ }^{\mathrm{TM}}$, captured the imagination of the market in the initial phase, it was military applications that provided the significant early market demand. This demand gradually shifted over time to audio and communications applications and then more specifically to wireless and multimedia applications. The current market demand is for audio, video, wireless and multimedia applications across multiple sectors of the economy, but is still driven primarily by wireless phones. In addition to the market forces described here, technological forces also played an important role in shaping the evolution of DSP and are examined in the next section.

\section{Moore's Second Law and Gene's Law: Addressing What Moore's Law Left Out}

As described earlier in this study, Moore's Law states that the number of transistors on a chip doubles every 18-24 months. The emergence of merchant foundries reflects an industry phenomenon that has come to be known as Moore's Second Law, described below. ${ }^{47}$

Rising fixed costs give rise to Moore's Second Law: as the cost of transistors comes down, the cost of fabs goes up, albeit not at quite the same rate. In 1966 a new fab cost $\$ 14 \mathrm{~m}$. By 1995 the price had risen to $\$ 1.5$ billion. Today, says Intel, the cost of a leading-edge fab exceeds $\$ 6$ billion, including all the preparatory work. And the Taiwanese Semiconductor Manufacturing Company (TSMC) has built two "GigaFabs" for between $\$ 8$ billion and $\$ 10$ billion each, which would buy you four nuclear power stations. The output of such

\footnotetext{
${ }^{47}$ http://research.microsoft.com/en-us/um/people/gray/Moore_Law.html
} 
monsters depends on the mix of products, but they each could easily churn out 3 billion chips a year. ${ }^{48}$

Thus, ever-increasing costs have fueled the need for increasing specialization to achieve sufficient economies of scale in each stage of the value chain. This has led to the proliferation of merchant foundries and fabless semiconductors companies in all sectors of the market including DSP. ${ }^{49}$ The DSP industry as a whole has benefited from this reconfiguration of inter-firm alliances. Only when the economics of the semiconductor industry made the costs of owning and operating their own internal foundry prohibitive for all but the largest integrated device manufacturers (IDMs), did an active market for technology in DSP truly emerge. Based on previous studies on the economics of Moore's Law (Tuomi 2002), the conventional wisdom about the semiconductor industry in general is that the reconfiguration of inter-firm networks has substantially increased the diversity and rate of material innovation, thereby enabling organizations to overcome the performance barriers implicit in such technical benchmarks. However, this conclusion is somewhat controversial, and it is not universally shared, especially by leading DSP experts. Beyond Moore's

\footnotetext{
48 "The Semiconductor Industry: Under New Management," The Economist, April 2, 2009

${ }^{49}$ In this study, and in standard industry terminology, an integrated producer or integrated device manufacturer (IDM) is a semiconductor company which designs, manufactures, and sells chips integrated circuit (IC) products. The term integration refers to the fact that design and manufacturing of the IC are both done in-house. A foundry is a semiconductor company which manufactures ICs. IDMs have their own foundries or fabs for manufacturing ICs and these are typically referred to as "internal" or "captive" foundries, since they only produce chips for internal markets. "Merchant" or "pure-play" foundries are semiconductor companies that do not design their own chips but fabricate chips for other firms called fabless semiconductor companies, which focus only on designing chips. Thus one way to conceptualize the three types of companies, IDMs, foundries, and fabless semiconductor companies is that IDMs compete with dyads of fabless semiconductor companies that partner merchant foundries to produce chips. See (Yoon and Malerba 2009) fttp://asialics6.ust.hk/essays/2b/Yoon_Minho_015_Feb23.pdf. See also (Teece 2006).
} 
Law and Moore's Second Law, Gene Frantz, ${ }^{50}$ a Texas Instruments' Principal Fellow, has proposed the eponymous Gene's Law, to address what he and many other industry participants and observers view as a significant shortcoming of Moore's Law. Frantz was the program manager for the Speak \& Spell ${ }^{\mathrm{TM}}$ learning aid, and development team leader for all of the early speech products for $\mathrm{Tl}$; he has been at the forefront of commercializing signal processing over several technology generations. Gene's Law states that the power dissipation of semiconductor chips including DSPs will be reduced at approximately the same rate that performance increases. As described below, and in contrast to the prevailing wisdom, Frantz believes that architectural innovation, rather than material innovation, has been the primary means through which chip design engineers have dealt with the limitations of Moore's Law. Thus, in the DSP industry, different organizations may have dramatically different beliefs about the expected trajectories of the three types of innovations (mathematical, material, and architectural), which may lead to surprises if the actual introduction of innovations does not conform to the prior expectations of firms.

Most experts see Moore's Law continuing to follow the path it has held for nearly half a century. But there are things that Moore did not tell us about ICs that threaten the validity of his law. In terms of performance, as measured in terms of clock speed, we effectively fell of the 18-month cycle of doubling nearly a decade ago. Then, how does performance continue to increase, I hear you ask. Well,

\footnotetext{
${ }^{50}$ From Gene Frantz's official bio: "Gene Frantz is presently responsible for finding new opportunities and creating new businesses utilizing Tl's signal processing technology. In recognition of his leadership role in establishing $\mathrm{TI}$ as the world's leading DSP solutions provider, Frantz was elected as TI's Principal Fellow in 2002, a privilege enjoyed by less than 0.1 percent of Tl's technical personnel."
} 
we've managed to compensate for it with innovations in architecture such as deeper and deeper pipelines. ${ }^{51}$

Mahesh Mehendale, TI Fellow at Texas Instruments India, concurs with this assessment and posits that going forward, architectural innovation will play an even greater role in driving performance improvement, as indicated in his comments below.

The net result of this is that moving forward Gene's law cannot hold good riding on Moore's law but rather it will have to hold good inspite of Moore's law. Just as in the past whenever Moore's law was threatened, innovations and breakthroughs in the semiconductor manufacturing process have helped keep it on track, in case of Gene's law the breakthroughs will have to come from innovations at circuit design and architecture levels. Just as Moore's law took us from micrometer to nanometer, Gene's law will take us from volts to millivolts. As long as it makes business sense, technologists will find a way to make Gene's law hold true. So as I gaze at the technology trends crystal ball, it shows me this simple prediction: "Moore's law will hold good as long as Gene's law holds good". ${ }^{52}$

As discussed at the outset of this study, technical benchmarks such as Moore's Law may indeed be a self-fulfilling prophecy (see Table 15). As the ongoing and unresolved debate between proponents of Moore's Law and Gene's Law demonstrates, technologies such as DSP may evolve in ways that are not predicted by and even contradict these established benchmarks (Tuomi 2002). Unpredictability in technological evolution or seemingly contradictory technology trends may lead to errors in organizational beliefs which may ultimately result in surprising consequences for competing firms.

\footnotetext{
${ }^{51}$ Gene Frantz, "What Moore Didn't Tell Us About ICs" TI Video360 Blog, http://blogs.ti.com

52 http://www.vlsiconference.com/vlsi2009/mess_mahesh.html
} 


\section{Discussion and Summary of Historical Analysis}

A diverse and ongoing mixture of mathematical, material, and architectural innovations have shaped the evolution of signal processing from its ancient origins in Egypt to its current state as a multi-billion dollar global high-technology industry. From c. 2500 B.C., when the combination of the Palermo Stone, nilometers, and human stone carvers constituted the essential components of a primitive DSP — to the present day, when semiconductor-based DSP chips are used in virtually every digital application involving communications, audio, voice, video, image, and sensory data — the technological and economic importance of signal processing has grown exponentially.

If the birth of modern signal processing can be traced back to a single year, it is 1948, when three major research breakthroughs occurred: the introduction of information theory, the invention of the transistor, and the demonstration of the first stored-program computer. If the birth of modern signal processing can be traced back to a single organization, it is Bell Labs, which served as an intellectual crossroads for early scientific leaders who sought to build a unified information theory firmly grounded in mathematics and physics. The formalized and axiomatic nature of signal processing stemmed from its information-theoretic roots. This intrinsic characteristic of signal processing as mathematical science enabled conceptual exploration and practical application through the active combination and recombination of thought experiments and numerical experiments. Conducting these numerical experiments was largely made possible through the rediscovery by James Cooley and John Tukey in 
1965 of the Fast Fourier Transform (FFT) originally discovered by Carl Friedrich Gauss in 1805. If the successful commercialization of modern signal processing can be traced back to a single innovation, it is the rediscovery of the FFT.

Although the critical innovations which led to development of signal processing first emerged in 1948, it was not until 26 years later, in 1974, that the first commercially available DSP chips were actually produced, representing a significant lag between the initial mathematical innovations, and the subsequent architectural innovations which were further constrained by the technical limits of material innovations. From 1974-2008, a series of architectural improvements over six generations of technology facilitated the opening of new markets for a broad range of DSP applications and led to the reconfiguration of industry alliances, particularly between fabless DSP companies and their merchant foundries. While most semiconductor industry participants believe that material innovation was the primary factor in overcoming the performance barriers inherent in technical benchmarks such as Moore's Law during this time frame, some noted DSP experts believe that architectural innovation was the main driver.

This difference in perspective has not yet been reconciled but may nevertheless offer some valuable general insights for managers and researchers interested in the evolution of GPTs and their role in the formation and growth of knowledge-intensive industries. For example, although mathematical innovations are typically rigorously formalized and highly axiomatic, their impact on subsequent architectural innovations may be largely unpredictable and may 
generate errors which lead to surprises for firms. Without computationally efficient methods for conducting natural experiments to test the predictions of thought experiments, there may be a substantial lag between the discovery of a mathematical concept and its eventual instantiation in the form of a commercially available product.

While empirically-observed technical benchmarks may provide a useful framework for prioritizing and making resource allocation decisions among the different types of innovations (mathematical, material, and architectural), the causal mechanisms underlying these distinct types of innovation may be difficult to isolate and may interact in entirely unexpected and occasionally contradictory ways. In particular, dramatic changes in the materials themselves, as a physical building block, may radically alter the long-term trajectory of innovation. The history of signal processing is replete with examples of the unintentional loss and rediscovery of mathematical innovations, the unanticipated lag between architectural and mathematical innovations, and the unexpected rearrangement of firm alliances. All of these factors may contribute to a chaotic industry environment in which firm errors in threat perception and opportunity recognition are not only possible but highly probable. This may make the signal processing industry ideally suited to the study of strategic surprise.

In a fascinating preview of future possibilities in the advancement of DSP, recent studies have speculated that in the coming decades, the main materials for constructing DSPs will not be semiconductors made of silicon, but more exotic materials made of organic elements. In the future, DSP systems may be 
grown, rather than fabricated and be comprised of "chemical substrates, cells, organisms, or even DNA" and may even operate "without the use of electrical currents" (Tsaftaris and Katsaggelos 2008).

While this speculation may sound like science fiction, future observers may regard today's DSP chips to be as primitive in comparison to organic-based DSP systems as modern observers regard the stone-based DSP system of the ancient Egyptians. Perhaps an intriguing new mixture of mathematical, material, and architectural innovations awaits future signal processing researchers. Molecular biologists, genetic engineers, biophysicists, and organic chemists may someday join computer scientists, electrical engineers, transistor physicists and information theorists in influencing the ongoing evolution of the field of signal processing in surprising new ways. 


\section{REFERENCES}

Ackerman, M.S., C.A. Halverson, T. Erickson, W.A. Kellogg, W.J. Orlikowski. 2008. Using Technology and Constituting Structures: A Practice Lens for Studying Technology in Organizations Resources, Co-Evolution and Artifacts. Springer London, 255-305.

Aldrich, H.E., A.L. Kenworthy, eds. 1999. The accidental entrepreneur: Campbellian antinomies and organizational foundings. Sage Publications, Thousand Oaks, Calif.

Aldrich, H.E., M.A. Martinez. 2007. Many are Called, but Few are Chosen: An Evolutionary Perspective for the Study of Entrepreneurship. Á. Cuervo, D. Ribeiro, S. Roig, eds. Entrepreneurship. Springer Berlin Heidelberg, 293-311.

Allison, P.D. 2003. Logistic regression using the SAS system : theory and application. SAS Institute., Cary, N.C.

Alter, K.J., S. Meunier. 2009. The Politics of International Regime Complexity. Perspectives on Politics 7(01) 13-24.

Amit, R., P.J.H. Schoemaker. 1993. Strategic Assets and Organizational Rent. Strategic Management Journal 14(1) 33-46.

Anderson, P. 1999. Complexity Theory and Organization Science. Organization Science 10(3) 216-232.

Ardagh, J.C. 1889. Nilometers. Proceedings of the Royal Geographical Society and Monthly Record of Geography 11(1) 28-38.

Arora, A. 1997. Patents, licensing, and market structure in the chemical industry. Research Policy 26(4-5) 391-403.

Arora, A., M. Ceccagnoli. 2006. Patent Protection, Complementary Assets, and Firms' Incentives for Technology Licensing. Management science 52(2) 293-308.

Arora, A., A. Fosfuri. 2003. Licensing the market for technology. Journal of economic behavior \& organization 52(2) 277-295.

Arora, A., A. Fosfuri, A. Gambardella. 2001. Markets for Technology and their Implications for Corporate Strategy. Industrial and Corporate Change 10(2) 419451.

Arora, A., R.P. Merges. 2004. Specialized supply firms, property rights and firm boundaries. Industrial and Corporate Change 13(3) 451-475.

Arora, S., B. Barak. 2009. Computational complexity : a modern approach. Cambridge University Press, Cambridge; New York. 
Arrow, K.J. 1962. Economic welfare and the allocation of resources for invention. Rand Corp., Santa Monica, CA.

Aspray, W. 1985. The scientific conceptualization of information: a survey. IEEE Ann. Hist. Comput. 7(2) 117-140.

Atiya, A.F., S.M. El-Shoura, S.I. Shaheen, M.S. El-Sherif. 1999. A Comparison Between Neural-Network Forecasting Techniques River Flow Forecasting. IEEE Transactions on Neural Networks 10(2) 402-409.

Axelrod, R.M., M.D. Cohen. 1999. Harnessing complexity : organizational implications of a scientific frontier. Free Press, New York.

Baddeley, A.A. 1994. The magical number seven: Still magic after all these years? Psychological review 101(2) 353-356.

Baldwin, C.Y., K.B. Clark. 2000. Design rules. Volume 1, The power of modularity. MIT Press, Cambridge, Mass.

Barley, S.R. 1986. Technology as an Occasion for Structuring: Evidence from Observations of CT Scanners and the Social Order of Radiology Departments. Administrative Science Quarterly 31(1) 78-108.

Barney, J. 1991. Firm resources and sustained competitive advantage.

Barron, A., J. Rissanen, B. Yu. 1998. The Minimum Description Length Principle in Coding and Modeling. IEEE Transactions on Information Theory IT 44(6) 2743-2760.

Bass, M.J., C.M. Christensen. 2002. The Future of the Microprocessor Business IEEE spectrum. 39(4) 34.

Baumol, W.J., R.E. Quandt. 1964. Rules of Thumb and Optimally Imperfect Decisions. The American Economic Review 54(2) 23-46.

Bayus, B.L. 1997. Speed-to-market and new product performance trade-offs. Journal of Product Innovation Management 14(6) 485-497.

Bayus, B.L., R. Agarwal. 2007. The Role of Pre-Entry Experience, Entry Timing, and Product Technology Strategies in Explaining Firm Survival. Management science. 53(12) 1887.

Beinhocker, E.D. 2006. The origin of wealth : evolution, complexity, and the radical remaking of economics. Harvard Business School Press, Boston, Mass.

Berlinski, D. 2001. The advent of the algorithm : the 300-year journey from an idea to the computer. Harcourt, San Diego. 
Bessen, J. 2008. The value of U.S. patents by owner and patent characteristics. Research Policy 37(5) 932-945.

Bessen, J., E. Maskin. 2009. Sequential innovation, patents, and imitation. RAND Journal of Economics 40(4) 611-635.

Bettis, R.A., C.K. Prahalad. 1995. The dominant logic: Retrospective and extension. Strategic Management Journal 16(1) 5-14.

Bharadwaj, S.G., P.R. Varadarajan, J. Fahy. 1993. Sustainable Competitive Advantage in Service Industries: A Conceptual Model and Research Propositions. The Journal of Marketing 57(4) 83-99.

Bingham, C.B., K.M. Eisenhardt, N.R. Furr. 2007. What makes a process a capability? Heuristics, strategy, and effective capture of opportunities. Strategic Entrepreneurship Journal 1(1-2) 27-47.

Blum, M. 1967. A Machine-Independent Theory of the Complexity of Recursive Functions. Journal of the ACM 14(2) 322.

Boisot, M. 2000. Is There a Complexity Beyond the Reach of Strategy? Emergence 2(1) 114-134.

Boisot, M., A. Canals. 2004. Data, information and knowledge: have we got it right? Journal of Evolutionary Economics 14(1) 43-67.

Boisot, M., J. Child. 1999. Organizations as Adaptive Systems in Complex Environments: The Case of China. Organization Science 10(3) 237-252.

Boisot, M., I.C. MacMillan, K.S. Han. 2007. Explorations in information space : knowledge, agents, and organization. Oxford University Press, Oxford; New York.

Bolton, R.J., D.J. Hand. 2002. Statistical Fraud Detection: A Review. Statistical Science 17(3) 235-249.

Boulding, K.E. 1966. The Economics of Knowledge and the Knowledge of Economics. The American Economic Review 56(1/2) 1-13.

Branstetter, L.G., M. Sakakibara. 2002. When Do Research Consortia Work Well and Why? Evidence from Japanese Panel Data. The American Economic Review 92(1) 143-159.

Bresnahan, T.F., M. Trajtenberg. 1995. General purpose technologies 'Engines of growth'? Journal of Econometrics 65(1) 83-108.

Brin, S., L. Page. 1998. The anatomy of a large-scale hypertextual Web search engine. Computer networks and ISDN systems. 30(1-7) 107. 
Brown, S.L., K.M. Eisenhardt. 1995. Product Development: Past Research, Present Findings, and Future Directions. The Academy of Management Review 20(2) 343-378.

Buhrman, H., R. de Wolf. 2002. Complexity measures and decision tree complexity: a survey. Theoretical Computer Science 288(1) 21-43.

Burns, R.W., E. Institution of Electrical, M. Science. 1998. Television : an international history of the formative years. Institution of Electrical Engineers, London.

Cassiman, B., R. Veugelers. 2006. In Search of Complementarity in Innovation Strategy: Internal R\&D and External Knowledge Acquisition. Management science 52(1) 68-82.

Caves, R.E. 2000. Creative industries : contracts between art and commerce. Harvard University Press, Cambridge, Mass.; London.

Chabert, J.-L., É. Barbin. 1999. A history of algorithms : from the pebble to the microchip. Springer, Berlin [u.a.].

Chaitin, G. 2007. The Halting Probability Omega: Irreducible Complexity in Pure Mathematics. Milan Journal of Mathematics 75(1) 291-304.

Chaitin, G.J. 1975. A Theory of Program Size Formally Identical to Information Theory. J. ACM 22(3) 329-340.

Chaitin, G.J. 1997. Algorithmic information theory. New York (1968)(Journal Article).

Chang, H.F. 1995. Patent Scope, Antitrust Policy, and Cumulative Innovation. The Rand journal of economics 26(1) 34-57.

Chesbrough, H., A.K. Crowther. 2006. Beyond high tech: early adopters of open innovation in other industries. R\&D Management 36(3) 229-236.

Chiariglione, L. 1997. Signal processing and standardization. Signal Processing Magazine, IEEE 14(4) 33-34.

Chisum, D.S. 1985. Patentability of Algorithms, The. University of Pittsburgh law review 47959.

Choi, Y.R., D.A. Shepherd. 2004. Entrepreneurs' Decisions to Exploit Opportunities. Journal of Management 30(3) 377-395.

Christensen, C.M. 1992. Exploring the limits of the technology S-curve. Division of Research, Harvard Business School, [Boston]. 
Clark, K.B., T. Fujimoto. 1991. Product development performance : strategy, organization, and management in the world auto industry. Harvard Business School Press, Boston, Mass.

Clarke, S., R. Engelbach. 1990. Ancient Egyptian construction and architecture. Dover Publications, New York.

Clements, A. 2007. Honesty in History 37th ASEE/IEEE Frontiers in Education Conference. IEEE, Milwaukee, WI.

Cobham, A. 1965. The intrinsic computational complexity of functions. Y. BarHillel, ed. Proceedings of the International Congress on Logic, Methodology, and the Philosophy of Science, North Holland, Amsterdam, 24-30.

Cohen, M.A., J. Eliashberg, T.-H. Ho. 1996. New Product Development: The Performance and Time-to-Market Tradeoff. Management science 42(2) 173-186.

Cohen, W.M., S. Klepper. 1996. A Reprise of Size and R \& D. The Economic Journal 106(437) 925-951.

Cohen, W.M., D.A. Levinthal. 1990. Absorptive Capacity: A New Perspective on Learning and Innovation. Administrative Science Quarterly 35(1, Special Issue: Technology, Organizations, and Innovation) 128-152.

Companys, Y., J. McMullen. 2007. Strategic Entrepreneurs at Work: The Nature, Discovery, and Exploitation of Entrepreneurial Opportunities. Small business economics 28(4) 301-322.

Cooley, J.W. 1987. The re-discovery of the fast Fourier transform algorithm. Microchimica Acta 93(1) 33-45.

Cooley, J.W. 1992. How the FFT gained acceptance. Signal Processing Magazine, IEEE 9(1) 10-13.

Cooley, J.W., J.W. Tukey. 1965. An Algorithm for the Machine Calculation of Complex Fourier Series. Mathematics of Computation 19(90) 297-301.

Coriat, B., F. Orsi. 2002. Establishing a new intellectual property rights regime in the United States: Origins, content and problems. Research Policy 31(8-9) 14911507.

Cowan, G.A., D.E. Meltzer, D. Pines. 1999. Complexity : metaphors, models, and reality. Perseus Books, Cambridge, Mass.

Cowan, R., P. David, D. Foray. 2000. The explicit economics of knowledge codification and tacitness. Industrial and Corporate Change 9(2) 211-253. 
Cunningham, S.D. 2002. From cultural to creative industries: Theory, industry, and policy implications. Media International Australia Incorporating Culture and Policy: Quarterly Journal of Media Research and Resources(102) 54-65.

Dasgupta, P.S., P.A. David. 1985. Information disclosure and the economics of science and technology, London.

Datar, S., C. Jordan, S. Kekre, S. Rajiv, K. Srinivasan. 1997. New Product Development Structures and Time-to-Market. Management science 43(4) 452464.

David, P.A. 1990. The Dynamo and the Computer: An Historical Perspective on the Modern Productivity Paradox. The American Economic Review 80(2) 355361.

Davis, J.P., K.M. Eisenhardt, C.B. Bingham. 2007. Developing Theory Through Simulation Methods. Academy of Management Review 32(2) 480-499.

Davis, J.P., K.M. Eisenhardt, C.B. Bingham. 2009. Optimal Structure, Market Dynamism, and the Strategy of Simple Rules. Administrative Science Quarterly 54(3) 413-452.

Decarolis, D.M., D.L. Deeds. 1999. The Impact of Stocks and Flows of Organizational Knowledge on Firm Performance: An Empirical Investigation of the Biotechnology Industry. Strategic Management Journal 20(10) 953-968.

Deka, R. 1995. A comprehensive study of digital signal processing devices. Microprocessors and Microsystems 19(4) 209-221.

DeSanctis, G., M.S. Poole. 1994. Capturing the Complexity in Advanced Technology Use: Adaptive Structuration Theory. Organization Science 5(2) 121147.

Dierickx, I., K. Cool. 1989. Asset Stock Accumulation and Sustainability of Competitive Advantage. Management science 35(12) 1504-1511.

Diffie, W., M.E. Hellman. 1976. Multiuser cryptographic techniques Proceedings of the June 7-10, 1976, national computer conference and exposition. ACM, New York, New York, 109-112.

Diggle, P., M.G. Kenward. 1994. Informative Drop-Out in Longitudinal Data Analysis. Journal of the Royal Statistical Society. Series C (Applied Statistics) 43(1) 49-93.

Dosi, G. 2000. Innovation, organization and economic dynamics : selected essays. Edward Elgar, Cheltenham, UK; Northampton, Mass. 
Eckhardt, J.T., S.A. Shane. 2003. Opportunities and Entrepreneurship. Journal of management. 29(3) 333.

Eisenhardt, K.M., D.N. Sull. 2001. Strategy as Simple Rules. Harvard business review 79(1) 106-116.

Elias, P. 1955. Coding for noisy channels, IRE Conv. IRE 4(Journal Article) 37.

Eltahir, E.A.B., G. Wang. 1999. Climate and Ocean Sciences - Nilometers, El Nino, and climate variability (Paper 1999GL900013). Geophysical research letters. 26(4) 489.

Ethiraj, S.K., D. Levinthal. 2004. Modularity and Innovation in Complex Systems. Management science 50(2) 159-173.

Ethiraj, S.K., D. Levinthal, R.R. Roy. 2008. The Dual Role of Modularity: Innovation and Imitation. Management science 54(5) 939-955.

Eyre, J., J. Bier. 1998. DSP Processors Hit the Mainstream. Computer. 31(8) 51.

Eyre, J.J. 2000. The evolution of DSP processors. IEEE Signal Processing Magazine 17(2) 43-51.

Fiet, J.J.O. 1996. The informational basis of entrepreneurial discovery. Small business economics 8(6) 419-430.

Fortnow, L. 2003. A short history of computational complexity. Bulletin of the European Association for Theoretical Computer Science 80(Journal Article) 95.

Fosfuri, A. 2006. The licensing dilemma: understanding the determinants of the rate of technology licensing. Strategic management journal. 27(12) 1141.

Frantz, G. 1982. Design Case History: Speak \& Spell Learns to Talk. IEEE Spectrum 19(2) 45.

Frantz, G. 2000. Digital signal processor trends. Micro, IEEE 20(6) 52-59.

Frantz, G., P. Papamichalis. 1996. Introduction to DSP Solutions. Texas Instruments Technical Journal 13(2) 5-16.

Frenken, K. 2000. A complexity approach to innovation networks. The case of the aircraft industry (1909-1997). Research Policy 29(2) 257-272.

Frenken, K. 2006. Innovation, evolution and complexity theory. Edward Elgar Pub., Cheltenham, UK; Northampton, MA.

Galbraith, J.R. 1977. Organization design. Addison-Wesley Pub. Co., Reading, Mass. 
Gallini, N.T. 1984. Deterrence by Market Sharing: A Strategic Incentive for Licensing. The American Economic Review 74(5) 931-941.

Gallini, N.T. 2002. The Economics of Patents: Lessons from Recent U.S. Patent Reform. The Journal of Economic Perspectives 16(2) 131-154.

Galunic, D.C., K.M. Eisenhardt. 2001. Architectural Innovation and Modular Corporate Forms. The Academy of Management Journal 44(6) 1229-1249.

Galunic, D.C., R. Simon. 1998. Resource Recombinations in the Firm: Knowledge Structures and the Potential for Schumpeterian Innovation. Strategic Management Journal 19(12) 1193-1201.

Ganco, M., R. Agarawal. 2009. Performance Differentials between Diversifying Entrants and Entrepreneurial Start-Ups: a Complexity Approach. Academy of Management Review 34(2) 228-252.

Ganco, M., G. Hoetker. 2009. NK modeling methodology in the strategy literature: Bounded search on a rugged landscape. Research methodology in strategy and management 5(5) 237-268.

Gardiner, A.H., M. Gauthier-Laurent. 1927. Egyptian grammar : being an introduction to the study of hieroglyphs. Clarendon Press, Oxford.

Gavetti, G., D. Levinthal. 2000. Looking Forward and Looking Backward: Cognitive and Experiential Search. Administrative Science Quarterly 45(1) 113137.

Gell-Mann, M. 1995. What is complexity. Complexity (New York, N.Y.) 1(1) 16.

Gibbs, J.W., H.A. Bumstead, R.G. Van Name. 1906. The scientific papers of J. Willard Gibbs. Longmans, Green and Co., London; New York.

Gilbert, R.J. 2004. Antitrust for patent pools: A century of policy evolution. Stanford technology law review 3(Journal Article).

Glas, E. 1999. Thought-experimentation and mathematical innovation. Studies In History and Philosophy of Science Part A 30(1) 1-19.

Gobet, F., H.A. Simon. 1998. Expert chess memory: revisiting the chunking hypothesis. Memory (Hove, England) 6(3) 225-255.

Goldreich, O. 2008. Computational complexity : a conceptual perspective. Cambridge Univ. Press, Cambridge [u.a.].

Goldwasser, S., S. Micali. 1984. Probabilistic encryption. Journal of Computer and System Sciences 28(2) 270-299. 
Gonzalez-Zugasti, J.P., K.N. Otto, J.D. Baker. 2000. A Method for Architecting Product Platforms. Research in Engineering Design 12(2) 61.

Graham, S.J., D.C. Mowrey. 2004. Submarines in software? continuations in US software patenting in the 1980s and 1990s. Economics of Innovation \& New Technology 13(5) 443-456.

Granovetter, M. 1985. Economic Action and Social Structure: The Problem of Embeddedness. The American Journal of Sociology 91(3) 481-510.

Grant, R.M. 1996a. Prospering in Dynamically-Competitive Environments: Organizational Capability as Knowledge Integration. Organization Science 7(4) 375-387.

Grant, R.M. 1996b. Toward a Knowledge-Based Theory of the Firm. Strategic Management Journal 17(, Special Issue: Knowledge and the Firm) 109-122.

Grindley, P.C., D.J. Teece. 1997. Managing Intellectual Capital: Licensing and Cross-Licensing in Semiconductors and Electronics. California Management Review 39(2) 8-41.

Grossman, G.M., C. Shapiro. 1986. Research Joint Ventures: An Antitrust Analysis. Journal of law, economics, \& organization 2(2) 315-337.

Grünwald, P.D. 2007. The minimum description length principle. MIT Press, Cambridge, Mass.

Gulati, R., N. Nohria, A. Zaheer. 2000. Strategic Networks. Strategic Management Journal 21(3, Special Issue: Strategic Networks) 203-215.

Hall, B.H., M. MacGarvie. 2010. The private value of software patents. Research Policy 39(7) 994-1009.

Hall, B.H., R.H. Ziedonis. 2001. The Patent Paradox Revisited: An Empirical Study of Patenting in the U.S. Semiconductor Industry, 1979-1995. The Rand Journal of Economics 32(1) 101-128.

Hambrick, D.C., P.A. Mason. 1984. Upper Echelons: The Organization as a Reflection of Its Top Managers. The Academy of Management Review 9(2) 193206.

Hartley, R.V.L. 1970. Papers, 1920-1970.

Hayek, F.A. 1945. The Use of Knowledge in Society. The American Economic Review 35(4) 519-530.

Heckman, J.J., G.J. Borjas, B. University of Chicago. Center for Mathematical Studies in, Economics. 1979. Does unemployment cause future unemployment? 
: definitions, questions and answers from a continuous time model of heterogeneity and state dependence. University of Chicago, Chicago.

Heideman, M.T., D.H. Johnson, C.S. Burrus. 1985. Gauss and the history of the fast Fourier transform. Archive for History of Exact Sciences 34(3) 265-277.

Heirman, A. 2005. The imprinting effect of initial resources and market strategy on the early growth path of start-ups. Academy of Management Journal(Journal Article).

Helfat, C.E., M.B. Lieberman. 2002. The birth of capabilities: market entry and the importance of pre-history. Industrial and Corporate Change 11(4) 725.

Helfer, L.R. 2009. Regime shifting in the international intellectual property system. Perspect. Polit. Perspectives on Politics 7(1) 39-44.

Helpman, E. 1998. General purpose technologies and economic growth. MIT Press, Cambridge, Mass.

Henderson, R.M., K.B. Clark. 1990. Architectural Innovation: The Reconfiguration of Existing Product Technologies and the Failure of Established Firms.

Administrative Science Quarterly 35(1, Special Issue: Technology, Organizations, and Innovation) 9-30.

Hendler, J., T. Berners-Lee. 2010. From the Semantic Web to social machines: A research challenge for Al on the World Wide Web. Artificial intelligence. 174(2) 156.

Hendricks, K.B., V.R. Singhal. 1997. Delays in New Product Introductions and the Market Value of the Firm: The Consequences of Being Late to the Market. Management science 43(4) 422-436.

Hill, C.W.L. 1992. Strategies for Exploiting Technological Innovations: When and When Not to License. Organization Science 3(3) 428-441.

Hill, C.W.L. 1997. Establishing a Standard: Competitive Strategy and Technological Standards in Winner-Take-All Industries. The Academy of Management Executive (1993-2005) 11(2) 7-25.

Hirsch, P.M. 1972. Processing Fads and Fashions: An Organization-Set Analysis of Cultural Industry Systems. The American Journal of Sociology 77(4) 639-659.

Hobday, M. 1998. Product complexity, innovation and industrial organisation. Research Policy 26(6) 689-710.

Hobday, M., H. Rush, J. Tidd. 2000. Innovation in complex products and system. Research Policy 29(7-8) 793-804. 
Hoff, M.E., Jr. 1962. Learning phenomena in networks of adaptive switching circuits, Stanford University.

Homer, S., A.L. Selman. 2001. Computability and complexity theory. Springer, New York.

Hosmer, D.W., S. Lemeshow. 2008. Applied logistic regression. Wiley, New York [u.a.].

Hu, Y.H. 1997. The Past, Present, and Future of Multimedia Signal Processing. IEEE Signal Processing Magazine 14(4) 28-51.

Huffman, D.A. 2006. A method for the construction of minimum-redundancy codes. Resonance - Heidelberg 11(2) 91-99.

Hutcheson, G.D. 2005. The Economic Implications of Moore's Law. Springer Series in Advanced Microelectronics(16) 1-30.

Jaffe, A.B. 2000. The U.S. patent system in transition: policy innovation and the innovation process. Research Policy 29(4-5) 531-557.

Jarvis, C.S. 1964. Flood-stage records of the river Nile : A paper. Foundation for the study of cycles, Pittsburgh.

Johnson, B., E. Lorenz, B.Å. Lundvall. 2002. Why all this fuss about codified and tacit knowledge? Industrial and Corporate Change 11(2) 245-262.

Jonker, R., A. Volgenant. 1987. A shortest augmenting path algorithm for dense and sparse linear assignment problems. Computing 38(4) 325-340.

Joshi, A.M., A. Nerkar. 2011. When do strategic alliances inhibit innovation by firms? evidence from patent pools in the global optical disc industry. Strategic Management Journal n/a-n/a.

Kahn, D. 1967. The codebreakers; the story of secret writing. Macmillan, New York.

Karmarkar, N. 1984. A new polynomial-time algorithm for linear programming. Combinatorica 4(4) 373-395.

Kauffman, S., S. Levin. 1987. Towards a general theory of adaptive walks on rugged landscapes. Journal of theoretical biology 128(1) 11-45.

Kauffman, S.A., E.D. Weinberger. 1989. The NK model of rugged fitness landscapes and its application to maturation of the immune response. Journal of theoretical biology 141(2) 211-245. 
Kim, Y., N.S. Vonortas. 2006. Determinants of technology licensing: the case of licensors. Managerial and Decision Economics 27(4) 235-249.

King, A.W., C.P. Zeithaml. 2001. Competencies and Firm Performance:

Examining the Causal Ambiguity Paradox. Strategic Management Journal 22(1) 75-99.

Kirzner, I.M. 1997. Entrepreneurial Discovery and the Competitive Market Process: An Austrian Approach. Journal of Economic Literature 35(1) 60-85.

Kleint, C., J.E. Lilienfeld. 1998. Julius Edgar Lilienfeld : Life and profession. Pergamon, New York.

Klemens, B. 2006. Math you can't use : patents, copyright, and software. Brookings Institution Press, Washington, D.C.

Klepper, S., S. Sleeper. 2005. Entry by Spinoffs. Management science 51(8) 1291-1306.

Kline, S., N. Rosenberg. 1986. The Positive sum strategy : harnessing technology for economic growth. R. Landau, ed. National Academy Press, National Academy of Engineering, Washington, D.C.

Knudsen, T., D.A. Levinthal. 2007. Two faces of search: alternative generation and alternative evaluation. Organization Science 18(1) 39(16).

Knuth, D.D.E. 1968. Semantics of context-free languages. Mathematical systems theory 2(2) 127-145.

Knuth, D.E. 1997. The art of computer programming. Volume 1, Fundamental algorithms. Addison-Wesley, Reading (Mass.); Harlow; Menlo Park [et al.].

Knuth, D.E. 2000. Selected papers on analysis of algorithms. Calif.] : Center for the study of language and information, Leland Stanford junior university, Stanford.

Kogut, B., U. Zander. 1992. Knowledge of the Firm, Combinative Capabilities, and the Replication of Technology. Organization Science 3(3, Focused Issue: Management of Technology) 383-397.

Kogut, B., U. Zander. 1993. Knowledge of the Firm and the Evolutionary Theory of the Multinational Corporation. Journal of International Business Studies 24(4) 625-645.

Kolmogorov, A.A.N. 1968. Three approaches to the quantitative definition of information. International journal of computer mathematics 2(1) 157-168. 
Kortum, S., J. Lerner. 1998. Stronger protection or technological revolution: what is behind the recent surge in patenting? Carnegie-Rochester Conference Series on Public Policy 48 247-304.

Lanjouw, J.O., M. Schankerman. 2001. Characteristics of Patent Litigation: A Window on Competition. The Rand journal of economics 32(1) 129-151.

Lavington, S.H. 1993. Manchester Computer Architectures, 1948-1975. IEEE Ann. Hist. Comput. 15(3) 44-54.

Lee, E.A. 1988. Programmable DSP architectures. I. ASSP Magazine, IEEE 5(4) 4-19.

Lee, E.A. 1989. Programmable DSP architectures. II. ASSP Magazine, IEEE 6(1) 4-14.

Lenox, M.J., S.F. Rockart, A.Y. Lewin. 2006. Interdependency, Competition, and the Distribution of Firm and Industry Profits. Management science 52(5) 757-772.

Lerner, J. 2002. 150 Years of Patent Protection. The American Economic Review 92(2, Papers and Proceedings of the One Hundred Fourteenth Annual Meeting of the American Economic Association) 221-225.

Levinthal, D.A. 1997. Adaptation on Rugged Landscapes. Management science 43(7) 934-950.

Li, M., P.M.B. Vitányi. 2008. An introduction to Kolmogorov complexity and its applications : with 49 figures. Springer, New York.

Lichtenthaler, U., H. Ernst. 2009. Technology licensing strategies: the interaction of process and content characteristics. Strategic organization 7(2) 183-221.

Lieberman, M.B. 2006. Why Do Firms Imitate Each Other? The Academy of Management Review 31(2) 366.

Lieberman, M.B., D.B. Montgomery. 1998. First-mover (dis)advantages: retrospective and link with the resource-based view. Strategic Management Journal 19(12) 1111-1125.

Lillrank, P. 2003. The Quality of Standard, Routine and Nonroutine Processes. Organization Studies 24(2) 215-233.

Linden, G. 2003. System-on-a-chip integration in the semiconductor industry: industry structure and firm strategies. Industrial and Corporate Change 12(3) 545. 
Linden, G., D. Somaya. 2003. System-on-a-chip integration in the semiconductor industry: industry structure and firm strategies. Industrial and Corporate Change 12(3) 545-576.

Lippman, S.A., R.P. Rumelt. 1982. Uncertain Imitability: An Analysis of Interfirm Differences in Efficiency under Competition. The Bell journal of economics 13(2) 418-438.

Lipsey, R.G., K. Carlaw, C. Bekar. 2005. Economic transformations : general purpose technologies and long-term economic growth. Oxford University Press, Oxford; New York.

Loftus, G.R., E.F. Loftus. 1976. Human memory : the processing of information. L. Erlbaum Associates ; Distributed by the Halsted Press Division of John Wiley, Hillsdale, N.J.; New York.

Lucas, A., J.R. Harris. 1962. Ancient Egyptian materials and industries. Arnold, London.

Lyons, R.G. 1997. Understanding digital signal processing. Addison Wesley Pub. Co., Reading, Mass.

MacCormack, A., J. Rusnak, C.Y. Baldwin. 2006. Exploring the Structure of Complex Software Designs: An Empirical Study of Open Source and Proprietary Code. Management science 52(7) 1015-1030.

MacKay, D.J.C. 2003. Information theory, inference, and learning algorithms. Cambridge University Press, Cambridge, UK; New York.

Makadok, R. 1998. Can first-mover and early-mover advantages be sustained in an industry with low barriers to entry/imitation? Strategic Management Journal 19(7) 683-696.

Malerba, F. 2010. Knowledge-intensive entrepreneurship and innovation systems : evidence from Europe. Routledge, London; New York.

Malerba, F., L. Orsenigo. 1993. Technological Regimes and Firm Behavior. Industrial and Corporate Change 2(1) 45-71.

Maliniak, L. 2005. Harry Nyquist A Founding Father Of Digital Communications. Electronic Design 53(23) 90-91.

Manoug, T.L. 1889. Nilometers. Proceedings of the Royal Geographical Society and Monthly Record of Geography 11(4) 245-246.

Mansfield, E. 1961. Technical Change and the Rate of Imitation. Econometrica 29(4) 741-766. 
Mansfield, E. 1988. The Speed and Cost of Industrial Innovation in Japan and the United States: External vs. Internal Technology. Management science 34(10) 1157-1168.

March, J.G., H.S. Guetzkow, H.A. Simon. 1958. Organizations. Wiley [u.a.], New York [u.a.

March, J.G., R.I. Sutton. 1997. Organizational Performance as a Dependent Variable. Organization Science 8(6) 698-706.

Markman, G.D., M.I. Espina, P.H. Phan. 2004. Patents as Surrogates for Inimitable and Non-Substitutable Resources. Journal of Management 30(4) 529544.

McKelvey, B. 1999. Avoiding Complexity Catastrophe in Coevolutionary Pockets: Strategies for Rugged Landscapes. Organization Science 10(3, Special Issue: Application of Complexity Theory to Organization Science) 294-321.

Merges, R. 2001. Institutions for Intellectual Property Transactions: The Case of Patent Pools. R.C. Dreyfuss, D.L. Zimmerman, H. First, eds. Expanding the boundaries of intellectual property : innovation policy for the knowledge society. Oxford University Press, Oxford [England]; New York.

Miller, G.G.A. 1956. The magical number seven, plus or minus two: some limits on our capacity for processing information. Psychological review 63(2) 81-97.

Millson, M.R., S.P. Raj, D. Wilemon. 1992. A survey of major approaches for accelerating new product development. Journal of Product Innovation Management 9(1) 53-69.

Mitleton-Kelly, E. 2003. Complex systems and evolutionary perspectives on organisations : the application of complexity theory to organisations. Pergamon, Oxford.

Mollick, E. 2006. Establishing Moore's Law. Annals of the History of Computing, IEEE 28(3) 62-75.

Moore, G.E. 1995. Lithography and the future of Moore's law. R.D. Allen, ed. SPIE, Santa Clara, CA, USA, 2-17.

Moore, G.E. 1998. Cramming More Components Onto Integrated Circuits. Proceedings of the IEEE 86(1) 82-85.

Mosakowski, E. 1997. Strategy Making under Causal Ambiguity: Conceptual Issues and Empirical Evidence. Organization Science 8(4) 414-442.

Motohashi, K. 2008. Licensing or not licensing? An empirical analysis of the strategic use of patents by Japanese firms. Research Policy 37(9) 1548-1555. 
Nebeker, F. 1998a. Fifty Years of Signal Processing. IEEE History Center, New Jersey, 58.

Nebeker, F. 1998b. The IEEE signal processing society : fifty years of service ; 1948 to 1998. IEEE History Center, New Brunswick, NJ.

Nebeker, F. 1998c. Signal processing : the emergence of a discipline, 1948 to 1998. IEEE History Center, New Brunswick, NJ.

Nelson, R.R., S.G. Winter. 1982. An evolutionary theory of economic change. Belknap Press of Harvard University Press, Cambridge, Mass.

Nerkar, A. 2003. Old Is Gold? The Value of Temporal Exploration in the Creation of New Knowledge. Management science 49(2) 211-229.

Novak, S., S.D. Eppinger. 2001. Sourcing by Design: Product Complexity and the Supply Chain. Management science 47(1) 189-204.

O'Brien, J.P. 2003. The capital structure implications of pursuing a strategy of innovation. Strategic Management Journal 24(5) 415-431.

Oddi, S. 1993. An Uneasier Case for Copyright than for Patent Protection of Computer Programs.

Oppenheim, A.V., R.W. Schafer. 1975. Digital signal processing. Prentice-Hall, Englewood Cliffs, N.J.

Orlikowski, W.J. 1992. The Duality of Technology: Rethinking the Concept of Technology in Organizations. Organization Science 3(3) 398-427.

Papadimitriou, C.H. 1994. Computational complexity. Addison-Wesley, Reading, Mass.

Pate-Cornell, E., R. Dillon. 1998. Challenges in the management of faster-bettercheaper space missions Aerospace Conference, 1998. Proceedings., IEEE, 507514 vol.505.

Pate-Cornell, M.E., R.L. Dillon. 2001. Success factors and future challenges in the management of faster-better-cheaper projects: lessons learned from NASA. Engineering Management, IEEE Transactions on 48(1) 25-35.

Pentland, B.T., M.S. Feldman. 2005. Organizational routines as a unit of analysis. Industrial and Corporate Change 14(5) 793-815.

Pentland, B.T., H.H. Rueter. 1994. Organizational Routines as Grammars of Action. Administrative Science Quarterly 39(3) 484-510. 
Planck, M. 1901. Ueber das Gesetz der Energieverteilung im Normalspectrum. [J.A. Barth], [Leipzig].

Porter, M.M.E. 1985. Technology and Competitive Advantage. The Journal of business strategy 5 (3) 60-78.

Powell, T.C., D. Lovallo, C. Caringal. 2006. Causal Ambiguity, Management Perception, and Firm Performance. Academy of Management Review 31(1) 175196.

Prahalad, C.K., R.A. Bettis. 1986. The Dominant Logic: A New Linkage between Diversity and Performance. Strategic Management Journal 7(6) 485-501.

Prandoni, P., M. Vetterli. 2008. Signal processing for communications. EPFL Press ; Distributed by CRC Press, Lausanne, Switzerland; Boca Raton.

Rader, C., N. Brenner. 1976. A new principle for fast Fourier transformation. Acoustics, Speech and Signal Processing, IEEE Transactions on 24(3) 264-266.

Reed, R., R.J. DeFillippi. 1990. Causal Ambiguity, Barriers to Imitation, and Sustainable Competitive Advantage. The Academy of Management Review 15(1) 88-102.

Richardson, T., R. Urbanke. 2003. The Renaissance of Gallager's Low-Density Parity-Check Codes. IEEE Commmunications Magazine 41 126-131.

Riordan, M., L. Hoddeson. 1998. Crystal fire : the invention of the transistor and the birth of the information age. Norton, New York.

Rissanen, J. 1986. Stochastic complexity and modeling. The Annals of statistics(Journal Article) 1080.

Rissanen, J.J. 1996. Fisher Information and Stochastic Complexity. IEEE transactions on information theory / 42(1) 40.

Rivkin, J.W. 2000. Imitation of Complex Strategies. Management science 46(6) 824-844.

Rivkin, J.W. 2001. Reproducing Knowledge: Replication without Imitation at Moderate Complexity. Organization Science 12(3) 274-293.

Rosenkopf, L., A. Nerkar. 1999. On the Complexity of Technological Evolution: Exploring Coevolution Within and Across Hierarchical Levels in Optical Disc Technology. D.T. Campbell, J.A.C. Baum, B. McKelvey, eds. Variations in organization science : in honor of Donald T. Campbell. Sage Publications, Thousand Oaks, Calif. 
Rosenkopf, L., A. Nerkar. 2001. Beyond Local Search: Boundary-Spanning, Exploration, and Impact in the Optical Disk Industry. Strategic Management Journal 22(4) 287-306.

Rothaermel, F.T., D.L. Deeds. 2004. Exploration and exploitation alliances in biotechnology: a system of new product development. Strategic Management Journal 25(3) 201-221.

Sakakibara, M. 2002. Formation of R\&D Consortia: Industry and Company Effects. Strategic Management Journal 23(11) 1033-1050.

Samuelson, P., S. Scotchmer. 2002. The Law and Economics of Reverse Engineering. Yale Law Journal 111(7) 1575-1663.

Sanchez, R., J.T. Mahoney. 1996. Modularity, Flexibility, and Knowledge Management in Product and Organization Design. Strategic Management Journal 17(, Special Issue: Knowledge and the Firm) 63-76.

Sanger, F. 2004. Determination of Nucleotide Sequences in DNA. Bioscience Reports 24(4-5) 4-5.

Saviotti, P.P. 2001. Variety, growth and demand. Journal of Evolutionary Economics 11(1) 119-142.

Schilling, M.A. 2000. Toward a General Modular Systems Theory and Its Application to Interfirm Product Modularity. The Academy of Management Review 25(2) 312-334.

Schoemaker, P.J.H. 1990. Strategy, Complexity and Economic Rent. Management science 36(10, Focussed Issue on the State of the Art in Theory and Method in Strategy Research) 1178-1192.

Schumpeter, J.A. 1934. The theory of economic development; an inquiry into profits, capital, credit, interest, and the business cycle. Harvard University Press, Cambridge, Mass.

Shane, S. 2000. Prior Knowledge and the Discovery of Entrepreneurial Opportunities. Organization Science 11(4) 448-469.

Shane, S. 2001. Technology Regimes and New Firm Formation. Management science 47(9) 1173-1190.

Shane, S., S. Venkataraman. 2000. The Promise of Enterpreneurship as a Field of Research. The Academy of Management Review 25(1) 217-226.

Shannon, C.E. 1948. A mathematical theory of communication. American Telephone and Telegraph Co., New York. 
Shapiro, C. 2000. Navigating the Patent Thicket: Cross Licenses, Patent Pools, and Standard Setting. Innovation Policy and the Economy 1(Journal Article) 119150.

Siggelkow, N., D.A. Levinthal. 2003. Temporarily Divide to Conquer: Centralized, Decentralized, and Reintegrated Organizational Approaches to Exploration and Adaptation. Organization Science 14(6) 650-669.

Siggelkow, N., J.W. Rivkin. 2005. Speed and Search: Designing Organizations for Turbulence and Complexity. Organization Science 16(2) 101-122.

Simon, H.A. 1959. Theories of Decision-Making in Economics and Behavioral Science. The American Economic Review 49(3) 253-283.

Simon, H.A. 1962. The Architecture of Complexity. Proceedings of the American Philosophical Society 106(6) 467-482.

Simon, H.A. 1974. How Big Is a Chunk? By combining data from several experiments, a basic human memory unit can be identified and measured. Science (New York, N.Y.) 183(4124) 482.

Simon, H.A. 1976. Administrative behavior : a study of decision-making processes in administrative organization. Free Press, New York.

Sipser, M. 1997. Introduction to the theory of computation. PWS Pub. Co., Boston.

Smircich, L. 1983. Concepts of Culture and Organizational Analysis. Administrative Science Quarterly 28(3) 339-358.

Smith, S.W. 1997. The scientist and engineer's guide to digital signal processing. California Technical Pub., San Diego, Calif.

Solow, D., A. Burnetas, T. Roeder, N.S. Greenspan. 1999. Evolutionary Consequences of Selected Locus-specific Variations in Epistasis and Fitness Contribution in Kauffman'sNKModel. Journal of theoretical biology 196(2) 181196.

Somaya, D. 2003. Strategic Determinants of Decisions Not to Settle Patent Litigation. Strategic Management Journal 24(1) 17-38.

Sorenson, O. 2005. Social Networks, Informational Complexity and Industrial Geography. International Studies in Entrepreneurship(6) 79-96.

Sorenson, O., J.W. Rivkin, L. Fleming. 2006. Complexity, networks and knowledge flow. Research Policy 35(7) 994-1017. 
Sosa, M.E., S.D. Eppinger, C.M. Rowles. 2004. The Misalignment of Product Architecture and Organizational Structure in Complex Product Development. Management science 50(12) 1674-1689.

Srinivasan, R., G.L. Lilien, A. Rangaswamy. 2004. First in, First out? The Effects of Network Externalities on Pioneer Survival. The Journal of Marketing 68(1) 4158.

St. John, M. 2003. The Palermo stone : an arithmetical view ; together with a computer graphics enhancement of the recto of the Palermo fragment. Museum Bookshop Publications, London.

Stem, R.H. 1991. Tales from the Algorithm War: Benson to Iwahashi, It's Deja Vu All Over Again. AIPLA quarterly journal 18(Journal Article) 371.

Stoltzner, M. 2003. The Dynamics of Thought Experiments. A Comment on David Atkinson. Boston studies in the philosophy of science. 232 243-258.

Strauss, W. 2007. DSP Chip Strategies '07: A Study of IC Markets Driven by Digital Signal Processing Technology. Forward Concepts.

Strauss, W. 2008. Market Changes in DSP Silicon Warrants New Analysis According To Study. Forward Concepts.

Teece, D., G. Pisano. 1994. The Dynamic Capabilities of Firms: an Introduction. Industrial and Corporate Change 3(3) 537-556.

Teece, D.J. 1986. Profiting from technological innovation: Implications for integration, collaboration, licensing and public policy. Research Policy 15(Journal Article) 285.

Teece, D.J. 2006. Reflections on "Profiting from Innovation". Research Policy 35(8) 1131-1146.

Teece, D.J., G. Pisano, A. Shuen. 1997. Dynamic Capabilities and Strategic Management. Strategic Management Journal 18(7) 509-533.

Thomke, S., W. Kuemmerle. 2002. Asset accumulation, interdependence and technological change: evidence from pharmaceutical drug discovery. Strategic Management Journal 23(7) 619-635.

Tollin, K. 2008. Mindsets in Marketing for Product Innovation: An Explorative Analysis of Chief Marketing Executives' Ideas and Beliefs about How to Increase Their Firms' Innovation Capability. Journal of Strategic Marketing 16(5) 363-390.

Tsaftaris, S.A., A.K. Katsaggelos. 2008. The Not So Digital Future of Digital Signal Processing [Point of View]. Proceedings of the IEEE 96(3) 375-377. 
Tuomi, I. 2002. The Lives and Death of Moore's Law. First Monday 7(11-4).

Tushman, M.L., D.A. Nadler. 1978. Information Processing as an Integrating Concept in Organizational Design. The Academy of Management Review 3(3) 613-624.

Tushman, M.L., R.R. Nelson. 1990. Introduction: Technology, Organizations, and Innovation. Administrative Science Quarterly 35(1) 1-8.

Ulrich, K. 1995. The role of product architecture in the manufacturing firm. Research Policy 24(3) 419-440.

Verdu, S. 1998. Fifty Years of Shannon Theory. IEEE Transactions on Information Theory 44(6) 2057-2078.

Viterbi, A. 1967. Error bounds for convolutional codes and an asymptotically optimum decoding algorithm. IEEE Transactions on Information Theory 13(2) 260.

Waldrop, M.M. 2001. Claude Shannon: Reluctant Father of the Digital Age - A juggling unicyclist transformed "information" from a vague idea into a precise concept that underlies the digital revolution. MIT's Technology Review 104(6) 64.

Walker, G., D. Weber. 1984. A Transaction Cost Approach to Make-or-Buy Decisions. Administrative Science Quarterly 29(3) 373-391.

Walker, G., D.A. Weber. 1986. Supplier competition, uncertainty and make or buy decisions. Sloan School of Management, Massachusetts Institute of Technology, Cambridge, MA.

Walker, M. 2003. Science and ideology : a comparative history. Routledge, London; New York.

Walsh, J.P., G.R. Ungson. 1991. Organizational Memory. The Academy of Management Review 16(1) 57-91.

Wegener, I. 1987. The complexity of Boolean functions. B.G. Teubner ; J. Wiley, Stuttgart; Chicester [West Sussex]; New York.

Widrow, B., S. Haykin. 2003. Least-mean-square adaptive filters. John Wiley, Hoboken, NJ.

Widrow, B., S.D. Stearns. 1985. Adaptive signal processing. Prentice-Hall, Englewood Cliffs, N.J.

Wiener, N. 1949. Cybernetics or control and communication in the animal and the machine. Wiley [u.a.], New York. 
Wiklund, J., D. Shepherd. 2003. Knowledge-Based Resources, Entrepreneurial Orientation, and the Performance of Small and Medium-Sized Businesses. Strategic Management Journal 24(13) 1307-1314.

Wilkinson, T.A.H. 2000. Royal annals of ancient Egypt : the Palermo stone and its associated fragments. Kegan Paul International : Distributed by Columbia University Press, London; New York.

Williams, F.C., T. Kilburn. 1948. Electronic digital computers. Nature (London) 162(4,117) 487.

Williams, F.C., T. Kilburn. 1949. A storage system for use with binary-digital computing machines. s.n.], S.I.

Wilson, R.H., J.-C. Latombe. 1994. Geometric reasoning about mechanical assembly. Artificial Intelligence 71(2) 371-396.

Winter, S.G. 1986. The research program of the behavioral theory of the firm: Orthodox critique and evolutionary perspective. B. Gilad, S. Kaish, eds. Handbook of Behavioral Economics. JAI Press, Greenwich, CT, 151-188.

Winter, S.G., G. Szulanski. 2001. Replication as Strategy. Organization Science 12(6) 730-743.

Yao, A.C.-C. 1979. Some complexity questions related to distributive computing(Preliminary Report) Proceedings of the eleventh annual ACM symposium on Theory of computing. ACM, Atlanta, Georgia, United States, 209213.

Yayavaram, S., G. Ahuja. 2008. Decomposability in Knowledge Structures and Its Impact on the Usefulness of Inventions and Knowledge-base Malleability. Administrative science quarterly. 53(2) 333.

Yoon, M., F. Malerba. 2009. Evolution of fabless ecosystem: 'History-friendly' model of semiconductor industry.

Zander, U., B. Kogut. 1995. Knowledge and the Speed of the Transfer and Imitation of Organizational Capabilities: An Empirical Test. Organization Science 6(1) $76-92$.

Zeger, S.L., K.-Y. Liang. 1986. Longitudinal Data Analysis for Discrete and Continuous Outcomes. Biometrics 42(1) 121-130.

Zhao, Q., B. Mesman, T. Basten. 2002. Practical Instruction Set Design and Compiler Retargetability Using Static Resource Models Proceedings of the conference on Design, automation and test in Europe. IEEE Computer Society, 1021. 
Ziedonis, R.H. 2004. Don't Fence Me In: Fragmented Markets for Technology and the Patent Acquisition Strategies of Firms. Management science 50(6) 804820. 